\title{
Inhibition of Isoleucyl-tRNA Synthetase by the Hybrid antibiotic Thiomarinol
}

Rachel A. Johnson ${ }^{\#, \dagger}$, Andrew N. Chan ${ }^{\#, \dagger}$, Ryan D. Ward ${ }^{\S, \|, ~ C a y l i e ~ A . ~ M c G l a d e ~}{ }^{\dagger}$, Breanne M. Hatfield $^{\dagger}$, Jason M. Peters ${ }^{\S, \perp}$, Bo Li*,†, $^{*}$

${ }^{\dagger}$ Department of Chemistry, University of North Carolina at Chapel Hill, Chapel Hill, North Carolina 27599, United States

Department of Microbiology and Immunology, University of North Carolina at Chapel Hill, Chapel Hill, North Carolina 27599, United States

§Pharmaceutical Sciences Division, School of Pharmacy, University of Wisconsin-Madison, Madison, Wisconsin 53705, United States

"Laboratory of Genetics, University of Wisconsin-Madison, Madison, Wisconsin 53706, United States

${ }^{\perp}$ Great Lakes Bioenergy Research Center, Wisconsin Energy Institute, University of Wisconsin-Madison, Madison, Wisconsin 53726, United States

*Corresponding Author (E:) boli@email.unc.edu

\#These authors contributed equally to this study 


\section{Table of Contents}

I. List of Abbreviations and Symbols ............................................................................................ 4

II. Experimental Procedures ................................................................................................... 6

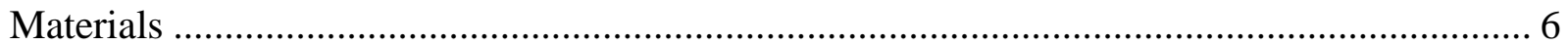

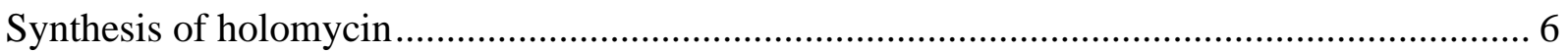

Synthesis of pseudomonyl C holothinamide (PAC-holo)................................................ 7

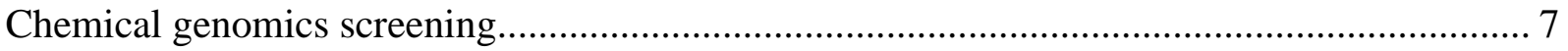

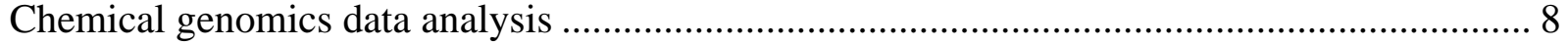

Bioinformatic identification of the thiomarinol gene cluster............................................ 8

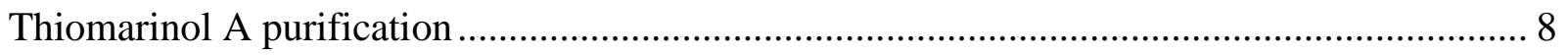

Determination of thiomarinol A and holomycin concentrations by UV-vis spectroscopy ...... 10

Thiomarinol titration with zinc sulfate under reduced conditions ..................................... 10

Growth assays of MRSA Newman and its zinc-import mutant $\Delta a d c A \Delta c n t A \ldots \ldots \ldots \ldots \ldots \ldots \ldots . . . . . . . . . .11$

Generating low-level mupirocin resistant $\left({ }^{\mathrm{LL}} \mathrm{MR}\right) \mathrm{MRSA}$ COL mutants............................. 11

Serial passaging of MRSA COL in the presence of thiomarinol A .................................... 12

Minimal inhibitory concentration determination ......................................................... 12

Antibiotic cytotoxicity against HEK293T cells ......................................................... 13

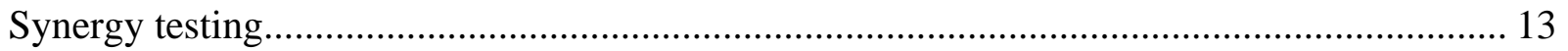

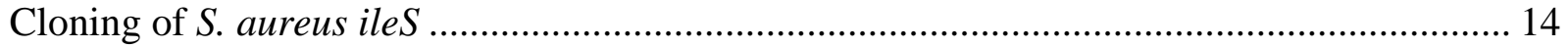

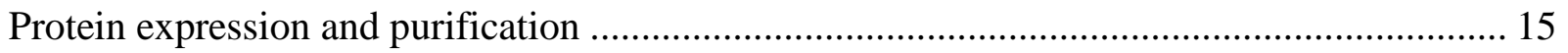

Kinetic characterization of IleRS and active site titration ............................................... 16

Inhibition of IleRS by mupirocin, holomycin and thiomarinol A ..................................... 17

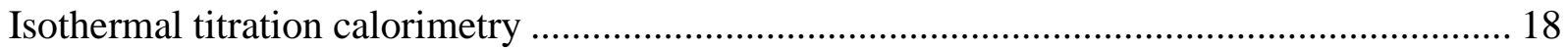

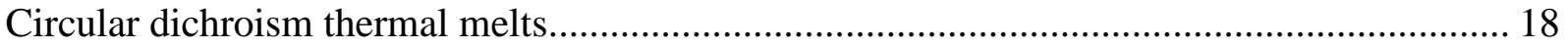

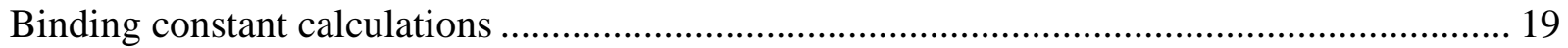

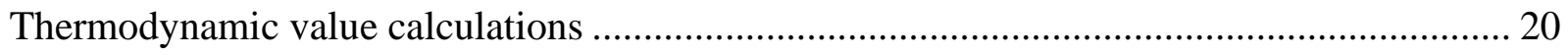

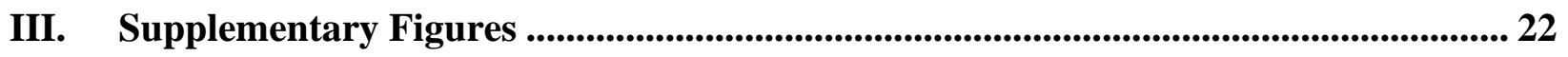

Figure S1. Chemical structures of the thiomarinol family of hybrid antibiotics $(A-G)$ and the other hybrids discussed in this paper: the simocyclinones, cefiderocol, and everninomicin P. 22 Figure S2. IleRS inhibitor natural products SB-203207 and furanomycin.......................... 23

Figure S3. Sequence alignment of MupA and IleRS................................................. 24

Figure S4. Thiomarinol biosynthetic gene clusters....................................................... 25 
Figure S5. LC-HRMS purity analysis of thiomarinol A used in this study.......................... 26

Figure S6. ${ }^{1} \mathrm{H}(600 \mathrm{MHz}) \mathrm{NMR}$ of thiomarinol A in MeOD............................................. 27

Figure S7. ${ }^{13} \mathrm{C}(151 \mathrm{MHz}) \mathrm{NMR}$ of thiomarinol A in MeOD. ........................................... 28

Figure S8. LC-HRMS purity analysis of synthesized molecules used in this study............... 29

Figure S9. ${ }^{1} \mathrm{H}(600 \mathrm{MHz}) \mathrm{NMR}$ of holomycin in DMSO-d6.......................................... 30

Figure S10. ${ }^{1} \mathrm{H}$ NMR $(600 \mathrm{MHz})$ of PAC-holothin in MeOD............................................ 31

Figure S11. ${ }^{1} \mathrm{H}(600 \mathrm{MHz}) \mathrm{NMR}$ of PAC in MeOD.................................................... 32

Figure S12. Cytotoxicity profiles for thiomarinol A and holomycin................................. 33

Figure S13. Chemical-gene interactions of disulfide-containing natural products from the

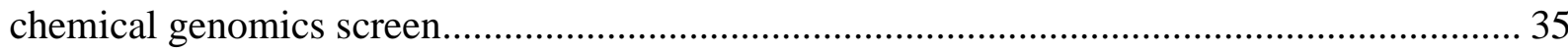

Figure S14. A total of $91 \%$ of the 257 essential B. subtilis genes have orthologs in S. aureus 36

Figure S15. Protein gel of purified isoleucyl tRNA synthetase......................................... 37

Figure S16. Isoleucine activation of IleRS assayed by ATP- $\left[{ }^{32} \mathrm{P}\right] \mathrm{PP}$ exchange and $\left[\gamma_{-}{ }^{32} \mathrm{P}\right] \mathrm{ATP}$

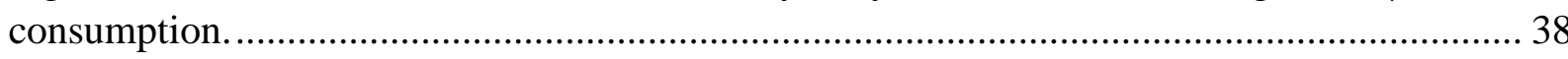

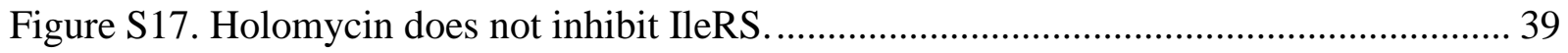

Figure S18. ITC analysis of mupirocin binding to IleRS. ................................................. 40

Figure S19. ITC analysis of IleRS and Thiomarinol binding under reducing conditions and

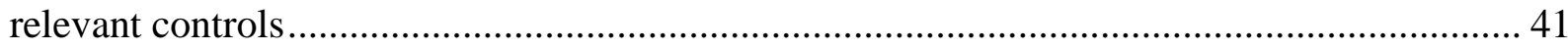

Figure S20. Representative CD spectra of IleRS ..................................................... 42

Figure S21. IleRS melting temperatures $\left(\mathrm{T}_{\mathrm{m}}\right)$ are consistent under nonreducing and reducing

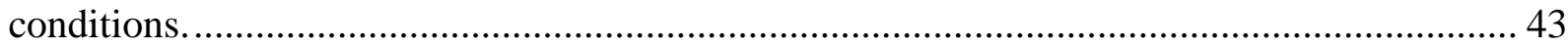

Figure S22. Thiomarinol chelates zinc under reduced conditions in a 2:1 ratio..................... 44

Figure S23. Thiomarinol reduces the growth of MRSA Newman zinc import mutant under zinc-deficient conditions. Growth curves of wildtype and the zinc deficient mutant

$\triangle a d c A \Delta c n t A$

Figure S24. Inhibitory effects of the thiomarinol A and PAC-holo constituents are additive

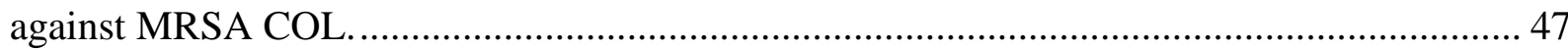

Figure S25. Serial passaging of MRSA to induce resistance to mupirocin or thiomarinol A. . 48

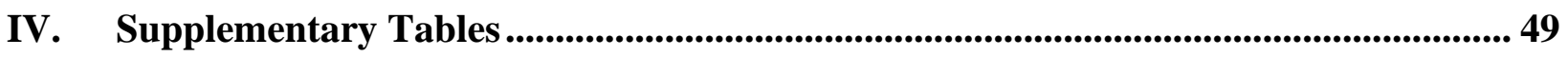

Table S1. Thermodynamic values for mupirocin and thiomarinol A binding to IleRS.......... 49

Table S2. Matrix of $p$ values comparing the IleRS melting temperatures in the presence of

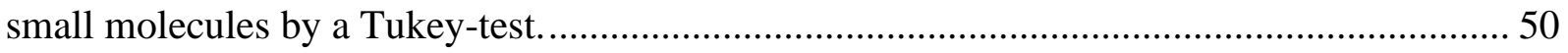

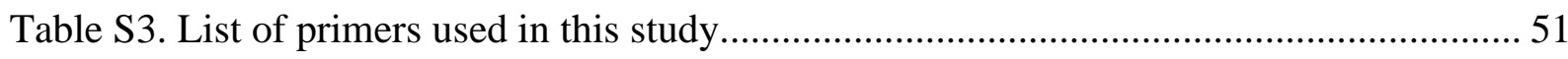

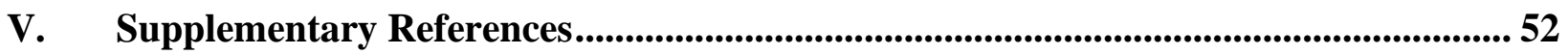




\section{List of Abbreviations and Symbols}

\begin{tabular}{|c|c|}
\hline AMP & adenosine monophosphate \\
\hline ATP & adenosine triphosphate \\
\hline cpm & counts per minute \\
\hline DMSO & dimethyl sulfoxide \\
\hline EDTA & ethylenediaminetetraacetic acid \\
\hline ESI & electrospray ionization \\
\hline FA & formic acid \\
\hline FIC & fractional inhibitory concentration \\
\hline FPLC & fast protein liquid chromatography \\
\hline $\mathrm{h}$ & hour(s) \\
\hline HEPES & 4-(2-hydroxyethyl)-1-piperazineethanesulfonic acid \\
\hline holo & holomycin \\
\hline HPLC & high-performance liquid chromatography \\
\hline $\mathrm{HV}$ & high voltage \\
\hline IleRS & isoleucyl tRNA synthetase \\
\hline IPTG & isopropyl $\beta$-D-1-thiogalactopyranoside \\
\hline $\mathrm{kb}$ & kilobase \\
\hline $\mathrm{kDa}$ & kilodalton \\
\hline LB & lysogeny broth \\
\hline $\mathrm{LC}$ & liquid chromatography \\
\hline LC-HRMS & liquid chromatography high resolution mass spectrometry \\
\hline LC-MS & liquid chromatography mass spectrometry \\
\hline mdeg & milidegrees \\
\hline $\mathrm{MeCN}$ & acetonitrile \\
\hline $\mathrm{MeOD}$ & deuterated methanol \\
\hline $\mathrm{MgCl}_{2}$ & magnesium chloride \\
\hline MIC & minimal inhibitory concentration \\
\hline $\min$ & minute(s) \\
\hline MRSA & methicillin-resistant Staphylococcus aureus \\
\hline
\end{tabular}




\begin{tabular}{|c|c|}
\hline MS & mass spectrometry \\
\hline $\mathrm{nm}$ & nanometer \\
\hline NMR & nuclear magnetic resonance spectroscopy \\
\hline PAA & pseudomonic acid A \\
\hline PAC & pseudomonic acid C \\
\hline PAC-holo & pseudomonyl C holothinamide \\
\hline PCR & polymerase chain reaction \\
\hline $\mathrm{PP}_{\mathrm{i}}$ & pyrophosphate \\
\hline QTOF & quadrupole time of flight \\
\hline $\operatorname{rcf}$ & relative centrifugal force \\
\hline RT & room temperature \\
\hline SD & standard deviation \\
\hline $\mathrm{s}$ & second(s) \\
\hline SEM & standard error of the mean \\
\hline SDS & sodium dodecyl sulfate \\
\hline TCEP & tris(2-carboxyethyl)phosphine \\
\hline $\mathrm{T}_{\mathrm{m}}$ & melting temperature \\
\hline UV & ultraviolet \\
\hline $\mathrm{V}$ & volts \\
\hline vis & visible \\
\hline${ }^{\circ} \mathrm{C}$ & degree Celsius \\
\hline$\Delta \mathrm{H}_{\mathrm{u}}$ & enthalpy of unfolding \\
\hline
\end{tabular}




\section{Experimental Procedures}

\section{Materials}

A stock of Pseudoalteromonas luteoviolacea 2 ta16 was gifted by Eric Allen (University of California, San Diego). Hospital-acquired methicillin-resistant Staphylococcus aureus (HAMRSA) COL was obtained from the Richardson lab (Department of Microbiology and Immunology, University of North Carolina at Chapel Hill). Low-level mupirocin-resistant mutants were generated in this study as described below. The high-level mupirocin-resistant MRSA strain (ATCC BAA-1556) containing MupA, also known as strain USA300 FPR3757, was purchased from the American Type Culture Collection (ATCC). MRSA Newman and MRSA Newman $\triangle a d c A \Delta c n t A$ were obtained from Thomas Kehl-Fie (University of Illinois, Urbana- Champaign). HEK293T/17 cells were purchased from the Tissue Culture Facility at the University of North Carolina at Chapel Hill. Mupirocin (AppliChem) was purchased from VWR, the purity and composition of which were confirmed by NMR and used without further purification. NMR solvents were purchased from Cambridge Isotopes Laboratory. Thiolutin and gliotoxin were purchased from Fermentek. Sodium phosphate dibasic and monobasic were purchased from Mallinckrodt Chemicals. Tetrasodium $\left[{ }^{32} \mathrm{P}\right]$ pyrophosphate and $\left[\gamma_{-}{ }^{32} \mathrm{P}\right] \mathrm{ATP}$ used for enzyme activity and inhibition assays and were purchased from Perkin Elmer. Dulbecco's Modified Eagle's Medium (DMEM), 100 I.U./ $\mu \mathrm{L}$ penicillin/streptomycin, and fetal bovine serum used for cytotoxicity assays were purchased from Gibco. The remaining chemicals were purchased from Thermo Fisher Scientific and VWR International: acetonitrile containing $0.1 \%$ formic acid (LCMS grade), water containing $0.1 \%$ formic acid (LC-MS grade), acetonitrile (HPLC grade), methanol (HPLC grade), lysogeny broth (LB), agar, glycerol (molecular biology grade), sodium chloride, HEPES, SDS, EDTA, nickel chloride, and potassium sulfate, dimethyl sulfoxide (molecular biology grade, Acros Organics), imidazole (Acros Organics), BD Difco Marine Broth 2216 (MB), BD Difco Mueller-Hinton Broth II, cation adjusted (MHBII), scintillation cocktail, and tris(2-carboxyethyl)phosphine (TCEP, Alfa Aesar), 37\% hydrochloric acid (HCl, Acros), triethylamine $\left(\mathrm{Et}_{3} \mathrm{~N}\right.$, Alfa Aesar), acetyl chloride (Acros), trichloroacetyl chloride (Sigma), pyridine (Alfa Aesar), 4-(dimethlyamino)pyridine (DMAP, Sigma), dichloromethane (DCM, Acros), tetrahydrofuran (THF, Acros), N,N-dimethylformamide (DMF, Acros), oxalyl chloride

(Acros), phenol-chloroform, isoamyl alcohol mixture (saturated with TRIS pH 8.0, Sigma), and isopropanol (HPLC grade). Cotton balls (100\% cotton) were purchased from CVS pharmacy.

\section{Synthesis of holomycin}

Trifluoroacetyl holothin was prepared as described, ${ }^{1}$ and purified by flash column chromatography (Hex/EtOAc 1:2, $\left.\mathrm{R}_{\mathrm{f}}=0.40\right)$ to obtain a yellow solid (5 steps, $13 \%$ overall yield). Trifluoroacetyl holothin $(5.00 \mathrm{mg}, 18.6 \mu \mathrm{mol})$ was dissolved in $\mathrm{MeOH}(1.0 \mathrm{~mL})$ and $37 \% \mathrm{HCl}(25 \mu \mathrm{L})$ was added dropwise. The reaction was refluxed for $2.5 \mathrm{~h}$, cooled to RT, and dried using rotary evaporation to obtain holothin hydrochloride as a yellow solid that was used without further purification. The synthesis of holomycin was completed by acylation with acetyl chloride in the presence of $\mathrm{Et}_{3} \mathrm{~N}$ (65-70\% yield, Figure S8A and S9). 


\section{Synthesis of pseudomonyl C holothinamide (PAC-holo)}

$(2 S, 3 S, 4 R, 5 S)-2-((\mathrm{E})-2-m e t h y l-4-o x o-4-((9-0 x o-9-((5-o x o-4,5-d i h y d r o-[1,2]$ dithiolo[4,3b]pyrrol-6- yl)amino)nonyl)oxy)but-2-en-1-yl)-5-((4R,5S,E)-4-methyl-5-(2,2,2trichloroacetoxy)hex-2-en-1-yl)tetrahydro-2H-pyran-3,4-diyl bis(2,2,2-trichloroacetate)

The synthetic analogue of thiomarinol, PAC-holo, was synthesized as described in Dunn et al. ${ }^{2}$ Pseudomonic acid C (PAC) was synthesized as described in Clayton et al. ${ }^{3}$ (Figure S8C and S11). To couple PAC to holothin hydrochloride, the hydroxyls of PAC were protected by dissolving PAC $(0.267 \mathrm{~g}, 0.55 \mathrm{mmol})$ in $\mathrm{CH}_{2} \mathrm{Cl}_{2}(9.2 \mathrm{~mL})$ and cooling to $0{ }^{\circ} \mathrm{C}$. Trichloroacetyl chloride $(0.31 \mathrm{~mL}, 2.75 \mathrm{mmol})$ and pyridine $(0.19 \mathrm{~mL}, 2.38 \mathrm{mmol})$ were added dropwise, followed by addition of $4-N, N$-dimethylaminopyridine $(6.7 \mathrm{mg}, 0.055 \mathrm{mmol})$. The reaction was warmed to RT and stirred for $2.5 \mathrm{~h}$. The mixture was diluted with $\mathrm{CH}_{2} \mathrm{Cl}_{2}(10 \mathrm{~mL})$ and washed with $1 \mathrm{~N} \mathrm{HCl}(2 \times 5 \mathrm{~mL})$.

Holothin hydrochloride $(0.385 \mathrm{~g}, 0.42 \mathrm{mmol})$ was dissolved in $\mathrm{CH}_{2} \mathrm{Cl}_{2}(7.0 \mathrm{~mL})$ and cooled to $0{ }^{\circ} \mathrm{C}$. Oxalyl chloride $(71 \mu \mathrm{L}, 0.84 \mathrm{mmol})$ was added dropwise followed by one drop of $\mathrm{N}, \mathrm{N}$ dimethylformamide. The reaction was stirred at $\mathrm{rt}$ for $3 \mathrm{~h}$ and dried via rotary evaporation. The resulting crude acyl chloride was dissolved in THF $(2.13 \mathrm{~mL})$ and added dropwise to a $0{ }^{\circ} \mathrm{C}$ suspension of holothin hydrochloride $(87.1 \mathrm{mg}, 0.418 \mathrm{mmol})$ in THF $(19 \mathrm{~mL}) . \mathrm{Et}_{3} \mathrm{~N}(0.13 \mathrm{~mL}$, $0.931 \mathrm{mmol}$ ) was added dropwise to the mixture and reaction stirred at RT for $45 \mathrm{~min}$ and dried via rotary evaporation. Silica gel (60 mesh) purification with a methanol gradient $(0-5 \%)$ in chloroform $\left(\mathrm{R}_{\mathrm{f}}=0.75,5 \% \mathrm{MeOH}\right.$ in $\left.\mathrm{CHCl}_{3}\right)$ yielded PAC-holo $(0.271 \mathrm{~g}, 0.252 \mathrm{mmol})$ as a yellow foam (60\% overall yield, Figure S8B and S10).

\section{Chemical genomics screening}

Chemical genomics screening was performed simultaneously with published experiments as described. ${ }^{4}$ Briefly, $-80{ }^{\circ} \mathrm{C}$ glycerol stocks of the B. subtilis essential gene knockdown library were thawed at $37^{\circ} \mathrm{C}$, pinned onto rectangular LB plates in 384-well colony format, grown for $\sim 8 \mathrm{~h}$ at $37^{\circ} \mathrm{C}$, and subsequently pinned in 1536-colony format using a ROTOR HDA High Throughput Screening Robot (Singer Instruments). To test the library against different chemical conditions, the strains were then pinned in 1536-colony format to rectangular agar plates containing the indicated concentration of inhibitory compound (Supplemental Data Set 1). Sublethal concentrations of each compound were used. Each plate contained four technical replicates for each knockdown strain and each concentration of compound was replicated at least twice. Compound concentrations that inhibited more than $50 \%$ of growth were discarded from analysis. Pinned cells were grown on compound plates for $7-14 \mathrm{~h}$ at $37{ }^{\circ} \mathrm{C}$ and imaged with a custom light box. 


\section{Chemical genomics data analysis}

$\underline{\text { Gene ontology (GO) analysis }}$

Functionally enriched GO processes were identified using String-DB (Supplemental Data Set 3). For each compound, chemical-gene scores corresponding to the median responses were submitted to the Proteins with Values/Ranks web interface using the parameters: lenient false discovery rate (FDR) stringency and Bacillus subtilis subsp. subtilis str. 168 (organism). FDR metrics were calculated using either the Kolmogorov-Smirnov (KS) test or aggregate fold change (AFC) randomization. GO processes with many potentially implicated genes require prohibitively large computational resources to estimate FDR metrics using randomization, and as such the AFC is reserved only for small pathways and $\mathrm{KS}$ is used for all other instances. ${ }^{5}$

Determining chemical-gene scores and compound correlation

Differences in colony size calculated from plate images across conditions were used to score gene knockdowns as sensitive (negative scores) or resistant (positive scores) to a particular compound (i.e., chemical-gene scores - a variance-bounded $t$ test). ${ }^{6}$ Colony imaging analysis, normalization, and chemical-gene calculations were performed as previously described. ${ }^{7}$ Briefly, colony sizes were extracted using Iris, ${ }^{4}$ spatial effects were normalized using a quadratic function, median and variance of colony sizes were normalized between plates using MATLAB, and chemical-gene scores were calculated using software previously described. ${ }^{6}$ To simplify our analysis of chemicalgene score data collected across multiple compound concentrations, we calculated the median chemical-gene score for each chemical-gene interaction across concentrations of the same compound (i.e. median response matrix). Using this median response matrix, we calculated a chemical similarity matrix by correlating median chemical-gene scores by compounds (Supplemental Data Set 2). We then constructed a clustered heatmap using heatmap in $\mathrm{R}$ by calculating the average correlation $(r)$ between compounds and obtained a clustered dendrogram in which branches with similar patterns of chemical-gene interactions share nodes.

\section{Bioinformatic identification of the thiomarinol gene cluster}

The biosynthetic gene cluster for thiomarinol from Pseudoalteromonas sp. SANK 73390 was downloaded from the MiBiG repository. ${ }^{8}$ This cluster was used as an input query for MultiGeneBlast against the NCBI GenBank database. We identified two additional strains of Pseudoalteromonas spp. that contain clusters similar to thiomarinol, P. luteoviolacea 2 ta 16 and NCIMB 1944 (Figure S4), both of which were also reported to produce thiomarinols by Maansson et al. ${ }^{9}$

\section{Thiomarinol A purification}

A yellow colony of $P$. luteoviolacea 2 ta16 was identified, isolated, and used for purification due to lower production of violacein, an extremely abundant pigment produced by this strain, facilitating quicker phase separation during extraction and easier purification. A 25\% (v/v) glycerol stock of the P. luteoviolacea 2 ta16 yellow colony was streaked onto marine agar and 
grown overnight at $28{ }^{\circ} \mathrm{C}$. A starter culture was prepared by inoculating $5 \mathrm{~mL}$ of marine broth with a colony and was grown overnight at $28{ }^{\circ} \mathrm{C}, 225 \mathrm{rpm}$. A $2 \mathrm{~mL}$ sample of starter culture was used to inoculate $200 \mathrm{~mL}$ marine broth supplemented with approximately $3.5 \mathrm{~g}$ of sterile cotton. The cotton ball scaffold method for culturing $P$. luteoviolacea 2 ta 16 was adapted from Timmermans et al. ${ }^{10}$ The culture was grown at $30^{\circ} \mathrm{C}, 225 \mathrm{rpm}$ in a $1 \mathrm{~L}$ baffled flask for approximately $24 \mathrm{~h}$.

The extraction and purification of thiomarinol from cultures were adapted from those described in our previous work with minor modifications. ${ }^{11}$ Acetone was added to the culture in a 1:2 ratio (acetone:culture) and cooled at $4{ }^{\circ} \mathrm{C}$ for $30 \mathrm{~min}$. Liquid was decanted and cotton balls were rinsed with acetone and pressed over a Büchner funnel to collect flow through. The liquid and flow through were combined and centrifuged at $3500 \mathrm{~g}$ for $15 \mathrm{~min}$ to pellet cell debris. The supernatant was extracted with a 1:1 ratio of ethyl acetate:culture twice. The organic layer was dried via rotary evaporation.

The crude mixture was resuspended in methanol, followed by the addition of an equal volume of water, which resulted in a green/brown precipitate. The mixture was filtered using a $0.45 \mu \mathrm{m}$ and then a $0.2 \mu \mathrm{m}$ nylon syringe filter yielding a clear, yellow solution. The extract was purified using preparatory reverse phase chromatography (Agilent Prepstar solvent delivery system coupled with an Agilent 1260 Infinity II DAD) over a $250 \mathrm{~mm}$ x $21.20 \mathrm{~mm}$ Luna C18 Axia column (Phenomenex, $10 \mu \mathrm{m}, 100 \AA$ ) with the following gradient of mobile phase A1 (water) and mobile phase $\mathrm{B} 1(\mathrm{MeCN})$ :

\begin{tabular}{|c|c|c|}
\hline Time (min) & $\begin{array}{c}\text { Total Flow } \\
(\mathrm{mL} / \mathrm{min})\end{array}$ & $\begin{array}{c}\text { Percent } \\
\text { Mobile } \\
\text { phase B1 } \\
(\%)\end{array}$ \\
\hline 5 & 15 & 5 \\
\hline 10 & 15 & 60 \\
\hline 20 & 15 & 70 \\
\hline 25 & 15 & 95 \\
\hline 30 & 15 & 95 \\
\hline 35 & 15 & 5 \\
\hline
\end{tabular}

Using this method, thiomarinol A eluted between 65 and $66 \%$ B1 (at a retention time of approximately $15.3 \mathrm{~min}$ ) based on absorbance at $390 \mathrm{~nm}$. Fractions were dried via rotary evaporation and overnight high vacuum. Subsequent HR-LCMS and NMR analyses (described below) were used to assess compound purity.

A second round of purification was completed using the preparatory HPLC over the same column described above with the following isocratic gradient. Peak collection was performed manually. 


\begin{tabular}{|c|c|c|}
\hline Time (min) & $\begin{array}{c}\text { Total Flow } \\
(\mathrm{mL} / \mathrm{min})\end{array}$ & $\begin{array}{c}\text { Percent } \\
\text { Mobile } \\
\text { phase B1 } \\
(\%)\end{array}$ \\
\hline 5 & 15 & 5 \\
\hline 10 & 15 & 55 \\
\hline 15 & 15 & 55 \\
\hline 20 & 15 & 65 \\
\hline 25 & 15 & 95 \\
\hline 30 & 15 & 95 \\
\hline 35 & 15 & 5 \\
\hline
\end{tabular}

In the second round of purification, thiomarinol A eluted between 57 and 58\% B1 (at a retention time of approximately $16.2 \mathrm{~min}$ ) as determined by absorbance at $390 \mathrm{~nm}$. NMR spectra of the samples were acquired in MeOD using a $600 \mathrm{MHz}$ Bruker NMR spectrometer (Figure S6 and S7). Samples were also analyzed by LC-HRMS using an Agilent 1260 LC/Agilent 6520 Accurate-Mass Q-TOF mass spectrometer (Figure S5). The following mass spectrometer settings were used: gas temperature at $300{ }^{\circ} \mathrm{C}$, drying gas at $10 \mathrm{~L} / \mathrm{min}$, nebulizer gas at $45 \mathrm{psi}$, fragmentor voltage at 175 $\mathrm{V}$, skimmer voltage at $65 \mathrm{~V}$, octopole RF voltage at $750 \mathrm{~V}$, and capillary cap voltage at $3500 \mathrm{~V}$. Samples were separated on a $150 \mathrm{~mm}$ x $4.6 \mathrm{~mm}$ Kinetex C18 column (Phenomenex, $5 \mu \mathrm{m}, 100 \AA$ ) using the following gradient of mobile phase $\mathrm{A} 2\left[\mathrm{H}_{2} \mathrm{O}+0.1 \%\right.$ formic acid (FA)] to mobile phase $\mathrm{B} 2(\mathrm{MeCN}+0.1 \% \mathrm{FA})$ at a flow rate of $0.6 \mathrm{~mL} / \mathrm{min}$.

\begin{tabular}{|c|c|}
\hline Time (min) & $\begin{array}{c}\text { Mobile } \\
\text { phase B2 } \\
(\%)\end{array}$ \\
\hline 0 & 2 \\
\hline 2 & 2 \\
\hline 12 & 98 \\
\hline 14 & 98 \\
\hline 15 & 2 \\
\hline
\end{tabular}

\section{Determination of thiomarinol A and holomycin concentrations by UV-vis spectroscopy}

A Cary 100 series UV-vis spectrophotometer was used to collect spectroscopic data of solutions containing holomycin and thiomarinol $\mathrm{A}$ based on the signature absorbance from the dithiolopyrrolone chromophore. Data were collected in a $100 \mu \mathrm{L}$ submicro quartz cell (Starna Cells, Inc) from 600 to $200 \mathrm{~nm}$ at a scan rate of $600 \mathrm{~nm} / \mathrm{min}$ (source changeover at $350 \mathrm{~nm}$ ). A molar absorptivity of $11220 \mathrm{M}^{-1} \mathrm{~cm}^{-1}$ at $388 \mathrm{~nm}$ was used to determine stock concentrations in organic solvent (MeOH or DMSO). ${ }^{12}$

\section{Thiomarinol titration with zinc sulfate under reduced conditions}

Stock solutions of TCEP and zinc sulfate were prepared in deionized water. A solution of $1 \mathrm{~mL}$ of $45-55 \mu \mathrm{M}$ thiomarinol A was prepared from a $2 \mathrm{mM}$ stock solution in $\mathrm{MeOH}$ and diluted in PBS buffer ( $\mathrm{pH}$ 7.4). UV-vis spectrum of the thiomarinol A solution was collected in a $1 \mathrm{~mL}$ 
quartz cuvette (Starna Cells, Inc) from 600 to $200 \mathrm{~nm}$ at a scan rate of $600 \mathrm{~nm} / \mathrm{min}$. From here on, one spectroscopic scan was acquired with each addition to the solution. A $10 \mathrm{mM}$ stock solution of TCEP was added to a final concentration of $90-110 \mu \mathrm{M}$ in one-fold molar excess of thiomarinol, and the characteristic $340 \mathrm{~nm}$ peak for the reduced dithiolopyrrolone was observed. ${ }^{11}$ Twenty $3 \mu \mathrm{L}$ aliquots of a $1 \mathrm{mM}$ zinc sulfate solution were sequentially added to the reduced thiomarinol solution resulting in a total of $>1.2$ molar equivalents of zinc:thiomarinol. Absorbance scans were normalized to account for the increased volume of the solution with each addition. As zinc was titrated into reduced thiomarinol, absorbance at $340 \mathrm{~nm}$ for reduced thiomarinol decreased, and a new local maximum absorbance peak at $373 \mathrm{~nm}$ for the zincthiomarinol complex appeared. The normalized absorbance values at 340 and $373 \mathrm{~nm}$ were plotted as a function of the zinc:thiomarinol molar ratio (Figure S22). The absorbance values stabilized at $\sim 0.5$, denoting the completion of the titration and a 1:2 ratio for the zinc:thiomarinol complex as observed for other metal:DTP complexes. ${ }^{13}$

\section{Growth assays of MRSA Newman and its zinc-import mutant $\Delta a d c A \Delta c n t A$}

MRSA Newman and its mutant $\triangle a d c A \Delta c n t A$ were generously provided by the Kehl-Fie lab at University of Illinois at Urbana-Champaign (Department of Microbiology). Thiomarinol inhibitory activity was tested with or without zinc using the protocol by Grim et al. ${ }^{14}$ with minor adjustments. Strains were streaked on tryptic soy agar and incubated overnight at $37{ }^{\circ} \mathrm{C}$. A single colony for each strain was used to inoculate a $5 \mathrm{~mL}$ starter culture in tryptic soy broth (TSB), which was grown overnight at $37^{\circ} \mathrm{C}$ at $250 \mathrm{rpm}$. The starter culture was used to inoculate another $5 \mathrm{~mL}$ of TSB in a ratio of 1:50 that was grown for $1-2 \mathrm{~h}$ at $37^{\circ} \mathrm{C}, 250 \mathrm{rpm}$. Wildtype and mutant strains were normalized to OD 0.40-0.45 using TSB for the growth inhibition experiment. Metal content was limited by diluting the cultures 1:100 in modified NRPMI media (chelex-treated RPMI-1640 media supplemented with $25 \mu \mathrm{M} \mathrm{MnCl}_{2}$ and $25 \mu \mathrm{M} \mathrm{FeSO}_{4}$ ). Either $195 \mu \mathrm{L}$ of cell culture or the cell-free media control were added to a clear 96-well plate (Costar). Metal replete or zinc-free samples were prepared by adding $5 \mu \mathrm{L}$ of $1 \mathrm{M} \mathrm{ZnSO}_{4}(25 \mu \mathrm{M}$ final) or water, respectively, to each well. Antibiotic stocks were prepared in DMSO at concentrations 100 times the working solution. A sample of $2 \mu \mathrm{L}$ of the antibiotic stocks were added to the respective wells, resulting in subinhibitory concentrations of the antibiotics (1/4 and 1/8 of the MIC) and making up $1 \%$ DMSO of the final culture volume $(200 \mu \mathrm{L})$. For solvent-only controls, $2 \mu \mathrm{L}$ of DMSO was added. Growth assays were performed using a CLARIOstar plus plate reader at $37^{\circ} \mathrm{C}$. Absorbance at $600 \mathrm{~nm}$ was measured and corrected for volume (set to $200 \mu \mathrm{L}$ ) through the bottom optic (10 flashes per well) using scan mode orbital averaging ( $4 \mathrm{~mm}$ scan diameter). Measurements were collected every 10 min over a $15 \mathrm{~h}$ period with intermittent shaking between readings (Figure S23). Each sample was prepared and measured in triplicate. Significance was assessed using Tukey's HSD test in the RStudio program.

\section{Generating low-level mupirocin resistant ( $\left.{ }^{L L} \mathrm{MR}\right)$ MRSA COL mutants}

Three genetically distinct low-level mupirocin resistant MRSA COL strains were generated using methods adapted from Thomas et al. ${ }^{15}$ Briefly, three separate $5 \mathrm{~mL}$ starter MRSA COL cultures 
were grown in Difco nutrient broth (DNB) overnight at $37{ }^{\circ} \mathrm{C}, 250 \mathrm{rpm}$. Each starter culture was used to inoculate five $10 \mathrm{~mL} \mathrm{NB}$ cultures supplemented with mupirocin to $20,40,80,160$, and $200 \mathrm{nM}$ (2\% DMSO final concentration). Cultures were assessed after $24 \mathrm{~h}$ of growth at $37^{\circ} \mathrm{C}$, $250 \mathrm{rpm}$. The culture with visible growth by eye at the highest concentration of mupirocin, $40 \mathrm{nM}$, was used to inoculate a second round of MRSA daughter cultures, which included three $10 \mathrm{~mL}$ NB cultures where the concentration of mupirocin was 1, 1.25, and 1.5 times higher than the parent culture. For example, the culture containing $40 \mathrm{nM}$ mupirocin was used to inoculate cultures containing 40, 50, and $60 \mathrm{nM}$ of mupirocin in the following round. After 1 week, a culture 2 times higher than the parent culture was also included in the serial passaging. This process was repeated 12 additional times (1 passage per day) with final mupirocin concentrations of 23.5, 23.5, and 28 $\mu \mathrm{M}$ (Figure S25).

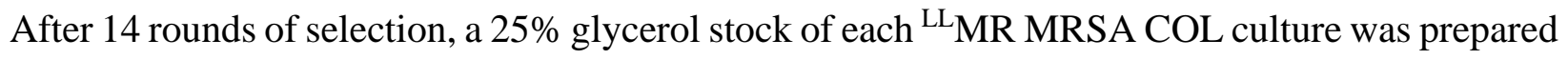
and plated on antibiotic-free LB-agar plates and incubated overnight at $37{ }^{\circ} \mathrm{C}$. Three individual colonies were selected from each plate and analyzed by colony PCR. The ileS gene was amplified using primers CAM-001 and CAM-002 (Table S3), visualized by agarose gel electrophoresis (1\% agarose), and purified using a Zymoclean Gel DNA recovery kit. PCR products were sequenced using primers CAM-001 - CAM-006 (Table S3, Eton Bioscience). Mutations were identified compared to wild type MRSA COL ileS using SnapGene.

\section{Serial passaging of MRSA COL in the presence of thiomarinol A}

From three biological samples, three thiomarinol resistant mutants were generated by serial passaging MRSA COL in the presence of thiomarinol using the methods described above for generation of ${ }^{\mathrm{LL}} \mathrm{MR}$ MRSA COL. Of the starter MRSA COL cultures at $0.0625,0.125,0.25,0.5$, 1 , and $2 \mathrm{nM}$ thiomarinol, the culture containing $0.25 \mathrm{nM}$ thiomarinol exhibited visible growth and was used to inoculate the next round of culture containing $0.25,0.3125$, and $0.375 \mathrm{nM}$ thiomarinol $(1,1.25$, and 1.5 times increase). After 1 week, a culture 2 times higher than the parent culture was also included in the serial passaging. This process was repeated 13 additional times (one passage per day) to reach thiomarinol concentrations of 205, 228, and $228 \mathrm{nM}$ (Figure S25). Mutations in the ile $S$ gene were assessed by sequencing colony PCR products as described above.

\section{Minimal inhibitory concentration determination}

The minimal inhibitory concentrations (MICs) of thiomarinol A, mupirocin, and holomycin against various MRSA strains were determined using the serial broth dilution method. Mupirocin susceptible, low-resistant, and high-resistant MRSA strains were plated on LB-agar and grown at $37^{\circ} \mathrm{C}$ for $12-16 \mathrm{~h}$. A $5 \mathrm{~mL}$ culture of MHBII was inoculated with a single bacterial colony and grown overnight at $37^{\circ} \mathrm{C}$ with shaking at $250 \mathrm{rpm}$.

An initial mupirocin stock solution of $100 \mathrm{mg} / \mathrm{mL}$ in DMSO was prepared fresh by weight and diluted as needed to generate the initial working concentration for MIC testing. A pseudomonic acid C (PAC) stock solution was prepared by weight in DMSO. Holomycin and thiomarinol A 
stock solutions were prepared by weight in DMSO and concentrations were verified by UV-vis spectroscopy $\left(\varepsilon_{388 \mathrm{~nm}}=11220 \mathrm{M}^{-1} \mathrm{~cm}^{-1}\right) .{ }^{12}$ The series of 50x concentrated antibiotic stock solutions for MIC testing were prepared by two-fold serial dilutions in DMSO. Samples of $100 \mu \mathrm{L}$ of the respective antibiotic stock dilutions were each added to $4.75 \mathrm{~mL}$ aliquots of MHBII in addition to a $100 \mu \mathrm{L}$ DMSO-only control. The optical density at $600 \mathrm{~nm}\left(\mathrm{OD}_{600}\right)$ of the MRSA starter culture was standardized to a 0.5 McFarland Standard. ${ }^{16,17}$ A sample of $25 \mu \mathrm{L}$ of the McFarland standardized MRSA overnight was added to solution to yield a final OD 600 of approximately 0.0005. Each antibiotic treatment was performed in triplicate and each MIC experiment was performed on different days at least 3 times. Cultures were incubated in a roller drum at $37{ }^{\circ} \mathrm{C}$ for $24 \mathrm{~h}$. The MIC was reported as the lowest concentration of compound that leads to no bacterial growth as determined by the $\mathrm{OD}_{600}$ (Table 1).

\section{Antibiotic cytotoxicity against HEK293T cells}

A stock of HEK293T/17 cells was obtained from the Tissue Culture Facility at UNC. The cell stock vial was warmed to $37^{\circ} \mathrm{C}$ and diluted 1:10 with supplemented DMEM (supplemented with $10 \%$ fetal bovine serum (FBS) and 100 I.U./ $\mu \mathrm{L}$ penicillin/streptomycin). Cells were grown under standard conditions $\left(37{ }^{\circ} \mathrm{C}\right.$ with $5 \% \mathrm{CO}_{2}$ ) to $50 \%$ confluency and assayed before 5 passages. To measure viability, $100 \mu \mathrm{L}$ of HEK293T/17 cells were aliquoted into a white, clear bottom, tissue culture-treated 96-well plate (Costar) at $\sim 10,000$ cells/well in supplemented DMEM. Cells were incubated for $24 \mathrm{~h}$ and treated at $\sim 50 \%$ confluency with various concentrations $(0.05-100 \mu \mathrm{M})$ of thiomarinol A, holomycin, mupirocin, and DMSO (1\%) for $24 \mathrm{~h}$.

Intracellular ATP was quantified to indicate cell viability using the CellTiter-Glo assay (Promega). A sample of $50 \mu \mathrm{L}$ of media was removed from each well and cells were incubated at RT for 30 min. Cells were lysed with the addition of $50 \mu \mathrm{L}$ of the CellTiter-Glo reagent to each well followed by orbital shaking of the 96-well plate for 2 min. Lysates were then incubated at RT without shaking for $10 \mathrm{~min}$ to stabilize luminescence signal, which was measured using the top optic of a CLARIOstar microplate reader at $0.5 \mathrm{~s}$ intervals. Each data point was performed in triplicate and repeated twice on independent days using a freshly prepared serial dilution of the antibiotics. Background luminescence was subtracted, and data were normalized to the DMSO control. A dose response curve was obtained by fitting normalized data using a four-parameter variable slope fit in GraphPad Prism to determine the half maximal effective concentration $\left(\mathrm{EC}_{50}\right)$ for each antibiotic (Figure S12).

\section{Synergy testing}

\section{$\underline{\text { Culture tube format }}$}

An overnight culture of MRSA COL was prepared in MHBII as described for MIC determination. A checkerboard of $10 \times 10$ was setup using $4.75 \mathrm{~mL}$ of MBHII, $25 \mu \mathrm{L}$ of standardized MRSA COL culture, $50 \mu \mathrm{L}$ of holomycin stock solutions in DMSO, and $50 \mu \mathrm{L}$ of mupirocin stock solution in DMSO (prepared as described above). Cultures were incubated in a roller drum at $37{ }^{\circ} \mathrm{C}$ for 24 
$\mathrm{h}$ and the $\mathrm{OD}_{600}$ was recorded. The fractional inhibitory concentration (FIC) was determined using the following equation:

$$
F I C=\frac{[\text { holomycin }]}{M I C_{\text {holomycin }}}+\frac{[\text { mupirocin }]}{M I C_{\text {mupirocin }}}
$$

MICs were determined as described above. The FIC values for five datasets indicate that holomycin and mupirocin are additive $(0.5<$ FIC $\leq 1$, Figure S24).

\section{Microplate Format}

The $\mathrm{OD}_{600}$ of an overnight of MRSA COL in MHBII was measured as a 1:10 dilution. Based on the $\mathrm{OD}_{600}, 30 \mathrm{~mL}$ of diluted culture was prepared in MHBII to yield a final $\mathrm{OD}_{600}$ of 0.0005 . This dilution was used directly in the checkerboard within $1 \mathrm{~h}$ of preparation.

Corning clear untreated 384-well plates were used for the assay (Corning 3680). A Thermo Scientific Multidrop Combi Nano Reagent Dispenser was used to backfill wells to achieve a final $2 \%$ DMSO concentration. Compounds were added to each 384-well plate using a Labcyte Echo 550 Liquid Handler. Drug volumes were determined using Labcyte's Dose Response software utilizing a stock antibiotic concentration of $0.05 \mathrm{mg} / \mathrm{mL}$ for PAC and $0.2 \mathrm{mg} / \mathrm{mL}$ for holomycin, each dissolved in DMSO. The assay volume was set to $50 \mu \mathrm{L}$ with a maximum allowed DMSO volume of $1 \%(0.5 \mu \mathrm{L})$ for each drug $(2 \%$ total or $1 \mu \mathrm{L})$. The plate layout was designed to produce 4 replicates of $8 \times 8$ checkerboards with appropriate controls as well as individual dose response curves for each compound.

The diluted MRSA culture in MHBII at an OD 600 of 0.0005 was dispensed in the prepared 384well plates using a Formulatrix TEMPEST Liquid Handler. Following cleaning with 100\% ethanol, the TEMPEST was used to deliver $49 \mu \mathrm{L}$ of inoculum to each compound well or $49 \mu \mathrm{L}$ of MHBII to control wells. Plates were incubated stationary for $20 \mathrm{~h}$ at $37^{\circ} \mathrm{C}$ in a Cytomax plate incubator. Plates were then read at $\mathrm{OD}_{600}$ using a BioTek Synergy Neo2 plate reader following shaking for $20 \mathrm{~s}$. The FIC values from 3 microplate setups indicate that holomycin and PAC are additive $(0.5<$ FIC $\leq 1$, Figure S24).

\section{Cloning of S. aureus ileS}

The isoleucyl tRNA synthetase gene (ileS) was cloned from MRSA COL. Genomic DNA from $S$. aureus COL was extracted via SDS lysis followed by phenol:chloroform:isoamyl alcohol (25:24:1) extraction and isopropanol precipitation. Cells from a $5 \mathrm{~mL}$ culture of MRSA COL were centrifuged and resuspended in $200 \mu \mathrm{L}$ of TE buffer $(10 \mathrm{mM}$ Tris, $1 \mathrm{mM}$ EDTA, pH 8.0) and treated with $50 \mu \mathrm{L}$ of a Zymobead slurry. The slurry was vortexed in $20 \mathrm{~s}$ pulses for 2 min total, with resting periods on ice. After mechanical lysis, $400 \mu \mathrm{L}$ of $10 \%$ SDS was added followed by vortexing for $1 \mathrm{~min}$. To the slurry, 1 volume of phenol:chloroform:isoamyl alcohol $(25: 24: 1)$ was added and vortexed. The extract was centrifuged at $20000 \mathrm{~g}$ for $5 \mathrm{~min}$ to separate the aqueous and organic layers. The aqueous layer was transferred to a new tube and 0.1 volume of $3 \mathrm{M}$ sodium acetate was added followed by addition of 1 volume of ice-cold isopropanol. The solution was 
then frozen at $-20{ }^{\circ} \mathrm{C}$ for $20 \mathrm{~min}$. The resulting chilled solution was centrifuged at $20000 \mathrm{~g}$ for 15 min at $4{ }^{\circ} \mathrm{C}$. The resulting pellet was washed with $70 \%$ ethanol and dried. The final DNA pellet was resuspended in $100 \mu \mathrm{L} \mathrm{TE}$ at $55^{\circ} \mathrm{C}$.

The ile $S$ gene was amplified from the gDNA using the primers in Table S3. The PCR product and the pET30a vector were digested using restriction enzymes BamHI and XhoI and ligated using T4 DNA ligase (NEB). The resulting pET30a-ileS construct was confirmed by sequencing (Eton BioScience) using primers AC-0367 - AC-0369 (Table S3).

\section{Protein expression and purification}

E. coli BL21 (DE3) Gold electrocompetent cells were transformed with pET30a-ileS. The cells were plated on a LB-agar plate with kanamycin (kan) at $50 \mu \mathrm{g} / \mathrm{mL}$. A single colony was picked and grown overnight in $5 \mathrm{~mL}$ of LB containing $50 \mu \mathrm{g} / \mathrm{mL}$ kan at $37{ }^{\circ} \mathrm{C}$ with shaking at $225 \mathrm{rpm}$. LB was inoculated with an overnight culture in a 1:500 dilution and grown at $37{ }^{\circ} \mathrm{C}, 250 \mathrm{rpm}$ until the culture reached an $\mathrm{OD}_{600}$ of $0.5-0.6$ (typically in $3.5 \mathrm{~h}$ ). Protein expression was induced with $0.2 \mathrm{mM}$ IPTG and the culture was grown at $16^{\circ} \mathrm{C}, 225 \mathrm{rpm}$ overnight (for approximately $16 \mathrm{~h}$ ).

The culture was centrifuged in a RC-3B refrigerated centrifuge (Sorvall Instruments) at $4000 \mathrm{~g}$ for $30 \mathrm{~min}$ at $4{ }^{\circ} \mathrm{C}$. Cells were resuspended in 5-10 $\mathrm{mL}$ of wash buffer (50 mM HEPES, $500 \mathrm{mM}$ $\mathrm{NaCl}, 25 \mathrm{mM}$ imidazole, $10 \%$ glycerol, $\mathrm{pH} 7.5)$ and sonicated at $30 \%$ amplitude for $90 \mathrm{~s}(0.5 \mathrm{~s}$ on, $1.5 \mathrm{~s}$ off) using a Sonic Dismembrator (Fisher Scientific model 500). Cell debris were pelleted at $14000 \mathrm{~g}$ for $20 \mathrm{~min}$ using a Sorvall RC-5B refrigerated superspeed centrifuge (Dupont Instruments). The supernatant was filtered through a $0.45 \mu \mathrm{m}$ nylon syringe filter (Corning) to remove particulates. The filtered supernatant was injected onto a $5 \mathrm{~mL}$ HisTrap HP (GE Healthcare) loaded with nickel chloride and separated using an ÄKTA Pure (Cytiva/GE Healthcare). The protein was eluted from the affinity column using a 0-100\% gradient of wash buffer to elution buffer (50 mM HEPES, $500 \mathrm{mM} \mathrm{NaCl}, 500 \mathrm{mM}$ imidazole, $10 \%$ glycerol, $\mathrm{pH}$ 7.5 ) over 8 column volumes (CVs). Hexa-histidine tagged protein eluted around $60-65 \%$ elution buffer. Fractions containing UV absorbance at $280 \mathrm{~nm}$ were collected and concentrated using a 10 kDa MWCO Amicon Ultra Centrifugal Filter to 1-3 mL.

The hexa-histidine tagged protein was further purified by size exclusion chromatography (SEC) using a Superdex 200 Increase 10/300 GL (GE Healthcare) at a flowrate of $0.35 \mathrm{~mL} / \mathrm{min}$. The column was first equilibrated with $2 \mathrm{CVs}(47 \mathrm{~mL})$ of storage buffer (50 mM HEPES, $150 \mathrm{mM}$ $\mathrm{NaCl}, 10 \%$ glycerol, $\mathrm{pH} 7.5$ ). The protein was loaded onto the column and eluted with $2 \mathrm{CVs}$ of storage buffer at a flowrate of $0.15 \mathrm{~mL} / \mathrm{min}$. Protein elution was monitored by UV at $280 \mathrm{~nm}$ and protein-containing fractions were analyzed using SDS-PAGE for purity. IleRS with a N-terminal $6 x$ His-tag have a molecular weight of $106 \mathrm{KDa}$. Fractions containing more than $90 \%$ pure IleRS were combined and concentrated in a $10 \mathrm{kDa}$ MWCO Amicon Ultra Centrifugal Filter to approximately $500 \mu \mathrm{L}$ and further assessed for purity using SDS-PAGE (Figure S15). The molar absorptivity constant of hexa-histidine tagged IleRS was calculated using ExPASy ProtParam (https://web.expasy.org/protparam/) as $155620 \mathrm{M}^{-1} \mathrm{~cm}^{-1}$ and used to estimate protein concentrations. The absorbance of concentrated proteins was measured at $280 \mathrm{~nm}$ using a Nanodrop One (Thermo Scientific). The average protein yield was about $5 \mathrm{mg} / \mathrm{L}$ of culture for IleRS. The protein was flash frozen using liquid nitrogen and stored at $-80{ }^{\circ} \mathrm{C}$. 


\section{Kinetic characterization of IleRS and active site titration}

\section{$\underline{\text { Kinetic Assays }}$}

The activity of IleRS from $S$. aureus COL was characterized using ATP-[ $\left.{ }^{32} \mathrm{P}\right]$ pyrophosphate $\left(\mathrm{PP}_{\mathrm{i}}\right)$ exchange (Figure S16). The enzyme was assayed in a buffer containing $50 \mathrm{mM}$ Tris- $\mathrm{HCl}(\mathrm{pH} 7.9)$, $50 \mathrm{mM}$ potassium chloride, $10 \mathrm{mM}$ magnesium chloride, $5 \mathrm{mM}$ TCEP, $2 \mathrm{mM}$ ATP, $1 \mathrm{mM}$ tetrasodium pyrophosphate (cold PPi), and $1 \mathrm{mM}$ tetrasodium $\left[{ }^{32} \mathrm{P}\right]$ pyrophosphate (hot PPi). For kinetic analysis, $10 \mathrm{nM}$ enzyme was used. Activity of the enzyme was measured at 6 concentrations of L-Ile $(200 \mu \mathrm{M}, 100 \mu \mathrm{M}, 50 \mu \mathrm{M}, 25 \mu \mathrm{M}$, and $12.5 \mu \mathrm{M})$. The general protocol is as follows.

A mastermix was prepared containing all reaction components excluding the enzyme, L-Ile and $\left[{ }^{32} \mathrm{P}\right] \mathrm{PPi}$. The $5 \mathrm{mM}\left[{ }^{32} \mathrm{P}\right] \mathrm{PPi}$ working solution was prepared by adding stock $\left[{ }^{32} \mathrm{P}\right] \mathrm{PPi}$ (Perkin Elmer) to cold $5 \mathrm{mM} \mathrm{PPi}$, such that the working solution had a specific activity of $10000 \mathrm{cpm} / \mu \mathrm{L}$ (measured in $14 \mathrm{~mL}$ of scintillation cocktail by a Beckman Coulter LS6500 scintillation counter).

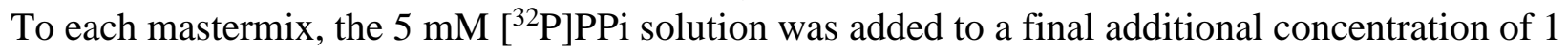
$\mathrm{mM}$ hot PPi ( $2 \mathrm{mM}$ total PPi). Reactions were initiated by addition of the enzyme to $10 \mathrm{nM}$ and incubated at RT. Time points of $100 \mu \mathrm{L}$ were taken and quenched at $0,5,10$ and $15 \mathrm{~min}$ using 500 $\mu \mathrm{L}$ of quench solution (1.6\% activated charcoal, $0.1 \mathrm{M}$ tetrasodium pyrophosphate, 3.5\% perchloric acid). After all time points were quenched, reactions were centrifuged at $20000 \mathrm{~g}$ for 12 min. The reactions were decanted, and the charcoal pellets were washed by resuspension in $1 \mathrm{~mL}$ of water. The reactions were centrifuged and decanted again before final resuspension in $500 \mu \mathrm{L}$ of water. Resuspended charcoal containing $\left[{ }^{32} \mathrm{P}\right] \mathrm{ATP}$ was transferred to $14 \mathrm{~mL}$ of scintillation cocktail and the specific activity was measured by scintillation counting.

\section{$\underline{\text { Kinetic analysis }}$}

Activity was corrected by subtracting the background activity of a substrate-free control from the activity of the full assay at each time point. Percent conversion was calculated based on the ratio of the activity of the time point to the total amount of activity added to the reaction. The ratio was then multiplied by the total amount of ATP added to the reaction $(2 \mathrm{mM})$ to calculate the concentration of $\left[{ }^{32} \mathrm{P}\right] \mathrm{ATP}$ at a given time point. Velocity data was plotted and used to determine the enzyme's kinetic parameters by fitting to the Michaelis-Menten equation using Graphpad Prism 6.0, $k_{\text {cat }}: 12.0 \pm 0.5 \mathrm{~s}^{-1}, K_{\mathrm{M}}: 40 \pm 5 \mu \mathrm{M}$; value $\pm \mathrm{SEM}$ (Figure S16).

\section{$\underline{\text { Active site titration }}$}

The fraction of active enzyme was determined by measuring the initial burst of $\left[\gamma^{32}{ }^{32}\right] \mathrm{ATP}$ consumption (Figure S16). ${ }^{18}$ The assay was performed similar to the kinetic assay with several changes. The assay contained $50 \mathrm{mM}$ Tris- $\mathrm{HCl}(\mathrm{pH} 7.9), 50 \mathrm{mM}$ potassium chloride, $10 \mathrm{mM}$ $\mathrm{MgCl}_{2}, 5 \mathrm{mM}$ TCEP, $2 \mathrm{U} / \mathrm{mL}$ yeast inorganic pyrophosphatase, and $5 \mu \mathrm{M}\left[\gamma_{-}{ }^{32} \mathrm{P}\right] \mathrm{ATP}$. A solution of $200 \mu \mathrm{M}$ ATP was diluted with $200 \mu \mathrm{M}\left[\gamma^{3}{ }^{32} \mathrm{P}\right] \mathrm{ATP}$ (Perkin Elmer) to obtain a final specific activity of $133333 \mathrm{cpm} / \mu \mathrm{L}$. This solution was then used to constitute all ATP in the reaction (a final specific activity of $3333 \mathrm{cpm} / \mu \mathrm{L}$ ). Reactions were performed in $150 \mu \mathrm{L}$ and initiated by addition of the enzyme at RT. Immediately following enzyme addition, a $15 \mu \mathrm{L}$ aliquot was 
quenched using the quench solution ( $250 \mu \mathrm{L}$ of $1.6 \%$ activated charcoal, $3.5 \%$ perchloric acid). Time points were taken at $0,1,2,5,10,15$, and $30 \mathrm{~min}$ as $15 \mu \mathrm{L}$ aliquots. After all time points were taken and quenched, reactions were centrifuged at $20000 \mathrm{~g}$ for $15 \mathrm{~min}$. The reactions were decanted, and the charcoal pellets were washed by resuspension in $500 \mu \mathrm{L}$ of water. The resuspensions were centrifuged and decanted again before final resuspension in $500 \mu \mathrm{L}$ of water. Resuspended charcoal was transferred to $10 \mathrm{~mL}$ of scintillation cocktail and specific activity was measured by scintillation counting.

Data was analyzed by fitting the linear portion of ATP consumption following the initial burst. ${ }^{18}$ The activity at $\mathrm{t}=0$ was used as the initial activity of the ATP in the reaction (value $\mathrm{x}$ ). The difference between the $y$-intercept (value y) and this value represents the initial ATP consumption. The number of active sites (n) was computed according to the following equation: ${ }^{18}$

$$
n=1.07\left(\frac{x-y}{x}\right)\left(\frac{[A T P]_{0}}{[E]_{0}}\right)
$$

For IleRS, $0.65 \pm 0.03$ (average $\pm \mathrm{SD}$ ) active sites per enzyme were determined.

\section{Inhibition of IleRS by mupirocin, holomycin and thiomarinol A}

Inhibition of IleRS was measured using a ATP- $\left[{ }^{32} \mathrm{P}\right] \mathrm{PP}_{\mathrm{i}}$ exchange assay, which was modified from a method reported by Pope et al. ${ }^{19}$ Each reaction contained $50 \mathrm{mM}$ Tris- $\mathrm{HCl}(\mathrm{pH}$ 7.9), $50 \mathrm{mM}$ potassium chloride, $5 \mathrm{mM} \mathrm{MgCl} 2,5 \mathrm{mM}$ TCEP, $2 \mathrm{mM}$ ATP, $2 \mathrm{mM} \mathrm{PPi}, 2 \mathrm{mM}$ L-isoleucine, antibiotic or solvent control (0.5\% DMSO or $2 \%$ methanol) and $10 \mathrm{nM}$ IleRS. Reactions were initiated by the addition of $2 \mathrm{mM}$ ATP and $2 \mathrm{mM}$ L-Ile and incubated at $37^{\circ} \mathrm{C}$. After $1 \mathrm{~h}$, a small volume of $\left[{ }^{32} \mathrm{P}\right] \mathrm{PP}_{\mathrm{i}}$ (Perkin Elmer) was spiked into the reaction to yield a specific activity of 2000 $\mathrm{cpm} / \mu \mathrm{L}$. Reactions were incubated at $37{ }^{\circ} \mathrm{C}$ for an additional $1 \mathrm{~h}$. Reactions were then quenched and processed in the same manner as for the kinetic analysis of IleRS. Relative activity was calculated as the ratio of background-corrected specific activity of the reaction containing antibiotics compared to the control reaction without antibiotics. For experiments for mupirocin using DMSO as a solvent, the control reaction containing DMSO was performed in triplicate and the average was used for comparison. For experiments for holomycin and thiomarinol A using methanol as a solvent, the control reaction containing methanol was performed in duplicate and the average was used for comparison. To account for tight binding of the inhibitors, the dose response data were fit to the Morrison equation ${ }^{20}$ using Graphpad Prism 6.

$$
\frac{v_{i}}{v_{0}}=1-\frac{\left([E]_{\mathrm{T}}+[I]_{\mathrm{T}}+K_{i}^{a p p}\right)-\sqrt{\left([E]_{\mathrm{T}}+[I]_{\mathrm{T}}+K_{i}^{a p p}\right)^{2}-4[E]_{\mathrm{T}}[I]_{\mathrm{T}}}}{2[E]_{\mathrm{T}}}
$$

Here, the inhibitor concentration-dependent relative activity of the enzyme $\left(\frac{v_{i}}{v_{0}}\right)$ is a real solution for the above quadratic solution where $[E]_{\mathrm{T}}$ is total active enzyme concentration, $\left[I_{\mathrm{T}}\right.$ is total inhibitor concentration, and $K_{i}^{a p p}$ is the apparent inhibitory constant. The equation below is used for a tight binding competitive inhibitor by Copeland et al.: ${ }^{20}$ 


$$
K_{i}^{a p p}=K_{i}\left(1+\frac{[S]}{K_{\mathrm{M}}}\right)
$$

The substrate concentration, [S]; Michaelis constant, $K_{\mathrm{M}}$; and $[E]_{\mathrm{T}}$ are set constant for the fit (2 $\mathrm{mM}$ of L-Ile, $40 \mu \mathrm{M}$ and $6.5 \mathrm{nM}$ respectively). Data are shown in Figure 4 and S17.

\section{Isothermal titration calorimetry}

Buffer was prepared fresh in $2 \mathrm{~L}$ deionized water $(10 \mathrm{mM}$ sodium phosphate, $50 \mathrm{mM}$ potassium sulfate, with or without $1 \mathrm{mM}$ TCEP, $\mathrm{pH} 7.4$ ), degassed, and refrigerated at $4{ }^{\circ} \mathrm{C}$. A slide-A-lyzer® dialysis cassette, $7 \mathrm{kDa}$ MWCO (ThermoScientific) was equilibrated in $600 \mathrm{~mL}$ of buffer for at least $5 \mathrm{~min}$. Approximately $500 \mu \mathrm{L}$ of thawed protein solution was added into the dialysis cassette and excess air was removed using a $1 \mathrm{~mL}$ syringe (Norm-Ject) and beveled needle (20 G, BD). The protein-containing cassette was placed in $600 \mathrm{~mL}$ of buffer and protein was dialyzed for 2-3 $\mathrm{h}$ three times using fresh buffer. The concentration of dialyzed protein was determined using the absorbance at $280 \mathrm{~nm}$ (Thermo Scientific Nanodrop One). Dialyzed proteins were diluted to the desired concentration in the same buffer and DMSO was added to $4 \%$.

The ligands (mupirocin and thiomarinol A) were resuspended in DMSO to a stock concentration of $1 \mathrm{mM}$. This stock was used to prepare the working solution for ITC experiments by dilution with dialysis buffer and a calculated volume of DMSO was added to the working solution to a total percentage of $4 \%$.

ITC titrant solutions were at a final concentration at least seven and a half times higher than the cell solutions. For each protein batch, a control titration of 225-350 $\mu \mathrm{M}$ mupirocin into 30-45 $\mu \mathrm{M}$ IleRS was performed to validate the concentration of active IleRS. If needed, the concentration of the protein was adjusted such that $\mathrm{n}=1$ when fitting to the One Set of Sites model. This adjusted protein concentration was used to back calculate the concentration of IleRS $(225-350 \mu \mathrm{M})$ used to titrate into mupirocin and thiomarinol $(30-45 \mu \mathrm{M})$.

All ITC experiments were performed at $25^{\circ} \mathrm{C}$ using a MicroCal Auto-ITC200 at the UNC Macromolecular Interactions Facility. Titrations were performed at a stirring speed of $750 \mathrm{rpm}$, spacing of 150 or $180 \mathrm{~s}$, and a with a reference power of $8 \mu \mathrm{cal} / \mathrm{s}$ in high feedback mode. The titrations began with a dummy injection of $0.2 \mu \mathrm{L}$ followed by $37 \times 1 \mu \mathrm{L}$ injections. A "plates prerinse syringe clean" method was used to rinse the syringe with buffer before the experiment. All data were fit to a one set of sites model using the Origin software with the exception of the experiments for thiomarinol A under reducing conditions, which could not be fitted well using the 1:1 model of thiomarinol binding (Figure 5, S18-S19).

\section{Circular dichroism thermal melts}

Secondary structure and thermal melt analysis of IleRS in the presence of mupirocin, holomycin, PAC-holo, or thiomarinol A were performed using a Chirascan spectrometer (Applied Photophysics) coupled to a water bath to regulate temperature (Figure S20-S21). The CD sample buffer was prepared using the following stocks: $10 \mathrm{mM}$ monobasic, $50 \mathrm{mM}$ potassium sulfate; 10 $\mathrm{mM}$ dibasic sodium phosphate, $50 \mathrm{mM}$ potassium sulfate; and $1 \mathrm{M}$ TCEP. For experiments completed under reducing conditions, TCEP was added to a final concentration of $0.5 \mathrm{mM}$. The 
$\mathrm{pH}$ was corrected to 7.4 using the aforementioned monobasic and dibasic stock solutions. IleRS was exchanged into the desired buffer for circular dichroism using a PD-10 column (GE Healthcare). Small molecule stock solutions were prepared in methanol and final CD samples were prepared to be $500 \mu \mathrm{L}$ with $5 \% \mathrm{MeOH}$. Samples were degassed and incubated on ice for approximately $1 \mathrm{~h}$ before analysis. Ellipticity (mdeg) was measured at $20^{\circ} \mathrm{C}$ in a $0.5 \mathrm{~mm}$ slide quartz cuvette from 280 to $180 \mathrm{~nm}$ ( $0.5 \mathrm{~nm}$ step, $1 \mathrm{~nm}$ bandwidth, $1 \mathrm{~s}$ per point).

A thermal melt of the protein in the presence of mupirocin, holomycin, PAC-holo or thiomarinol A was performed to assess shifts in protein stability in comparison to a $\mathrm{MeOH}$ control which is indicative of small molecule binding (Figure 5 and S21). The CD signal was measured at $210 \mathrm{~nm}$ increasing the temperature from $20{ }^{\circ} \mathrm{C}$ to $90{ }^{\circ} \mathrm{C}$ in $1{ }^{\circ} \mathrm{C}$ increments holding at $30 \mathrm{~s}$ per temperature increment. The exact temperature of the sample at the time of measurement was recorded (rather than the target value) for accuracy. The melting temperature $\left(T_{m}\right)$ was determined by fitting the derivative plot of the thermal melt data to the following equation as described by John and Weeks using Matlab: ${ }^{21}$

$$
\frac{d(\text { signal })}{d T}=A f(1-f) T^{2}
$$

Where $T$ is temperature in Kelvin, $A$ is an arbitrary scaling factor, and $f$ is described as:

$$
f=\frac{\exp \left[\frac{\Delta H_{u}}{R}\left(\frac{1}{T_{m}}-\frac{1}{T}\right)\right]}{\exp \left[\frac{\Delta H_{u}}{R}\left(\frac{1}{T_{m}}-\frac{1}{T}\right)\right]+1}
$$

Where $R$ is the universal gas law constant $\left(9.187 \times 10^{-3} \mathrm{kcal} / \mathrm{mol} \cdot \mathrm{K}\right)$ and an arbitrary scaling factor, $A$, the enthalpy of unfolding, $\Delta H_{u}(\mathrm{kcal} / \mathrm{mol})$, and the melting temperature, $T_{m}(\mathrm{~K})$, were outputs of the fit. The Matlab program is available upon request. Melting temperatures were statistically analyzed in RStudio using a Tukey HSD test (Table S2).

\section{Binding constant calculations}

Based on the integrated van't Hoff equations, the binding constant of ligand-protein interaction at melting temperature with ligand present can be described as: ${ }^{22}$

$$
K_{T m, L}=\frac{\exp \left[\frac{-\Delta H_{T_{m, 0}}}{R}\left(\frac{1}{T_{m, L}}-\frac{1}{T_{m, 0}}\right)+\frac{\Delta C_{p, T_{m, 0}}}{\mathrm{R}}\left(\ln \left(\frac{T_{m, L}}{T_{m, 0}}\right)+\frac{T_{m, 0}}{T_{m, L}}-1\right)\right]}{[L]-\frac{[P]}{2}}
$$

Here, $T_{m, 0}$ is the melting temperature of the protein, $P$, without any ligand, $L$, present and $T_{m, L}$ is the melting temperature in the presence of $L$. The $\Delta H_{T_{m, 0}}$ is the enthalpy of unfolding at the melting temperature and $\Delta C_{p, T_{m, 0}}$ is the heat capacity of unfolding.

The $\Delta H_{T_{m, 0}}$ for IleRS was determined to be $75 \mathrm{kcal} / \mathrm{mol}$ by differential scanning calorimetry and $\Delta C_{p, T_{m, 0}}$ was approximated to be $3 \mathrm{kcal} / \mathrm{mol} \cdot \mathrm{K}$ by Brown, $\mathrm{M}$. et al. ${ }^{23}$ These parameters were used in our calculations along with the melting temperatures with and without ligand we determined by $\mathrm{CD}$ thermal melts as described above. 
Thus, the binding dissociation constant of a 1:1 ligand-protein interaction at $25^{\circ} \mathrm{C}$ can be calculated using the enthalpy of the binding interaction at $25^{\circ} \mathrm{C}, 1$ atmospheric pressure, and $\mathrm{pH}$ $7.4, \Delta H^{\circ \prime}$, and the heat capacity, $\Delta C_{p, L}$ of the ligand protein complex:

$$
K_{d, 25^{\circ} \mathrm{C}}=\frac{1}{K_{T m, L} \exp \left[\frac{-\Delta H^{\circ \prime}}{R}\left(\frac{1}{T_{25^{\circ} \mathrm{C}}}-\frac{1}{T_{m, L}}\right)+\frac{\Delta C_{p, L}}{\mathrm{R}}\left(\ln \left(\frac{T_{25^{\circ} \mathrm{C}}}{T_{m, L}}\right)-\frac{T_{25^{\circ} \mathrm{C}}}{T_{m, L}}+1\right)\right]}
$$

Here, the enthalpy was determined through ITC experiments at $25{ }^{\circ} \mathrm{C}$ and the heat capacity is assumed to be negligible. ${ }^{22}$ Therefore:

$$
K_{d, 25^{\circ} \mathrm{C}}=\frac{1}{K_{T m, L} \exp \left[\frac{-\Delta H^{\circ \prime}}{R}\left(\frac{1}{T_{25^{\circ} \mathrm{C}}}-\frac{1}{T_{m, L}}\right)\right]}
$$

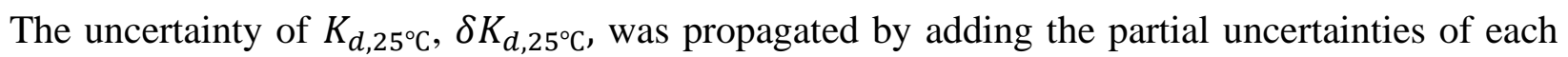
measured variable in quadrature as follows:

$$
\begin{aligned}
& \delta K_{d, 25^{\circ} \mathrm{C}} \\
& =\sqrt{\left(\frac{\partial K_{d, 25^{\circ} \mathrm{C}}}{\partial K_{T m, L}} \delta K_{T m, L}\right)^{2}+\left(\frac{\partial K_{d, 25^{\circ} \mathrm{C}}}{\partial \Delta H^{\circ \prime}} \delta \Delta H^{\circ \prime}\right)^{2}+\left(\frac{\partial K_{d, 25^{\circ} \mathrm{C}}}{\partial T_{m, L}} \delta T_{m, L}\right)^{2}+\left(\frac{\partial K_{d, 25^{\circ} \mathrm{C}}}{\partial T_{25^{\circ} \mathrm{C}}} \delta T_{25^{\circ} \mathrm{C}}\right)^{2}}
\end{aligned}
$$

Where $\delta \Delta H^{\circ \prime}, \delta T_{m, L}$, and $\delta T_{25^{\circ} \mathrm{C}}$ are the standard errors of the $\Delta H^{\circ \prime}, T_{m, L}$, and $T_{25^{\circ} \mathrm{C}}$ measurements. Here, $\delta K_{T m, L}$ is determined by the following expression:

$$
\delta K_{T m, L}=\sqrt{\left(\frac{\partial K_{T m, L}}{\partial L} \delta L\right)^{2}+\left(\frac{\partial K_{T m, L}}{\partial P} \delta P\right)^{2}+\left(\frac{\partial K_{T m, L}}{\partial T_{m, L}} \delta T_{m, L}\right)^{2}+\left(\frac{\partial K_{T m, L}}{\partial T_{m, o}} \delta T_{m, o}\right)^{2}}
$$

Again, $\delta T_{m, L}$ and $\delta T_{m, o}$ are the standard errors of these measurements and the standard error in $\mathrm{L}$ and $\mathrm{P}$ concentration were estimated to be $5 \cdot 10^{-7} \mathrm{M}$ (i.e. $0.5 \mu \mathrm{M}$ ). Data are listed in Figure 5 and Table S1.

\section{Thermodynamic value calculations}

The Gibbs free energy $\left(\Delta \mathrm{G}^{\circ \prime}\right)$ of the mupirocin and thiomarinol binding interactions with IleRS were calculated from the estimated dissociation constant $\left(K_{d}\right)$ at $25^{\circ} \mathrm{C}, \mathrm{pH} 7.4$ :

$$
\Delta G^{\circ \prime}=-R T \ln \left(1 / K_{d}\right)
$$

Where $\mathrm{R}$ is the universal gas law constant, $1.9859 \cdot 10^{-3} \mathrm{kcal} / \mathrm{mol} \cdot \mathrm{K}$, and $\mathrm{T}$ is the temperature in Kelvin, $298.15 \mathrm{~K}$, with an estimated error $(\delta T)$ of $0.05 \mathrm{~K}$.

The uncertainty of $\Delta G^{\circ \prime}, \delta \Delta G^{\circ \prime}$, was propagated by adding the partial uncertainties of each measured variable in quadrature as follows: 


$$
\delta \Delta G^{\circ \prime}=\sqrt{\left(\frac{\partial \Delta G^{\circ \prime}}{\partial T} \delta T\right)^{2}+\left(\frac{\partial \Delta G^{\circ \prime}}{\partial K_{d}} \delta K_{d}\right)^{2}}
$$

Which is equivalent to:

$$
\delta \Delta G^{\circ \prime}=\sqrt{\left(\left(-R \ln \left(\frac{1}{K_{d}}\right)\right) \delta T\right)^{2}+\left(\left(\frac{R T}{K_{d}}\right) \delta K_{d}\right)^{2}}
$$

Recall how standard enthalpy $\left(\Delta H^{\circ \prime}\right)$ and entropy $\left(\Delta S^{\circ \prime}\right)$ contribute to the Gibbs free energy of a reaction:

$$
\Delta G^{\circ \prime}=\Delta H^{\circ \prime}-T \Delta S^{\circ \prime}
$$

Rearranging the expression to solve for entropy:

$$
\Delta S^{\circ \prime}=\frac{\Delta H^{\circ \prime}-\Delta G^{\circ \prime}}{T}
$$

Where the enthalpy of the binding reaction was measured using ITC at $25^{\circ} \mathrm{C}\left(\Delta S^{\circ \prime}\right)$, the Gibbs free energy $\left(\Delta G^{\circ \prime}\right)$ was calculated as described above, and the temperature is $298.15 \pm 0.05 \mathrm{~K}$. The uncertainty of $\Delta S^{\circ \prime}, \delta \Delta S^{\circ \prime}$, was propagated by adding the partial uncertainties of each measured variable in quadrature as follows:

$$
\delta \Delta S^{\circ \prime}=\sqrt{\left(\frac{\partial \Delta S^{\circ \prime}}{\partial \Delta H^{\circ \prime}} \delta \Delta H^{\circ \prime}\right)^{2}+\left(\frac{\partial \Delta S^{\circ \prime}}{\partial \Delta G^{\circ \prime}} \delta \Delta G^{\circ \prime}\right)^{2}+\left(\frac{\partial \Delta S^{\circ \prime}}{\partial T} \delta T\right)^{2}}
$$

Which is equivalent to:

$$
\delta \Delta S^{\circ \prime}=\sqrt{\left(\frac{1}{T} \delta \Delta H^{\circ \prime}\right)^{2}+\left(\frac{-1}{T} \delta \Delta G^{\circ \prime}\right)^{2}+\left(\frac{\Delta G^{\circ \prime}-\Delta H^{\circ \prime}}{T^{2}} \delta T\right)^{2}}
$$

Here, $\delta \Delta H^{\circ \prime}$ is the respective standard error of the ITC measurements $\delta \Delta G^{\circ \prime}$ was determined above. Again, $\delta T$ is estimated to be 0.05 Kelvin. Data are listed in Table S1. 


\section{Supplementary Figures}
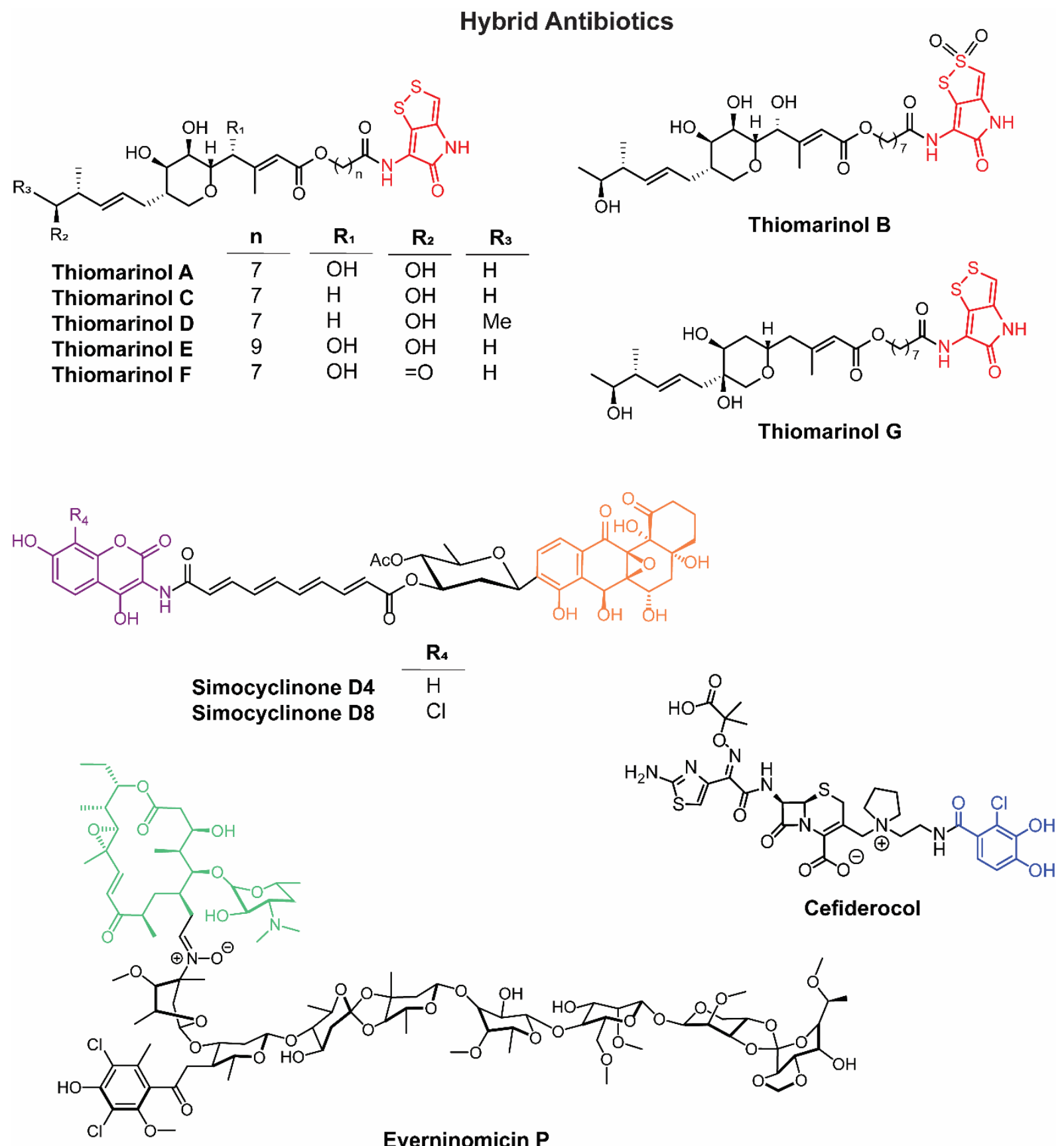

Figure S1. Chemical structures of the thiomarinol family of hybrid antibiotics (A-G) and the other hybrids discussed in this paper: the simocyclinones, cefiderocol, and everninomicin P. The dithiolopyrrolone (DTP) moieties of the thiomarinols are shown in red; the novobiocin component of the simocyclinones in purple and the gaudimycin B component in orange; the catecholate siderophore mimic of cefiderocol is shown in blue; the rosamicin component of everninomicin $\mathrm{P}$ in green. 


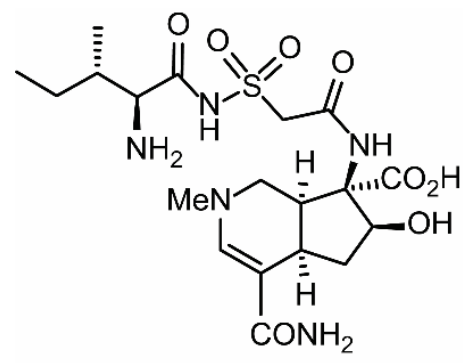

SB-203207

Streptomyces sp.

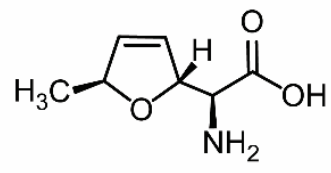

Furanomycin Streptomyces sp.

Figure S2. IleRS inhibitor natural products SB-203207 and furanomycin. 
\|leS/1-917 1 MDYKETLLMPKTDFPMRGGLPNKEPQI QEKMDAEDQYHKALEKNKGNETFILHDGPPYAN 60 MUPA/1-102 1 MTKKYLNTQNE I SAFWNTQKI FKKS I DNRKGQESFVFYDGPPTANGLPHAGHVLGRVIKD 60

\|leS/1-917 61 GNLHMGHALNKI LKDF I VRYKTMQGFYAPYVPGWDTHGLPIEQALTKKGVDRKKMSTAEF 120 MUPA 1-102 61 LVARLKTMQGFYVERKAGWDTHGLPVELEVEKKIGIKGKQDIEKYG IENFINECKKSVFN 120

\|eS/1-917 121 REKCKEFALEQIELQKKDFRRLGVRGDFNDPY I TLKPEYEAAQ IR I FGEMADKGL I YKGK 180 MupA/1-102 121 YEKEWRDF SKDLGYWDMDSPY I TLENNY I ESWWN I LSTFHKKGLLYKGHKVTPYCTHDQ 180

\|leS/1-917 181 KPVYWSPSSESSLAEAE I EYHDKRSAS I YVAFDVKDDKGVVDADAKF I IWT T TPWT I PSN 240 MUPA/1-102 181 TALSSHEVAQGYKNVKDLSAVVKFQL TNSKDTYFLSWT T TPWTLPANVALA INKDLNYSK 240

\|leS/1-917 241 VA I TVHPELKYGQYNVNGEKY | I AEALSDAVAEALDWDKAS I KLEKEYTGKELEYVVAQH 300 MUPA1-102 241 IRVENEYYILATDL INS I I TEKYEI IDTFSGSNL I NLKYI PPFESDGLVNAYYVVDGEFV 300

\|leS/1-917 301 PFLDRESLVINGDHVTTDAGTGCVHTAPGHGEDDY IVGQKYELPVISPIDDKGVFTEEGG 360 MUPA1-102 301 TNSEGTG I VH I APAHGEDDYQL VLERDLDFLNVI TREGVYNDRFPELVGNKAKNSD IE I । 360

/leS/1-917 361 QFEGMFYDKANKAVTDLLTEKGALLKLDF I THSYPHDWRTKKPVIFRATPQWFAS I SKVR 420 MUPA1-102 361 KLLSKKQLLYKKQKYEHNYPHCWRCGNPL I YYAMEGWF I KTTNFKNE I INNNNN I EWFPS 420

\|leS/1-917 421 QD I LDA I ENTNFKVNWGKTR I YNMVRDRGEWV I SRQRWWGVPLPVFYAENGE I I MTKETV 480 MUPA/1-102 421 HI KEGRMGNFLENMVDWN I GRNRYWGTPLNWWICNDCNHEYAPSS I KDLQNNS INKIDED 480

\|leS/1-917 481 NHVADLFAEHGSN IWFEREAKDLLPEGFTHPGSPNGTFTKETDIMDWWDSGSSHRGVLE 540 MUPAV1-102 481 I ELHRPYVDN I TLSCPKCNGKMSRVEEVIDWWDSGSMPFAQHHYPFDNQKIFNQHFPAD 540

\|leS/1-917 541 TRPELSFPADMYLEGSDQYRGWFNSSITTSVATRGVSPYKFLLSHGFVMDGEGKKMSKSL 600 MUPA1-102 541 FIAEGVDQTRGWFYSLLVIST I LKGKSSYKRALSLGH I LDSNGKKMSKSKGNVINPTEL I 600

\|eS/1-917 601 GNVIVPDQVVKQKGAD I ARLWVSSTDYLADVR I SDE I LKQTSDVYRKIRNTLRFMLGN I N 660 MUPA1-102 601 NKYGADSLRWAL I SDSAPWNNKRF SEN IVAQT KSKF IDTLDN I YKFYNMYNKIDHYNPNN 660

\|eS/1-917 661 DFNPDTDSI PESELLEVDRYLLNRLREFTAST INNYENFDYLNIYQEVQNFINVELSNFY 720 MUPA1-102 661 E I TKSRNTLDNWALSRLNTL I KESN I YVNNYDF TSAARL I NEYTNT I SNWY IRRSRGRFW 720

/leS/1-917 721 LDYGKD I LYIEQRDSHIRRSMQTVLYQILVDMTKLLAP I LVHTAEEWWHTPHVKEESVH 780 MUPA1-102 721 EQG I SNDKKDAYNTLYEILTTLSRLVAPFVPFISEKI HYNLTGKSVHLQDYPQYKESFIN 780

\|eS/1-917 781 LADMPKVVEVDQALLDKWRTFMNLRDDVNRALETARNEKVIGKSLEAKVTIASNDKFNAS 840 MUPA1-102 781 QALEDEMHTVIKIVELSRQARKNADLKI KQPLSKMVI KPNSQLNLSFLPNYYSI I KDELN 840

\|eS/1-917 841 EFLTSFDALHQLFIVSQVKVVDKLDDQATAYEHGDIVIEHADGEKCERCWNYSEDLGAVD 900 MupA/1-102 841 I KN I ELTDN I NDY I TYELKLNFSSVGPKLGNKTKN IQTL IDSLSEYDKKSL IESNNFKSL 900

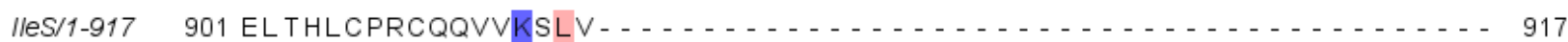
MUPA1-102 901 SSDAELTKDDF I I KTLPKDSYQL SEDNDCV I LLDKNLSPEL IREGHAREL IRL IQQLRKK 960

IIeS/1-917

MUPA1-102 961 KNLPINQR IDIYIGVTGELLES I KTNKNMFKENLL I KN I HLNVIDEYENT I HFNNKE I K I 1020 IleS/1-917 - - .

MUPA1-102 1021 SLLY

Figure S3. Sequence alignment of MupA and IleRS. Sequence alignment of IleRS from MRSA COL and MupA from ATCC MRSA BAA-1556 reveals a 29.65\% sequence identity (generated in Jalview 2.11.1.0) ${ }^{24}$ Conserved residues are colored using the Zappo color scheme (negative, red; positive, blue; aliphatic/hydrophobic, salmon; hydrophilic, green; conformationally special, magenta; aromatic, orange). MupA contains an additional $\mathrm{C}$-terminal domain characteristic of eukaryotic isoleucyl-tRNA synthetases (107 residues). 
Query: Pseudoalteromonas sp. SANK 73390 plasmid pTML1 carrying thiomarinol

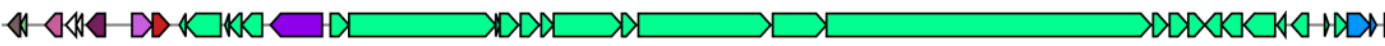

AUSV01000137 Pseudoalteromonas luteoviolacea 2ta16 PI2ta16_Contig176 Total score: 58.5 Cumulative Blast bit score: 54833

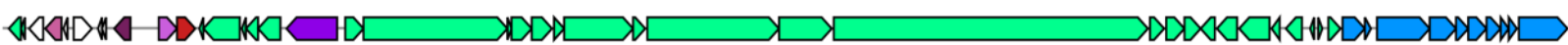

Figure S4. Thiomarinol biosynthetic gene clusters. From the first identified producer Pseudoaltermonas sp. SANK 73390 and the strain used in our study, P. luteoviolacea 2 ta16. MultiGeneBlast identified $P$. luteoviolacea 2 ta16 as possessing the thiomarinol cluster with $81 \%$ average sequence identity. 
(a)

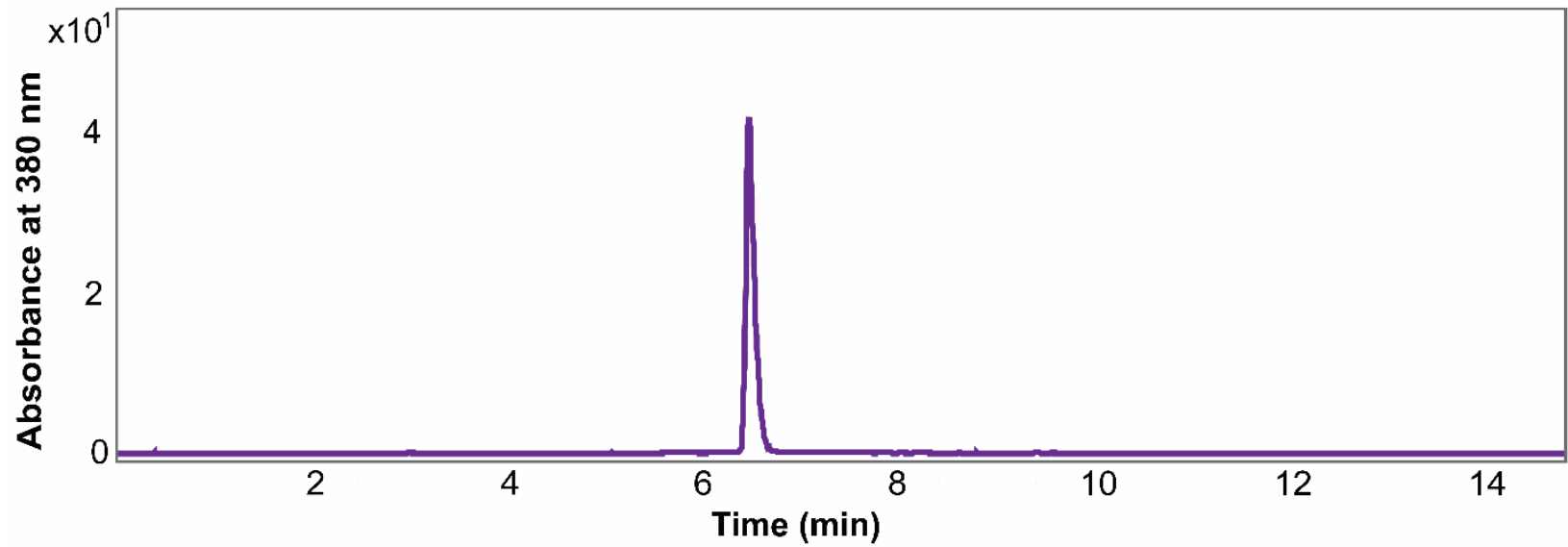

(b)

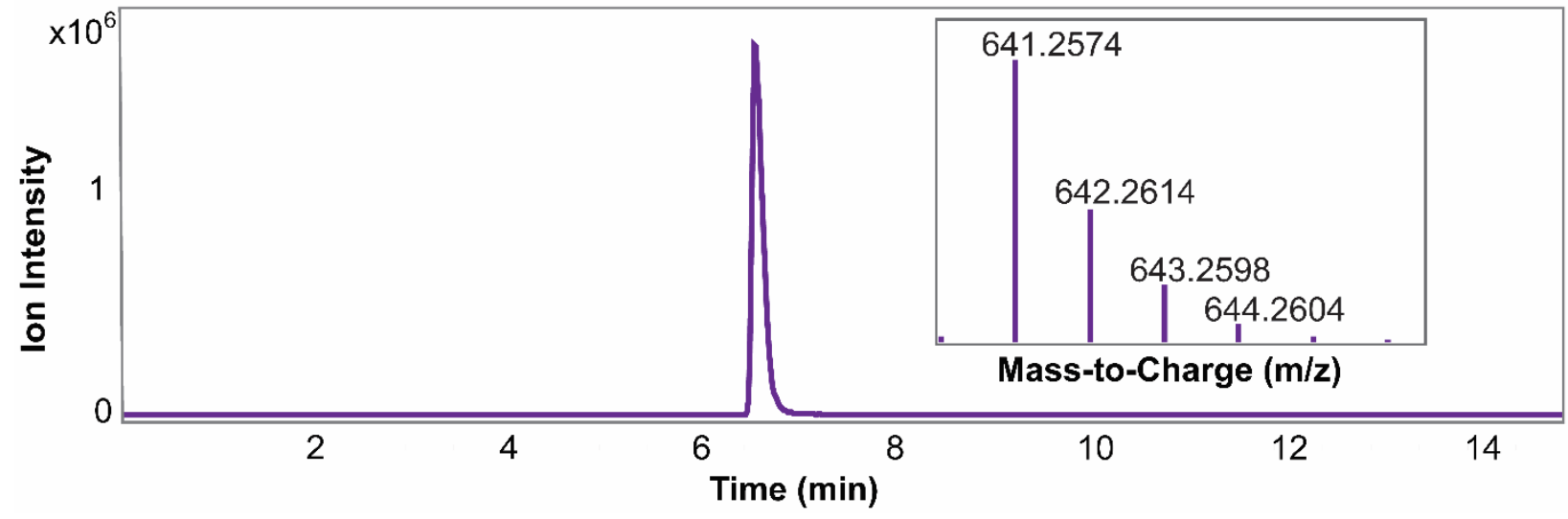

Figure S5. LC-HRMS purity analysis of thiomarinol A used in this study. (a) UV trace at 380 $\mathrm{nm}$ and (b) Total ion chromatogram (TIC) of thiomarinol where the solvent control was subtracted as background. Thiomarinol A was purified from P. luteoviolacea 2 ta16 and its mass spectrum is shown in the inset $\left([\mathrm{M}+\mathrm{H}]^{+}\right.$: calculated 641.2561, observed 641.2574). 


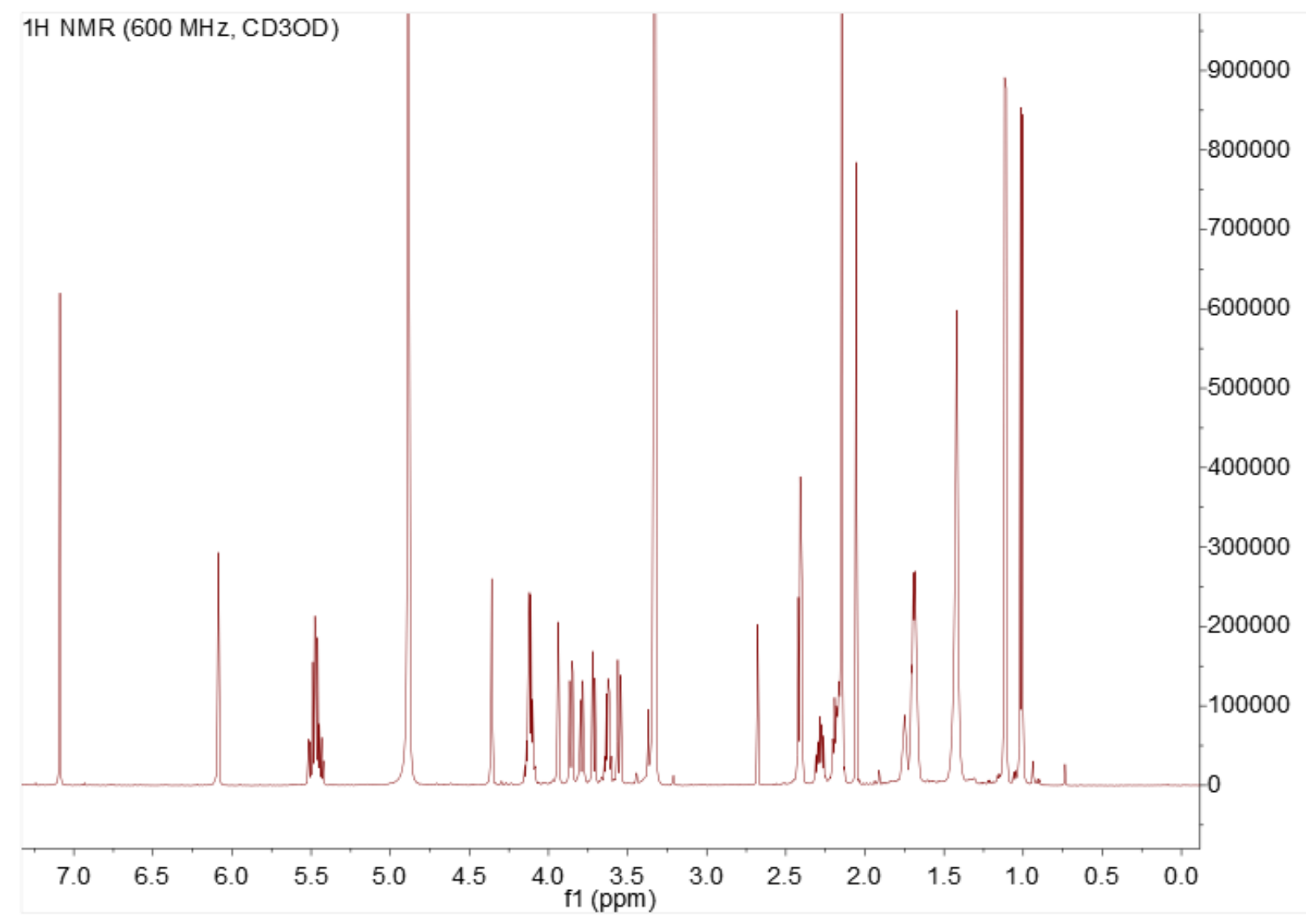

Figure S6. ${ }^{1} \mathrm{H}(600 \mathrm{MHz}) \mathrm{NMR}$ of thiomarinol A in MeOD. 


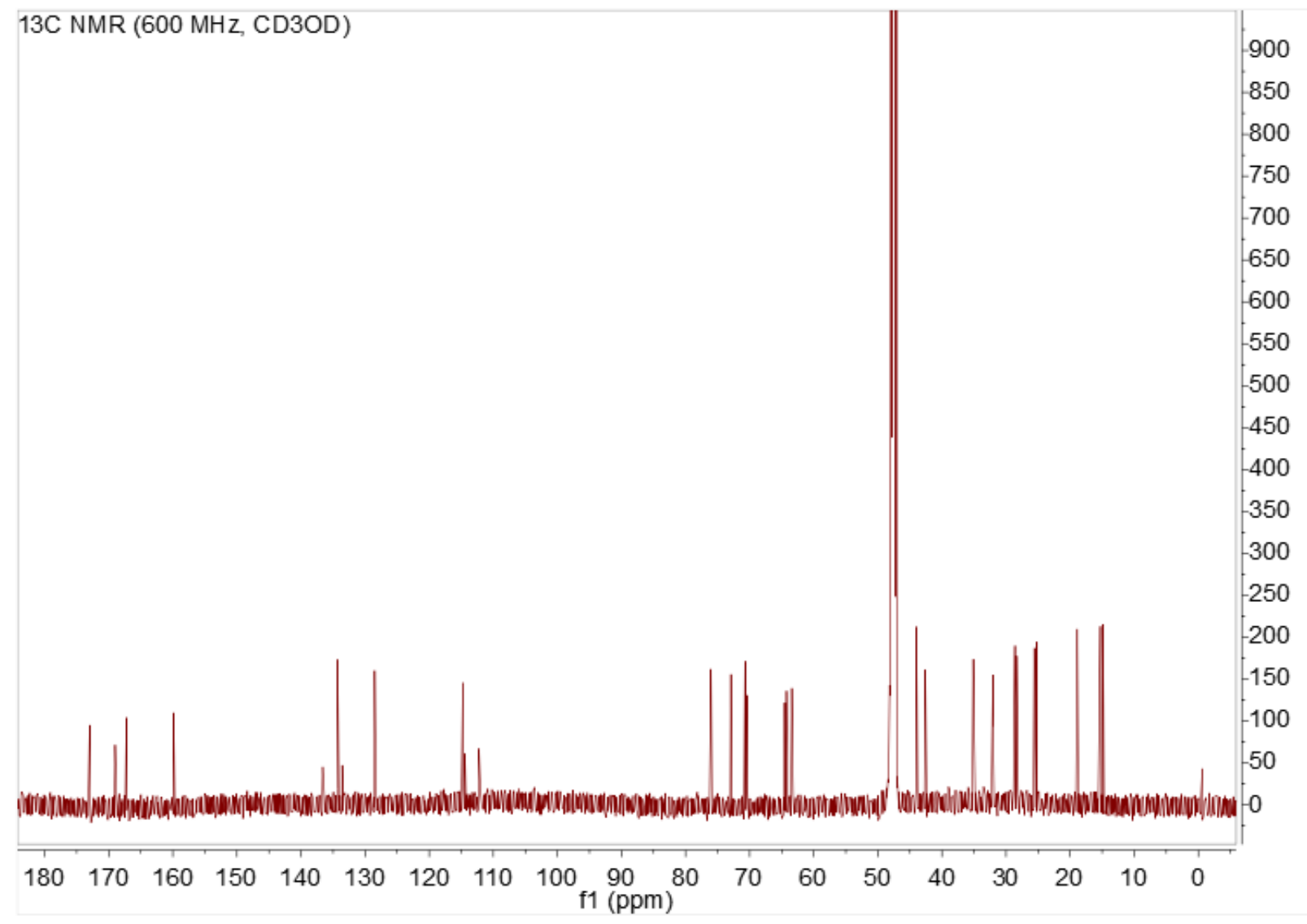

Figure S7. ${ }^{13} \mathrm{C}(151 \mathrm{MHz}) \mathrm{NMR}$ of thiomarinol A in MeOD. 
(a)

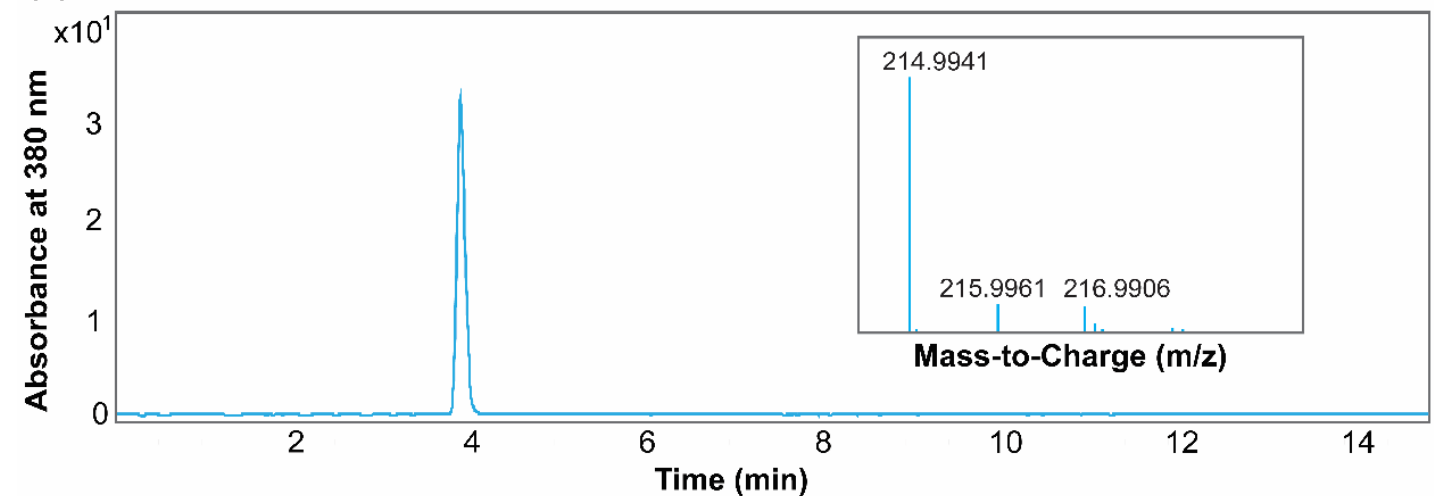

(b)

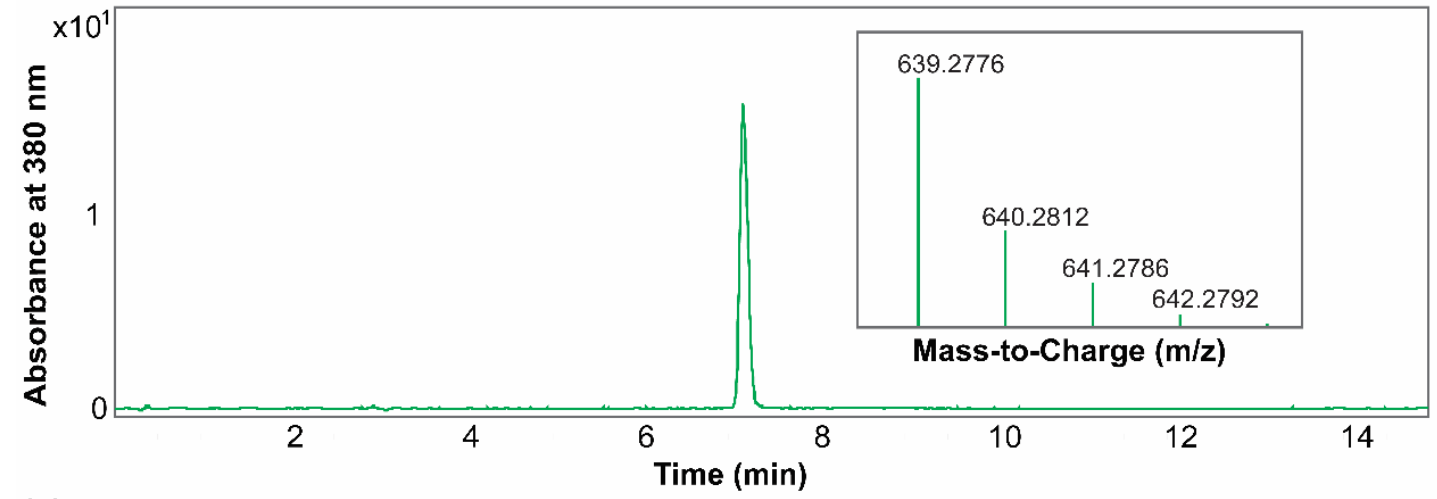

(c)

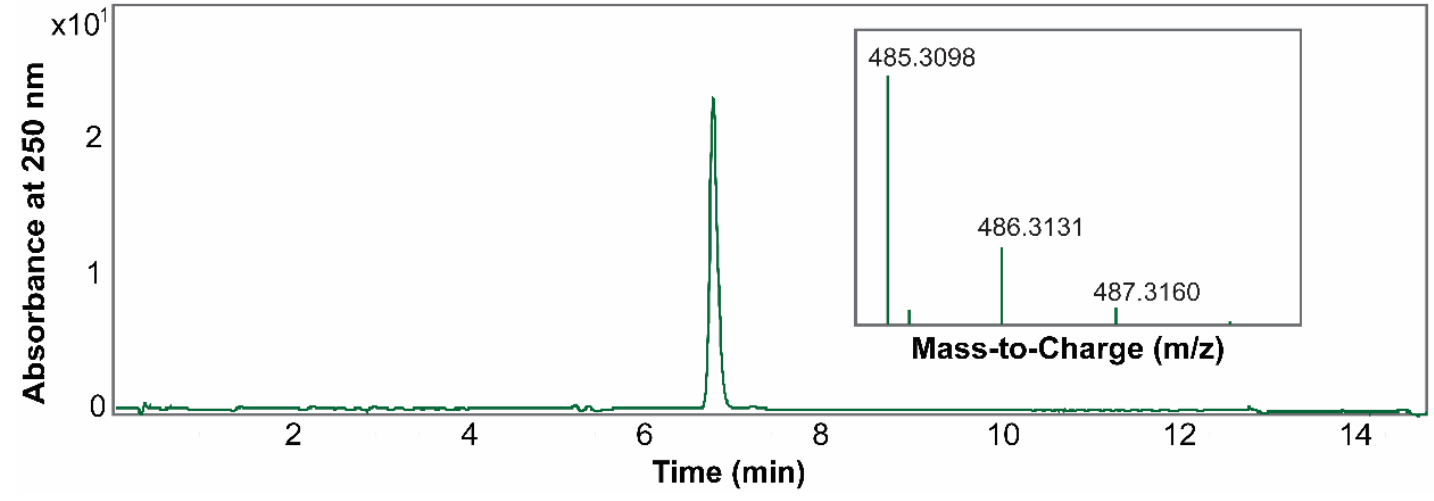

Figure S8. LC-HRMS purity analysis of synthesized molecules used in this study.

UV traces of (a) holomycin and (b) PAC-holo at $380 \mathrm{~nm}$, and (c) PAC at $250 \mathrm{~nm}$ where the solvent control was subtracted as background. Insets shows mass spectra with observed $[\mathrm{M}+\mathrm{H}]^{+}$of 214.9941, 639.2776, and 485.3098, respectively (expected masses of 214.9943, 639.2768, and 485.3109). 


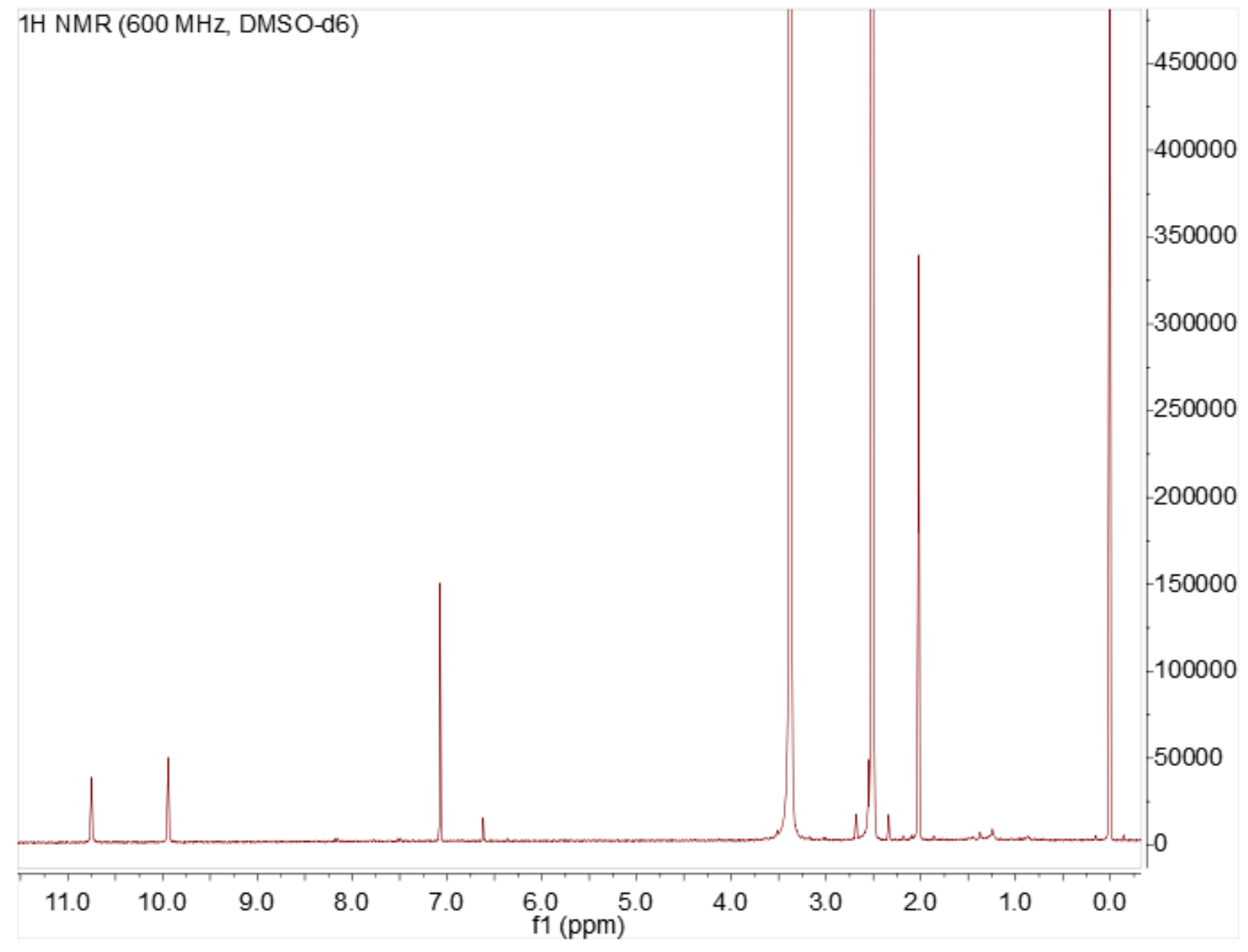

Figure S9. ${ }^{1} \mathrm{H}(600 \mathrm{MHz})$ NMR of holomycin in DMSO-d6. 


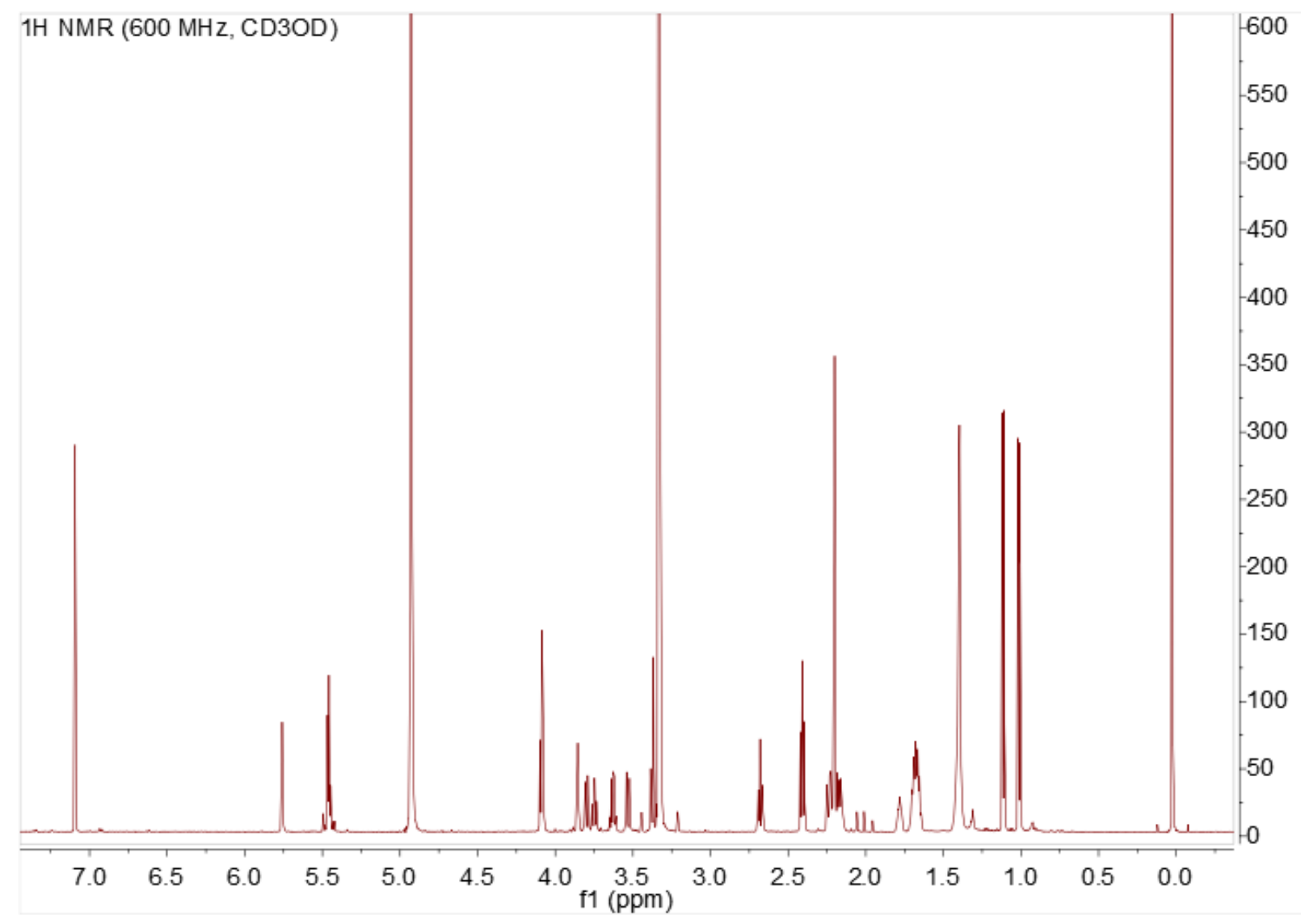

Figure S10. ${ }^{1} \mathrm{H}$ NMR $(600 \mathrm{MHz})$ of PAC-holothin in MeOD. 


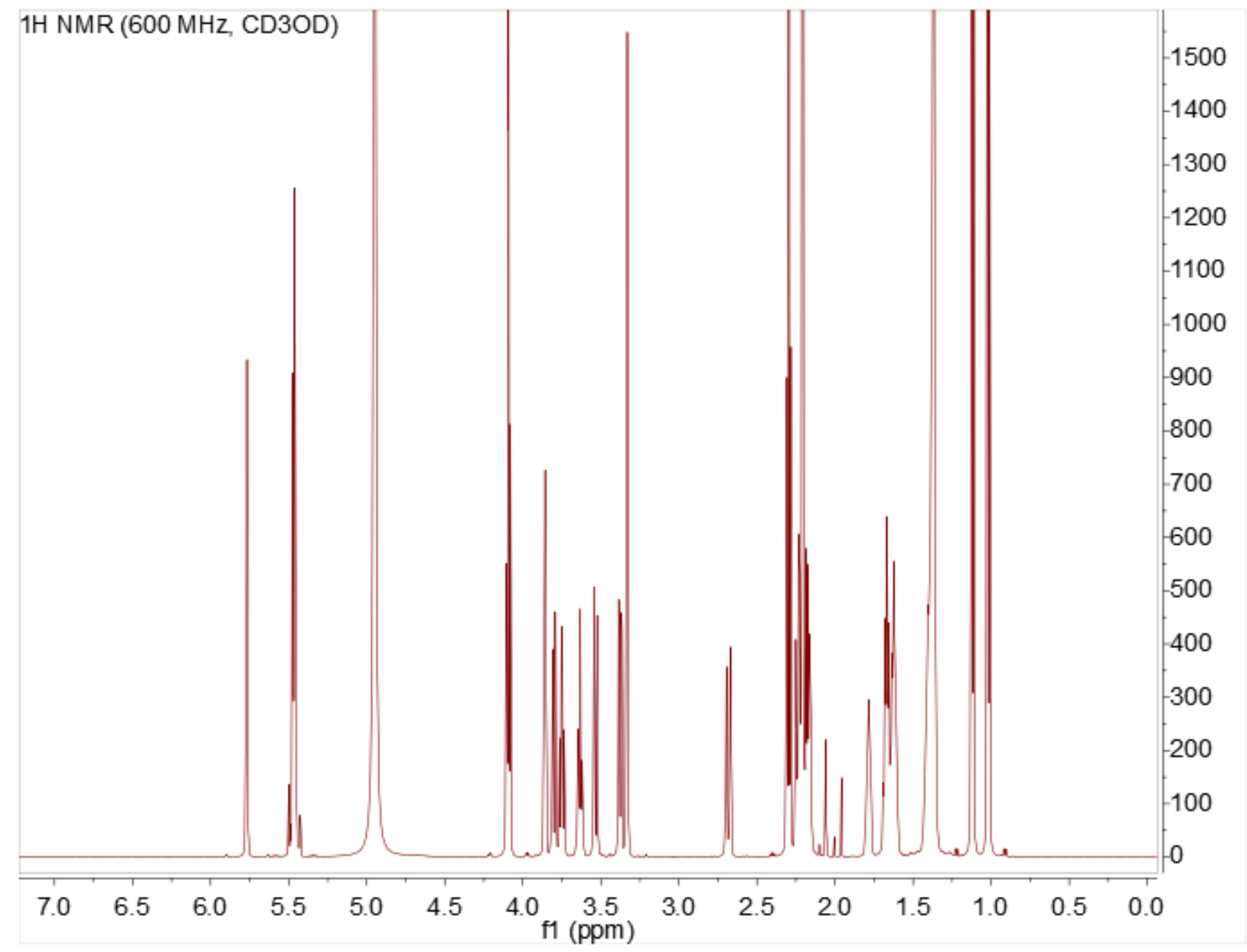

Figure S11. ${ }^{1} \mathrm{H}(600 \mathrm{MHz}) \mathrm{NMR}$ of PAC in MeOD. 


\section{HEK293T Cell Titer Assay}

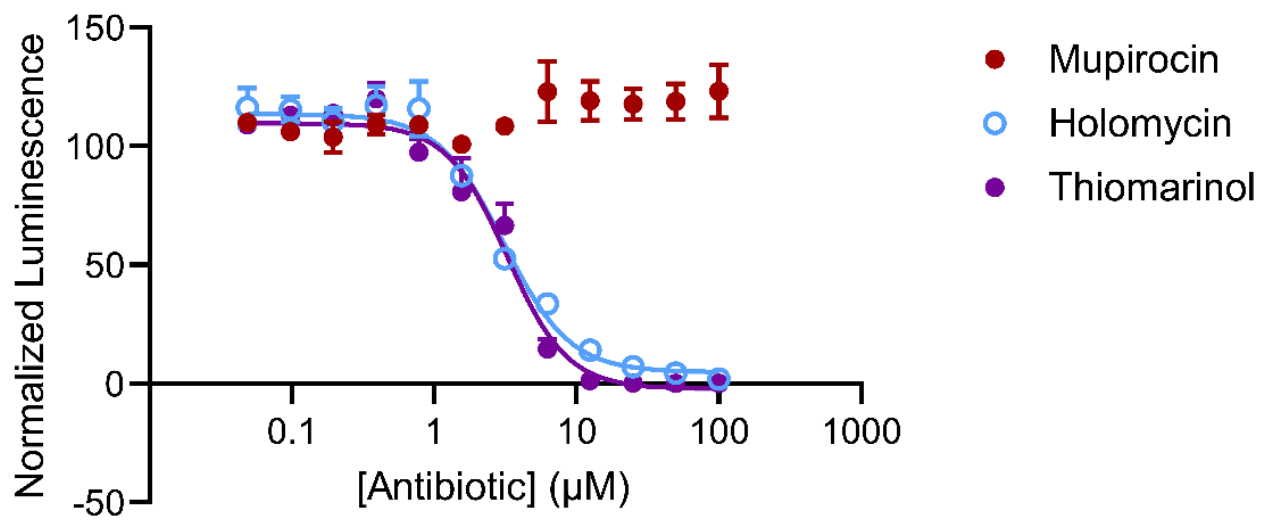

Figure S12. Cytotoxicity profiles for thiomarinol A and holomycin. Viabilities of HEK293T cells were measured based on luminescence that indicates ATP levels. Each experiment contains triplicate samples and results from two independent experiments are shown. Dose response curves were fitted using normalized data and $\mathrm{EC}_{50}$ of thiomarinol and holomycin were determined as $3.0 \pm 0.3 \mu \mathrm{M}$ and $3.0 \pm 0.3 \mu \mathrm{M}$, respectively. 
(a)

Holomycin

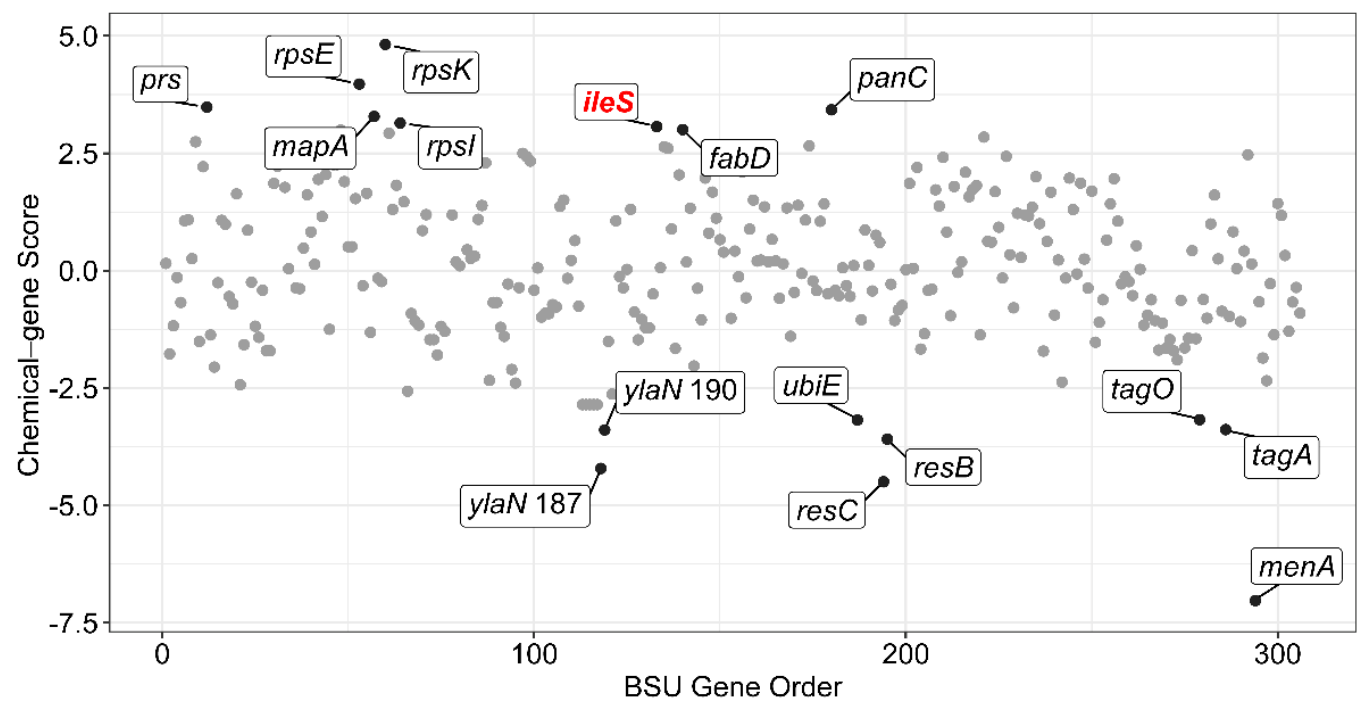

(b) Thiolutin

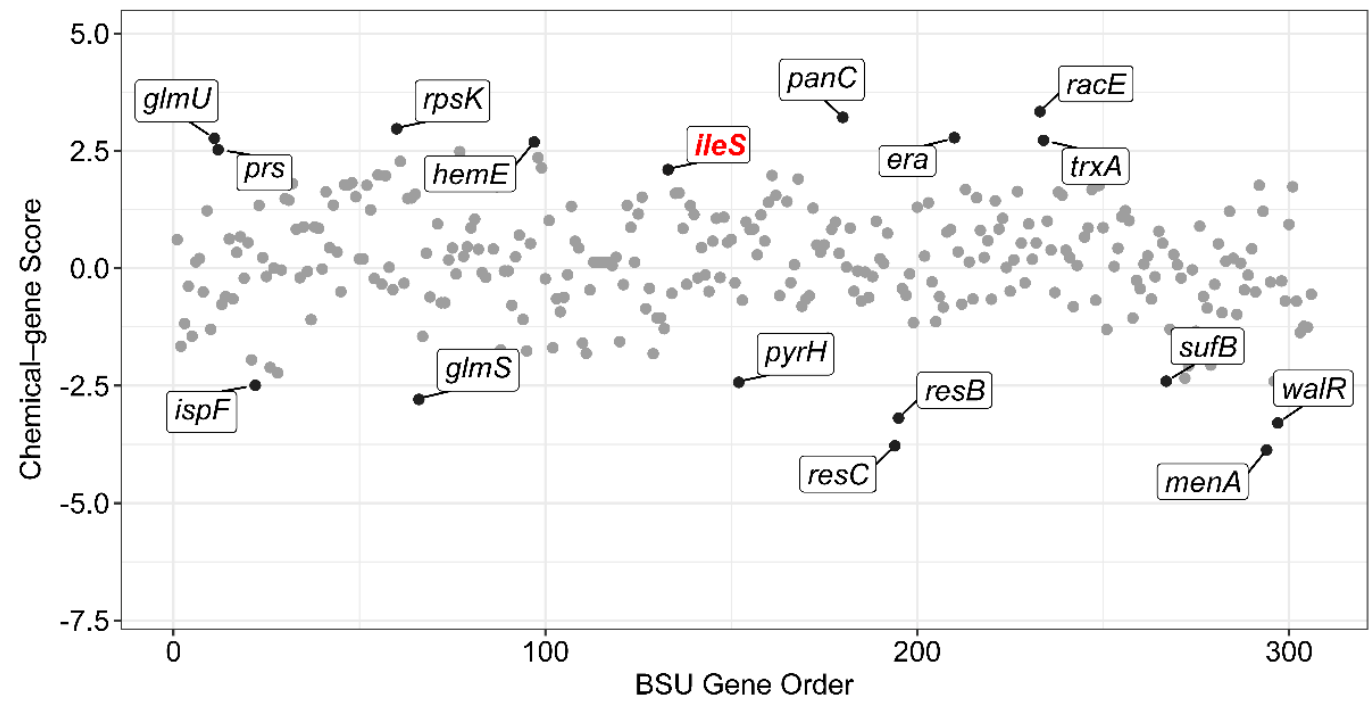


(c)

Gliotoxin

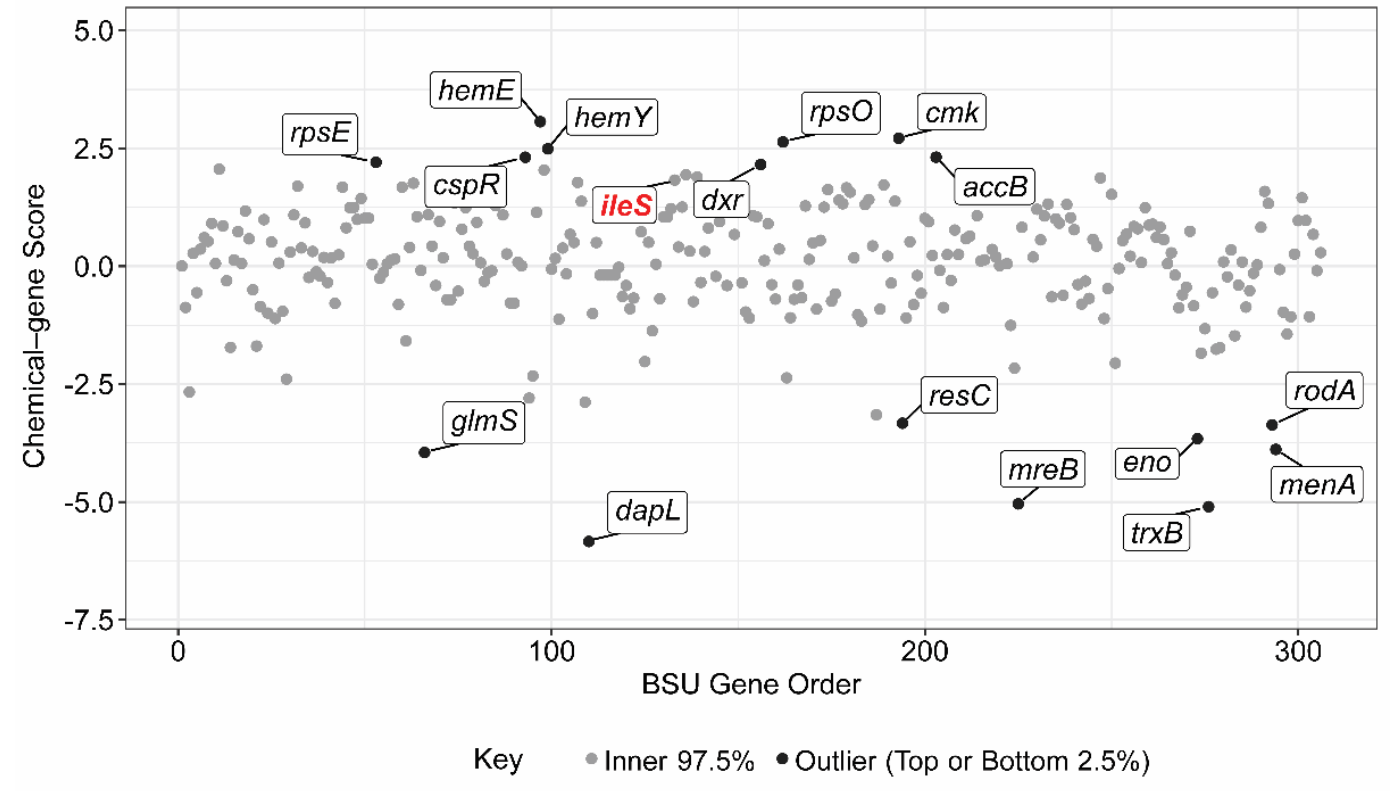

(d)<smiles>CC(=O)Nc1c2sscc-2[nH]c1=O</smiles>

Holomycin<smiles>CC(=O)Nc1c2sscc-2n(C)c1=O</smiles>

Thiolutin<smiles>CN1C(=O)C23CC4=CC=CC(O)[C@H]4N2C(=O)[C@]1(CO)SS3</smiles>

\section{Gliotoxin}

Figure S13. Chemical-gene interactions of disulfide-containing natural products from the chemical genomics screen. Chemical-gene scores for (a) holomycin, (b) thiolutin, and (c) gliotoxin. Top and Bottom 2.5\% outliers of chemical-gene score depicted in black and labeled with the gene name (ileS in red). Genes followed by numbers distinguish strains in the CRISPR library where different guides are used for gene targeting; the value represents the spacer position relative to the translation start of the gene. (d) Chemical structures of holomycin, thiolutin, and gliotoxin. 


\section{Orthologs of $S$. aureus genes within}

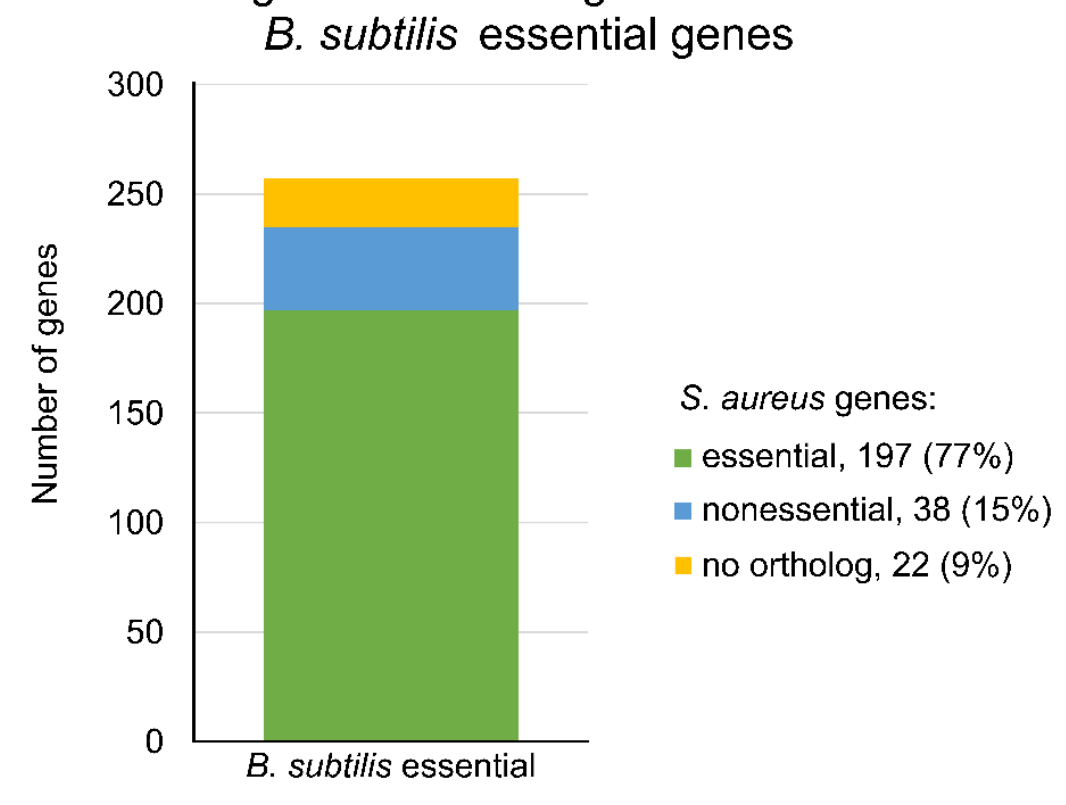

Figure S14. A total of $91 \%$ of the 257 essential $B$. subtilis genes have orthologs in $\mathbf{S}$. aureus. The breakdown of the $B$. subtilis essential genes in the CRISPRi chemical genomics library compared to $S$. aureus. The S. aureus orthologs for $77 \%$ of these genes are essential (green) and $15 \%$ are nonessential (blue). The remaining $9 \%$ of the $B$. subtilis genes have no orthologs in $S$. aureus (yellow). The high coverage of essential B. subtilis genes within $S$. aureus allows us to follow up with gene hits in MRSA. Data are based on studies by Koo et al. ${ }^{25}$ 


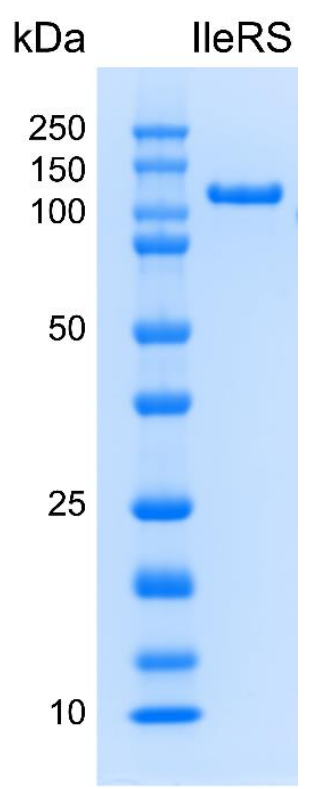

Figure S15. Protein gel of purified isoleucyl tRNA synthetase. Precision plus Kaleidoscope Protein Ladder (Bio-Rad), IleRS from HA-MRSA COL (106 kDa). Gel was stained with Coomassie Brilliant Blue and imaged on a BioRad Gel Doc EZ imager. 
(a)

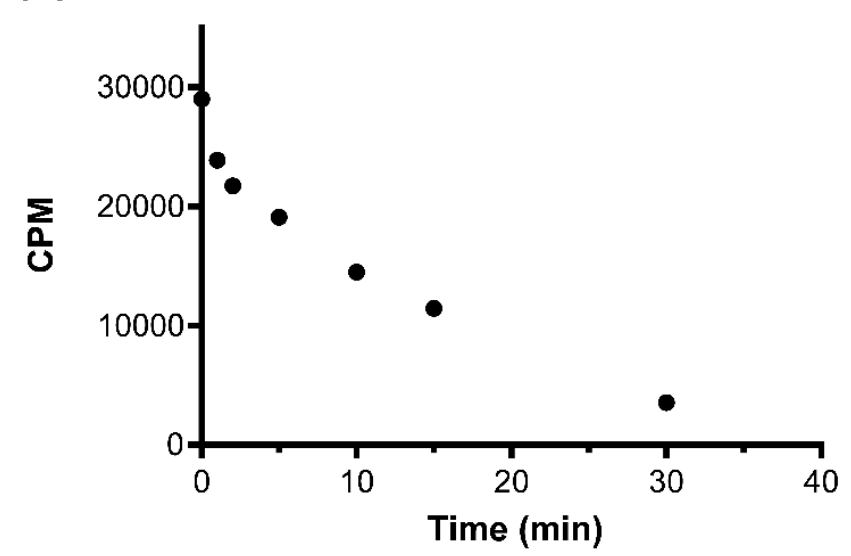

(b)

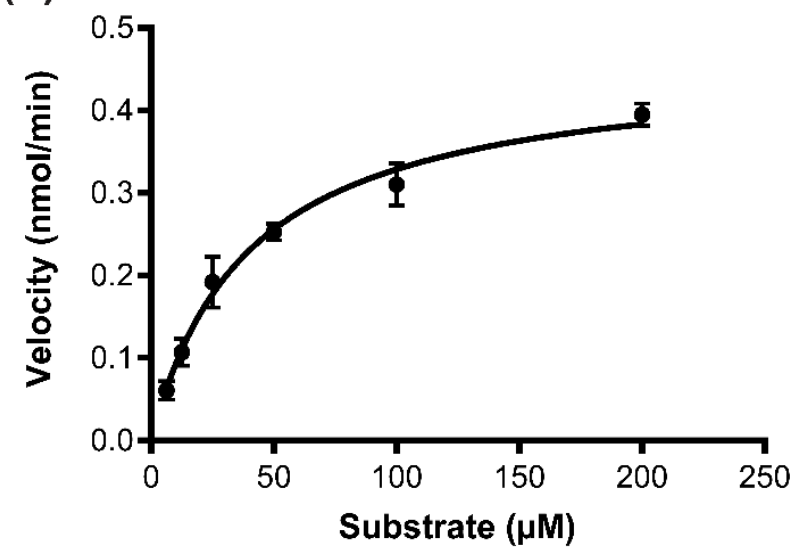

Figure S16. Isoleucine activation of IleRS assayed by ATP- $\left[{ }^{32} \mathrm{P}\right] \mathrm{PP}_{\mathrm{i}}$ exchange and $\left[\gamma-{ }^{32} \mathrm{P}\right] \mathrm{ATP}$ consumption. (a) Representative active site titration curve of IleRS. Each enzyme was determined to have $0.65 \pm 0.03$ active sites (average \pm SD) or $65 \%$ activity. (b) Michaelis-Menten plot for kinetic analysis of IleRS toward L-Ile, $K_{\mathrm{M}}: 40 \pm 5 \mu \mathrm{M}, k_{c a t}: 12.0 \pm 0.5 \mathrm{~s}^{-1}$ ( $k_{c a t}$ adjusted for $65 \%$ enzyme activity). 


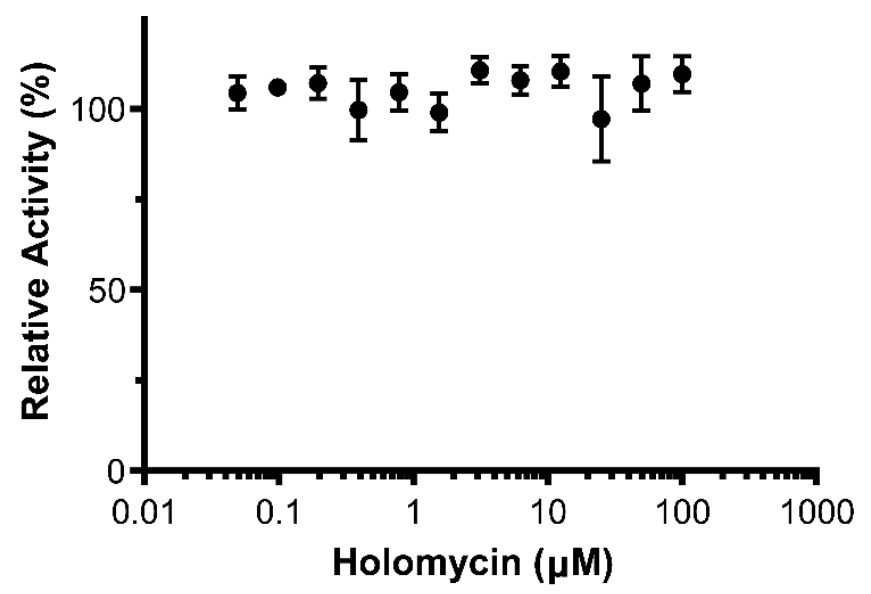

Figure S17. Holomycin does not inhibit IleRS. No inhibition is observed for treatment of $50 \mathrm{nM}$ IleRS with up to $100 \mu \mathrm{M}$ holomycin. 
(a)

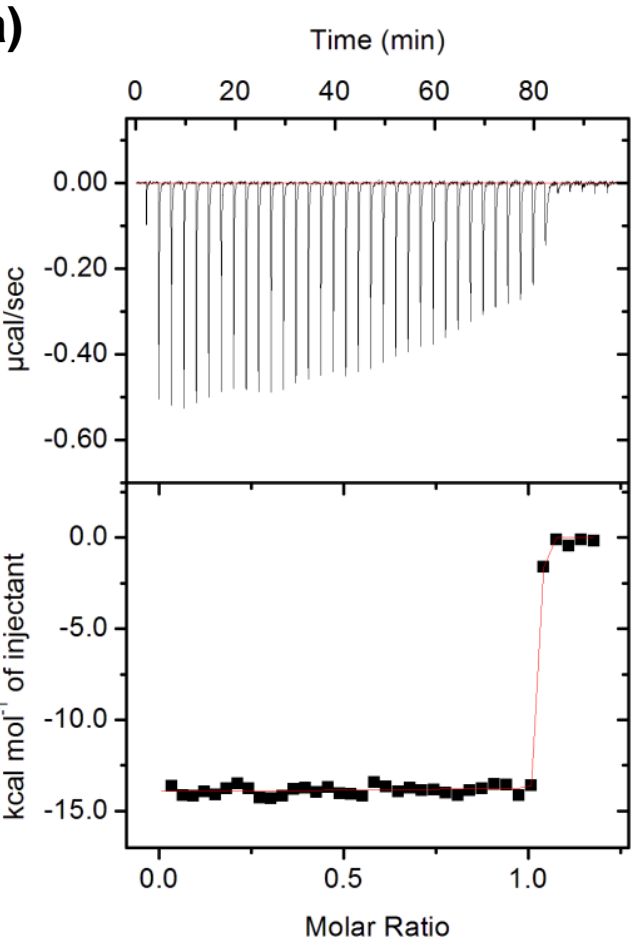

(c)

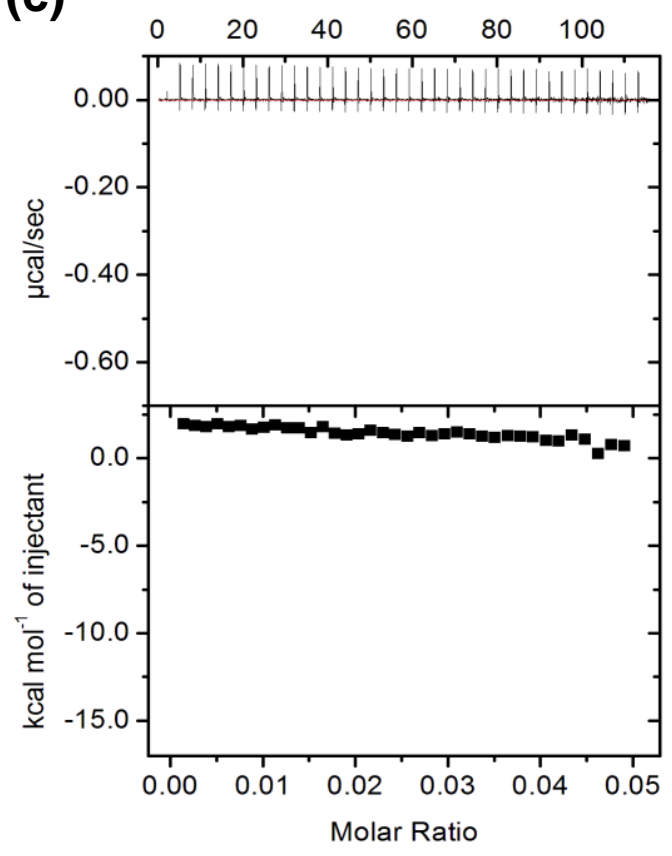

(b) Time (min)

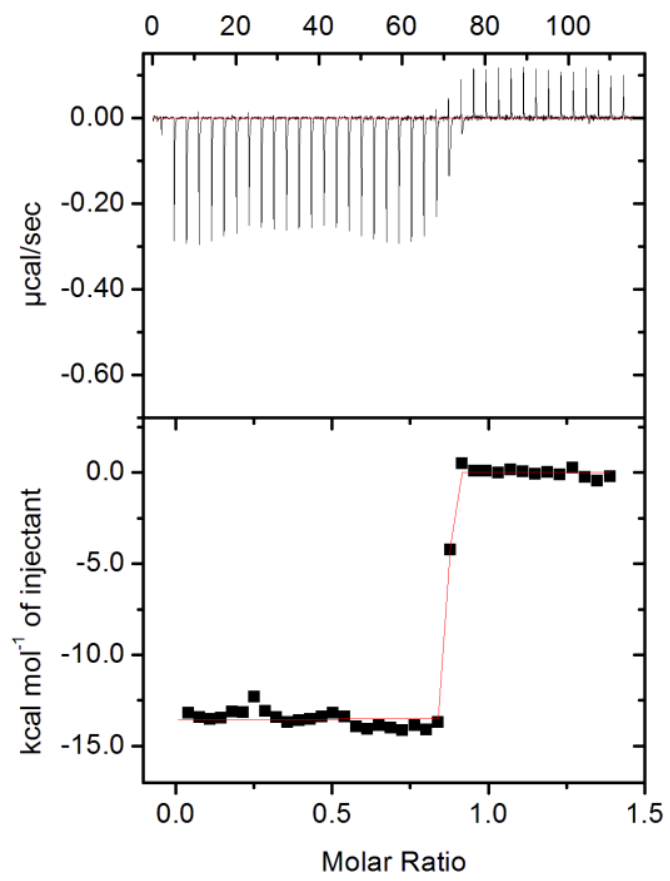

(d) Time (min)

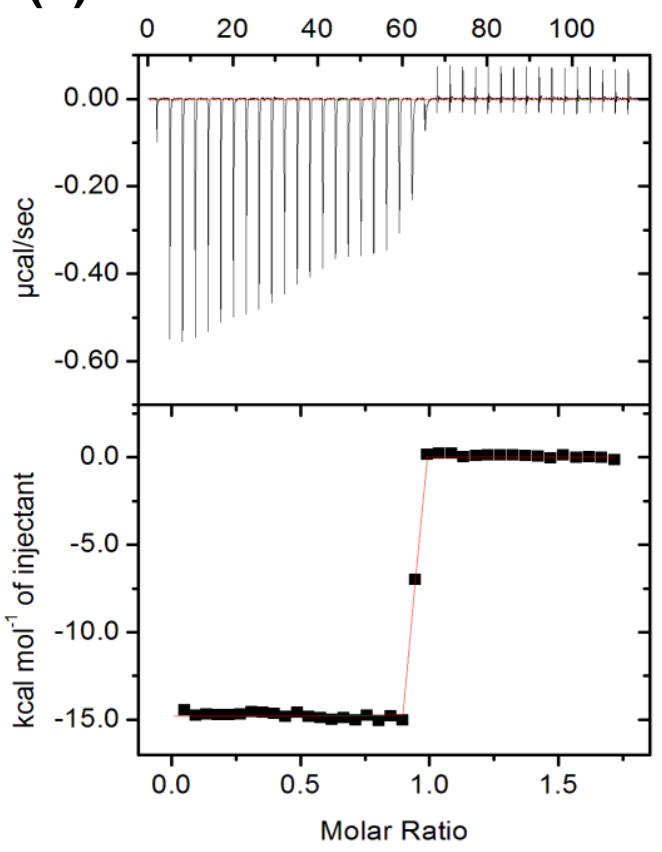

Figure S18. ITC analysis of mupirocin binding to IleRS. Titration of (a) $300 \mu \mathrm{M}$ mupirocin into $40 \mu \mathrm{M}$ IleRS, (b) $283 \mu \mathrm{M}$ IleRS into $40 \mu \mathrm{M}$ mupirocin, and (c) $283 \mu \mathrm{M}$ IleRS into buffer under non-reducing conditions. Related experimental values are shown in Table S1 and Figure 5C. Titration of (d) $350 \mu \mathrm{M}$ IleRS into $40 \mu \mathrm{M}$ mupirocin under reducing conditions containing 1 $\mathrm{mM}$ TCEP. Experiments were performed in triplicate and representative data is shown. 
(a)

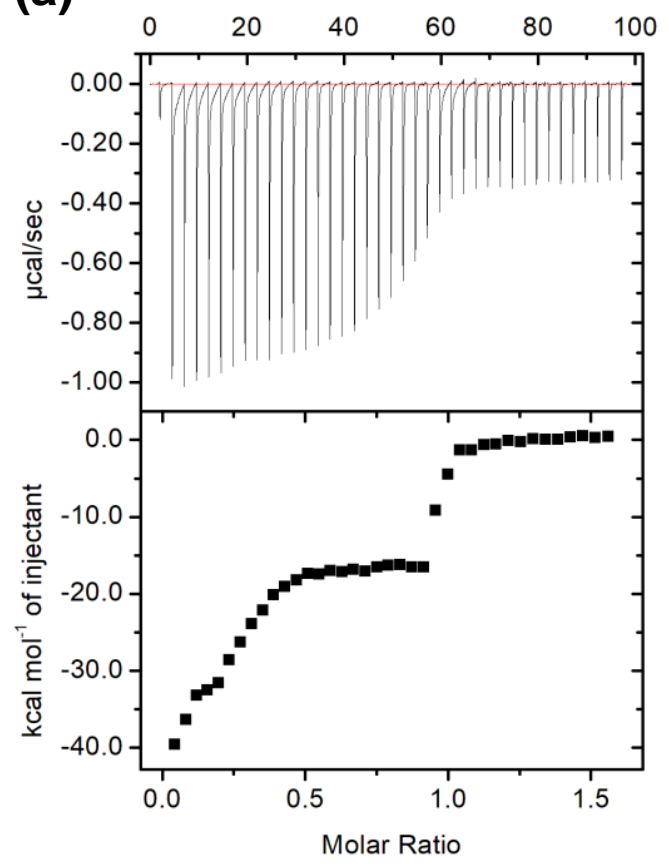

(c)

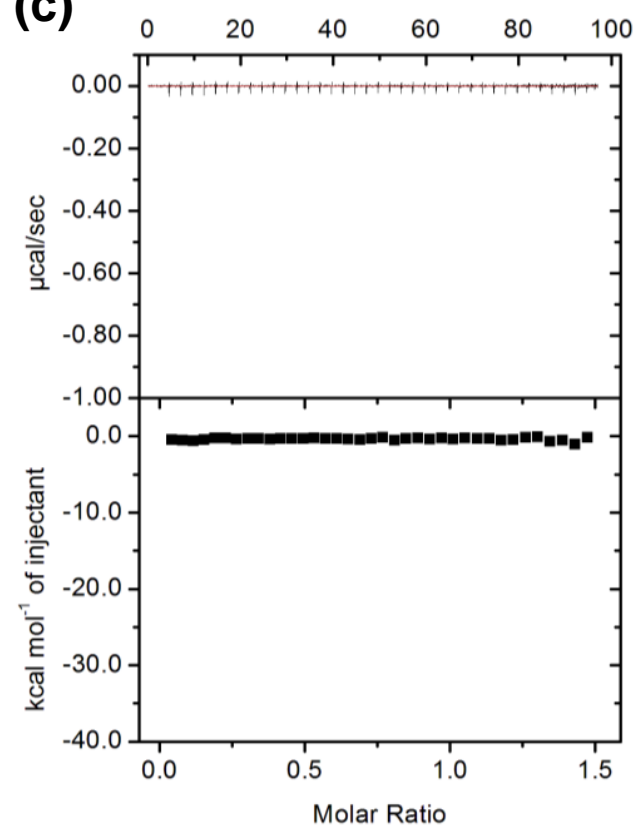

(b)

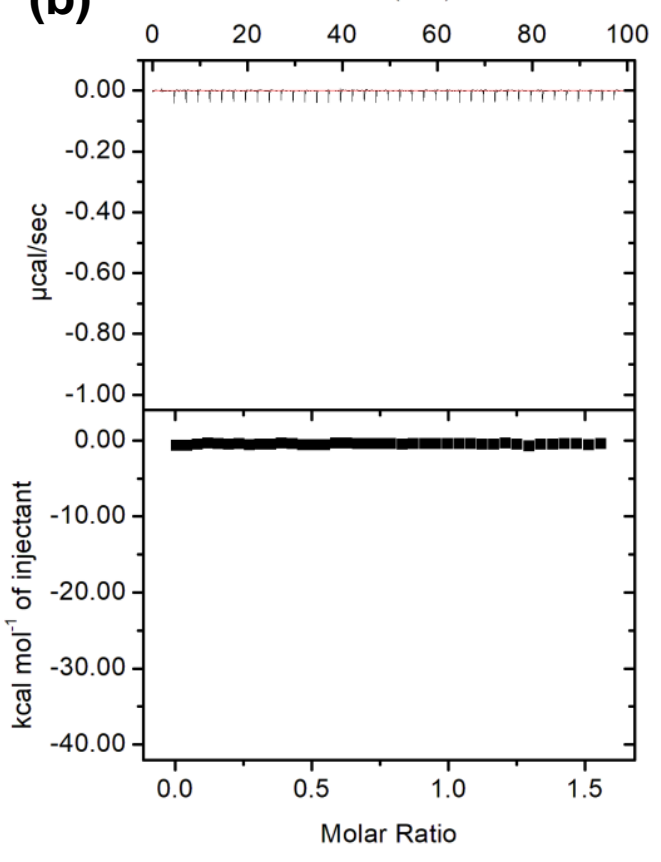

(d)

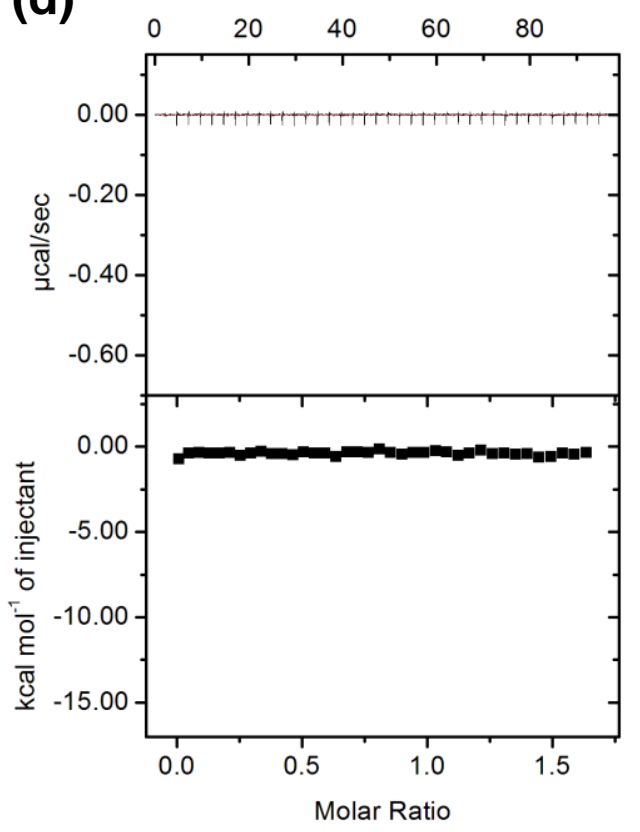

Figure S19. ITC analysis of IleRS and Thiomarinol binding under reducing conditions and relevant controls. Titration of (a) $346 \mu \mathrm{M}$ IleRS into $45 \mu \mathrm{M}$ thiomarinol, (b) buffer into $45 \mu \mathrm{M}$ thiomarinol, and (c) IleRS into buffer in the presence of $1 \mathrm{mM}$ TCEP. Experiments were performed in triplicate and representative data is shown. Under reducing conditions, the IleRSthiomarinol titration exhibited usually wide differential power $\left(\mu \mathrm{cal} \cdot \mathrm{s}^{-1}\right)$ peaks initially and a relatively large heat of dilution in comparison to buffer controls, therefore, we did not use data from the reducing conditions to determine the binding enthalpy. (d) Buffer into $30 \mu \mathrm{M}$ thiomarinol without TCEP. 
(a)

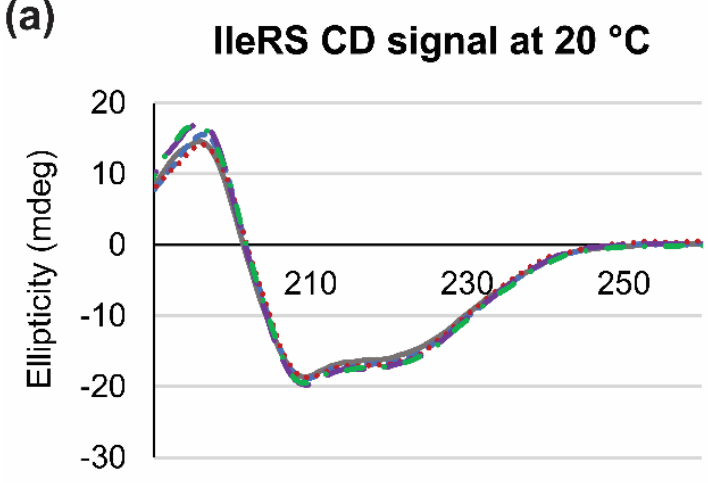

Wavelength $(\mathrm{nm})$ (b) IleRS HV signal at $20^{\circ} \mathrm{C}$

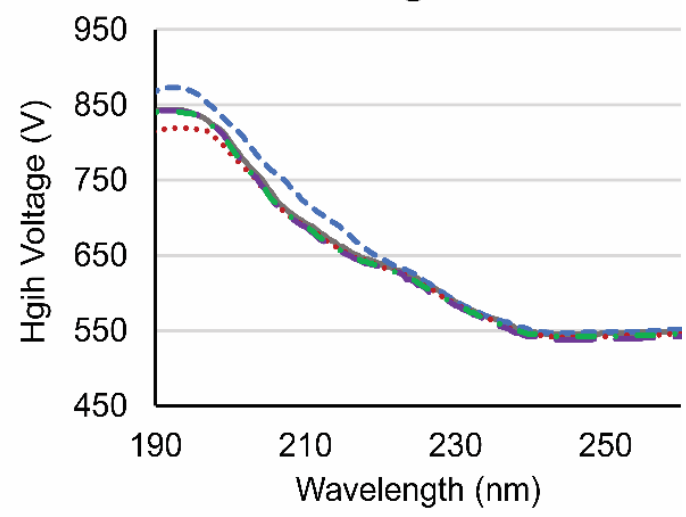

Mupirocin

- PAC-holo

Figure S20. Representative CD spectra of IleRS. (a) $2.5 \mu \mathrm{M}$ IleRS at $20{ }^{\circ} \mathrm{C}$ in the presence of $5 \mu \mathrm{M}$ mupirocin, PAC-holo, thiomarinol, holomycin in $10 \mathrm{mM}$ sodium phosphate, $50 \mathrm{mM}$ potassium sulfate, $0.5 \mathrm{mM}$ TCEP, $\mathrm{pH} 7.4$, and $5 \% \mathrm{MeOH}$ with respective small molecule in buffer subtracted as background. No significant difference in secondary structure is observed in the presence of small molecules in comparison to the $\mathrm{MeOH}$ control. (b) The corresponding high voltage (HV) plots of the IleRS CD spectra. 
(a)

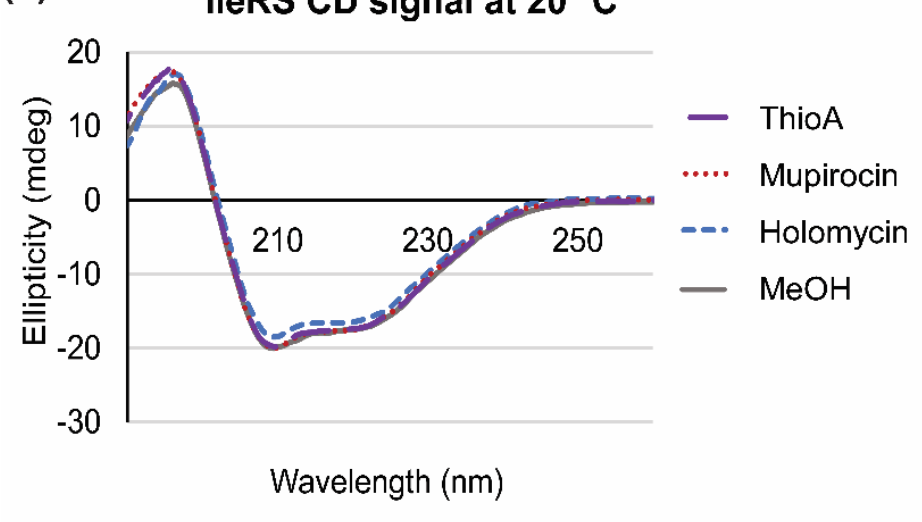

(c)

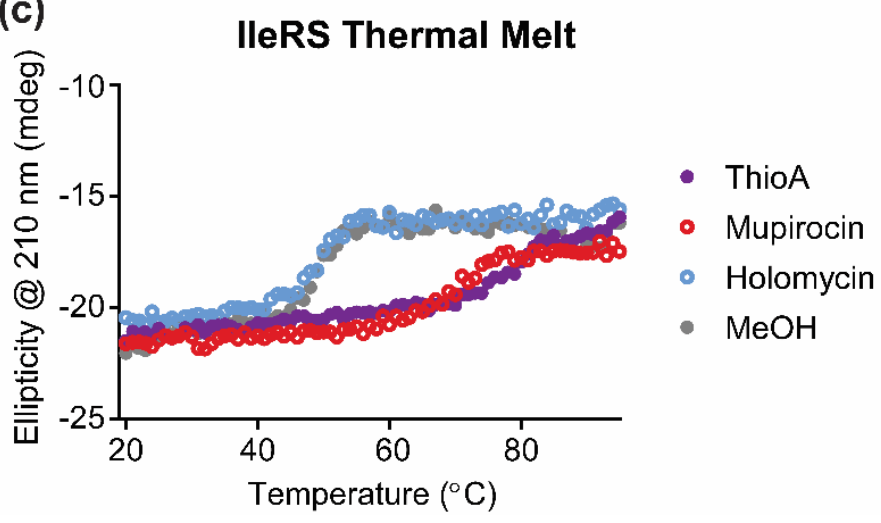

(b)

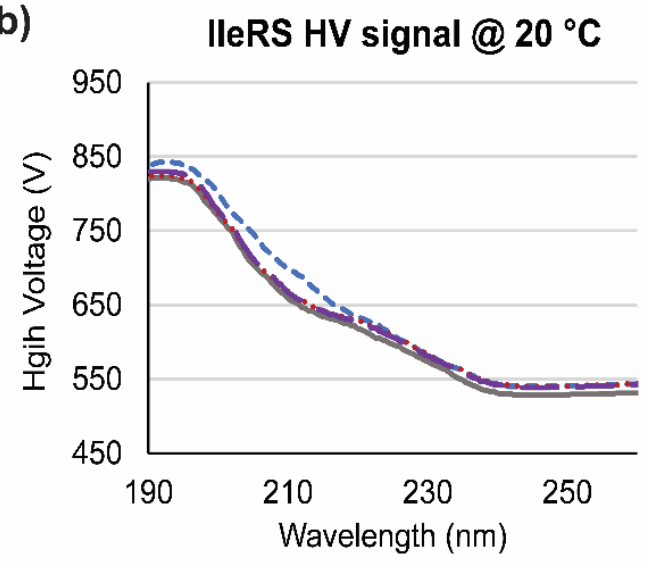

(d)

\begin{tabular}{|ccc|}
\hline $\begin{array}{c}\text { Small } \\
\text { Molecule }\end{array}$ & \multicolumn{2}{c|}{$\mathrm{T}_{\mathrm{m}}\left({ }^{\circ} \mathrm{C}\right)$} \\
\hline ThioA & $80 \pm 2$ & 78 \\
\hline Mupirocin & $68 \pm 1$ & 69 \\
\hline Holomycin & $49 \pm 1$ & 49 \\
\hline $\mathrm{MeOH}$ & $49 \pm 1$ & 48 \\
\hline
\end{tabular}

Figure S21. IleRS melting temperatures $\left(T_{m}\right)$ are consistent under nonreducing and reducing conditions. (a) $\mathrm{CD}$ spectra at $20^{\circ} \mathrm{C}$ and corresponding (b) high voltage (HV) plots of $2.5 \mu \mathrm{M}$ IleRS in the presence of $5 \mu \mathrm{M}$ mupirocin, PAC-holo, thiomarinol, or holomycin under nonreducing conditions (without TCEP) with respective small molecule in buffer subtracted as background. No significant difference in secondary structure is observed in the presence of small molecules in comparison to the $\mathrm{MeOH}$ control. (c) Thermal melt of the respective solutions and (d) table of melting temperature $\left(\mathrm{T}_{\mathrm{m}}\right)$ values under nonreducing versus reducing conditions. $\mathrm{T}_{\mathrm{m}}$ values show no significant difference with or without TCEP (average \pm SEM). 

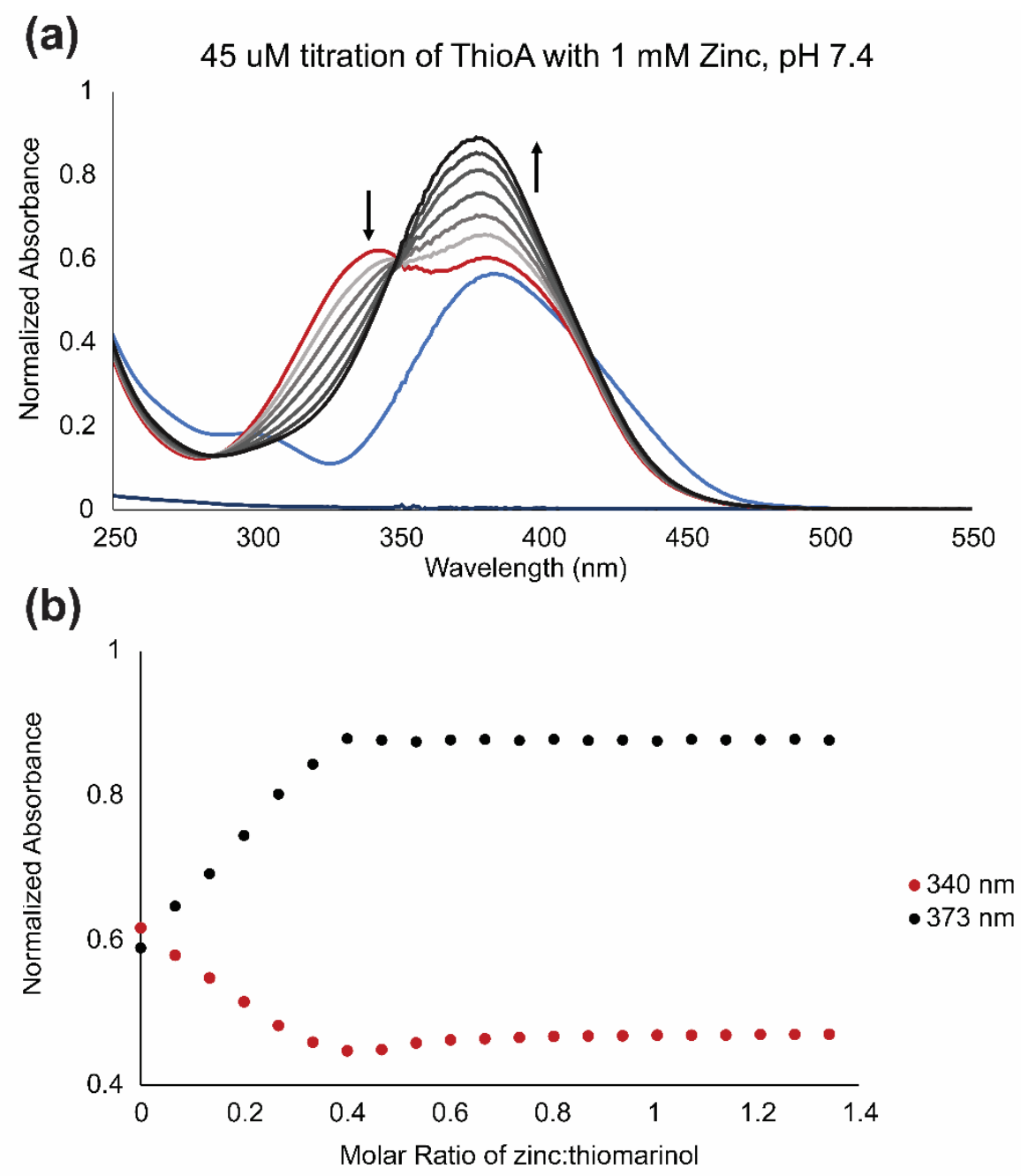

Figure S22. Thiomarinol chelates zinc under reduced conditions in a 2:1 ratio. (a) Thiomarinol A (blue) is reduced using 2 molar equivalents of TCEP (red) and titrated with $1 \mathrm{mM}$ zinc sulfate above 1 molar equivalents (black) in PBS (pH 7.4). Absorbances were normalized to account for the increased volume of solution after each addition of an aliquot. (b) Respective plot of normalized absorbance values for the maximum wavelength $\left(\lambda_{\max }\right)$ characteristic of reduced thiomarinol (340 nm, red) and a zinc-thiomarinol complex (373 nm, black) as a function of the zinc:thiomarinol molar ratio. Absorbances at $340 \mathrm{~nm}$ and $373 \mathrm{~nm}$ are stabilized at a molar ratio of 1:2 zinc: thiomarinol in three independent replicates, same as the 1:2 ratio observed for the zincholomycin complex. ${ }^{13}$ 
(a)

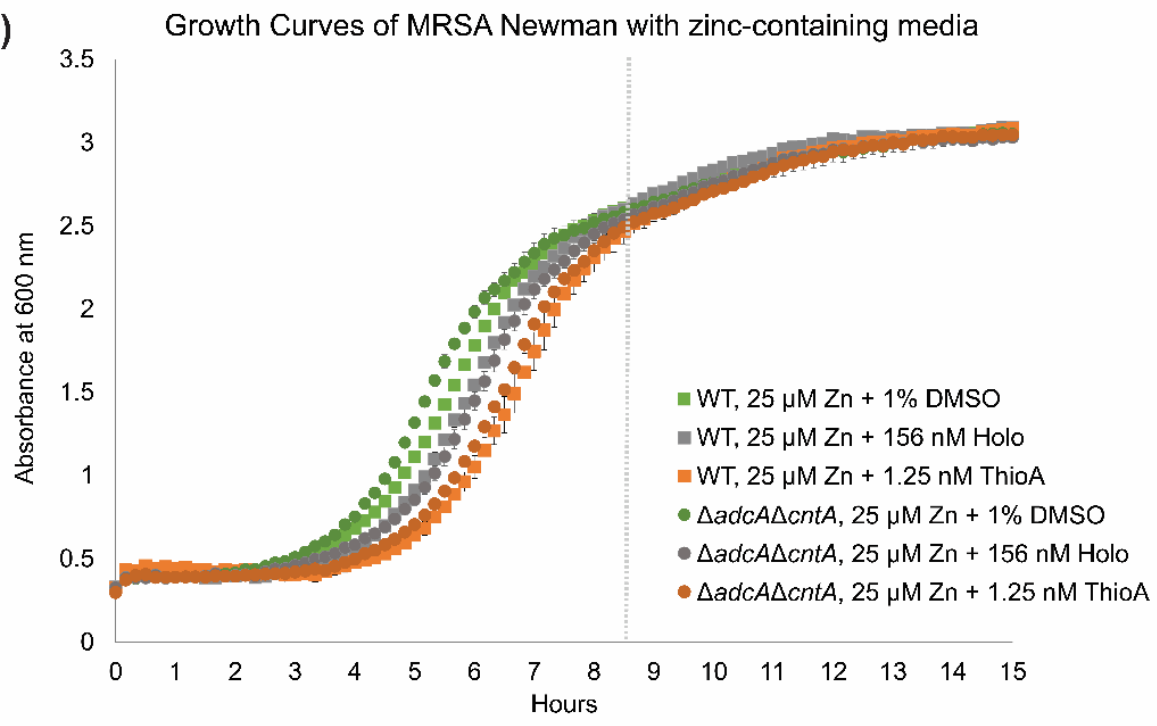

(b) Growth Curves of MRSA Newman in zinc-deprived media

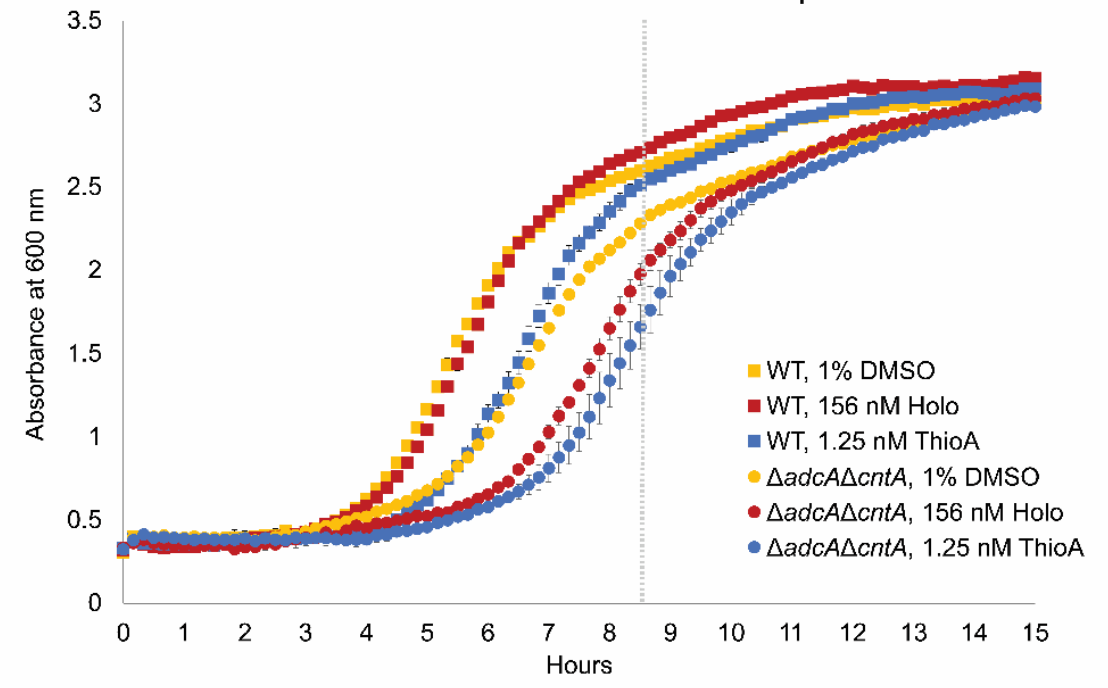



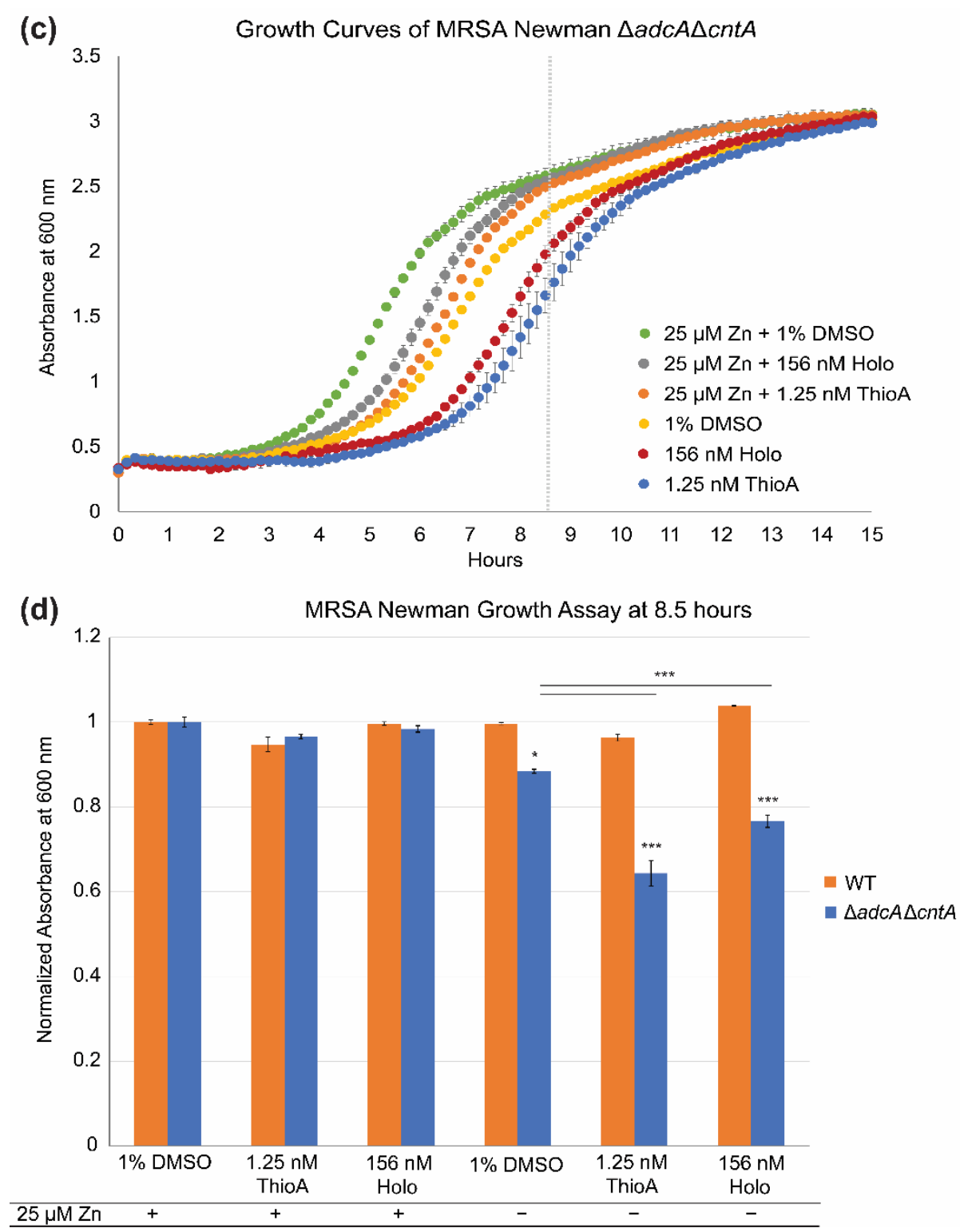

Figure S23. Thiomarinol reduces the growth of MRSA Newman zinc import mutant under zinc-deficient conditions. Growth curves of wildtype and the zinc deficient mutant $\triangle a d c A \Delta c n t A$ over $15 \mathrm{~h}$ with antibiotic treatments in modified NRPMI media (a) with and (b) without the addition of zinc (average \pm SD). For comparison of effects of thiomarinol and holomycin on the zinc deficient mutant, all $\triangle a d c A \Delta c n t A$ growth curves are shown in (c). (d) Cell density (OD 600$)$ of wildtype (orange) and $\triangle a d c A \Delta c n t A$ (blue) after $8.5 \mathrm{~h}$ of growth with various treatments in modified NRPMI media containing $25 \mu \mathrm{M} \mathrm{MnCl}_{2}$ and $25 \mu \mathrm{M} \mathrm{FeSO}_{4}$. Data are normalized to the metal replete sample of the respective strain. Significance was determined using a Tukey test $(* * *$, $p<0.0001 ; * *, p<0.001 ; *, \mathrm{p}<0.01)$. Each experiment contained triplicate samples and five independent experiments were performed on different days. The effects were observed in the presence of $0.625-1.25 \mathrm{nM}$ of thiomarinol; at thiomarinol concentrations of $1.25 \mathrm{nM}$ and above, the results exhibit a similar overall trend, but significant growth inhibition of wildtype was observed. Data from one representative experiment are shown (average \pm SEM). 

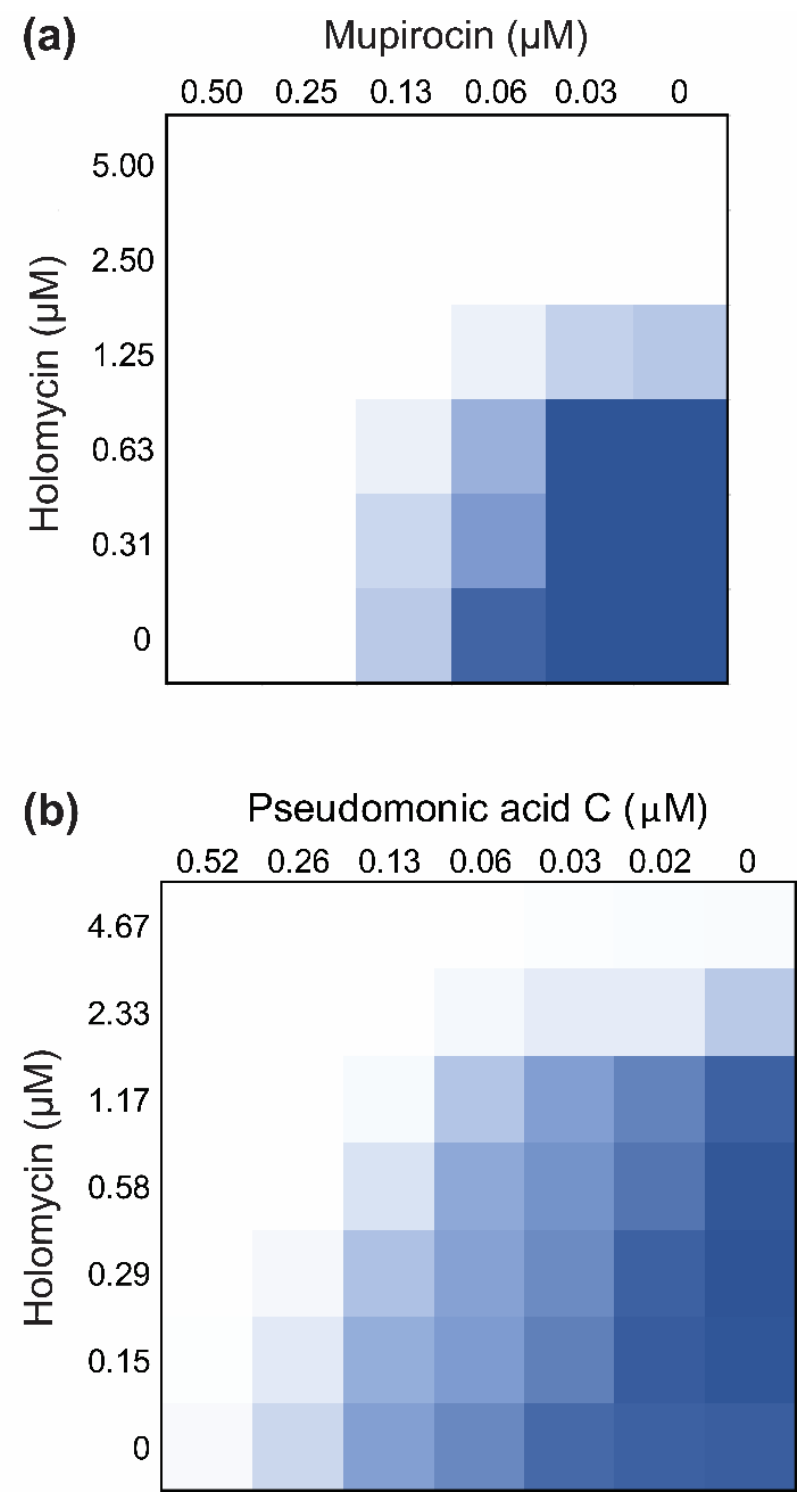

Figure S24. Inhibitory effects of the thiomarinol A and PAC-holo constituents are additive against MRSA COL. MRSA COL growth is shown in blue as measured by the OD600. (A) The activities of holomycin and mupirocin are additive against MRSA COL. The MIC of the combination contained $1.25 \mu \mathrm{M}$ holomycin and $0.125 \mu \mathrm{M}$ mupirocin while individual MICs are 2.5 and $0.25 \mu \mathrm{M}$ respectively. The fractional inhibitory concentration (FIC) index for the combination treatment of holomycin and mupirocin is 1 denoting an indifferent or additive effect. (B) The MIC's for holomycin and pseudomonic acid C (PAC) individually are 4.67 and $0.52 \mu \mathrm{M}$ respectively, the MIC of the combination contained $2.33 \mu \mathrm{M}$ holomycin and $0.13 \mu \mathrm{M}$ PAC. Thus, the FIC index is 0.75 for the combination treatment of holomycin and PAC denoting an indifferent or additive effect. 


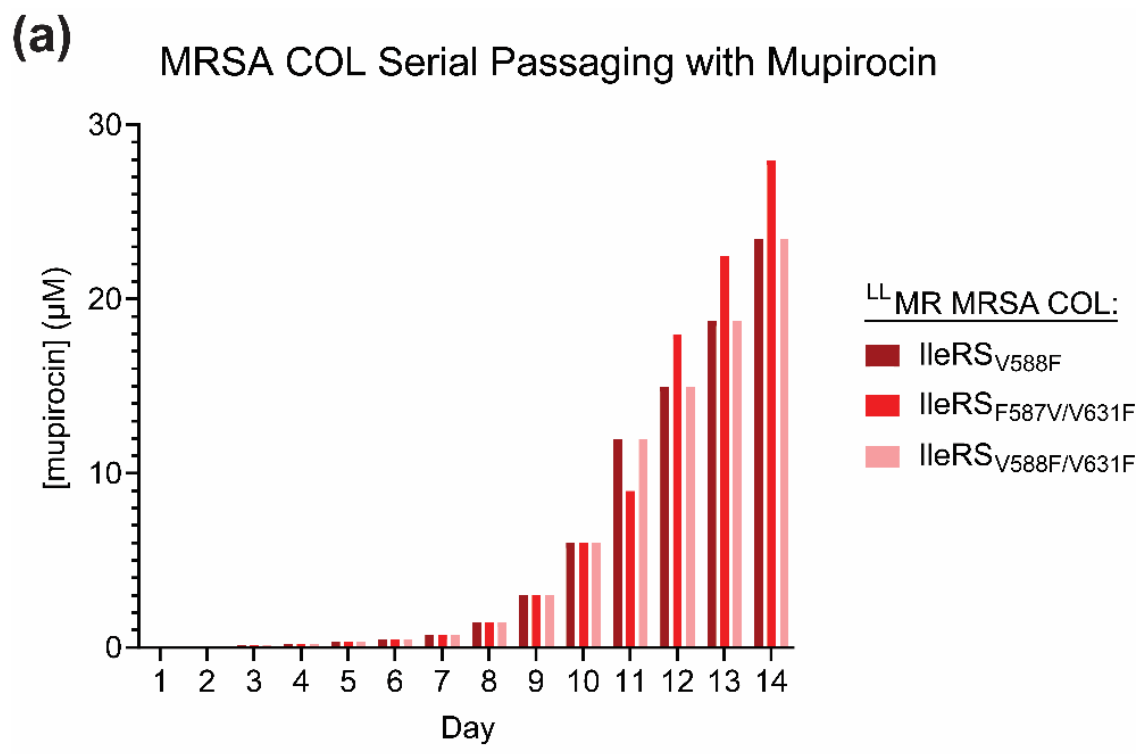

(b)

MRSA COL Serial Passaging with Thiomarinol A

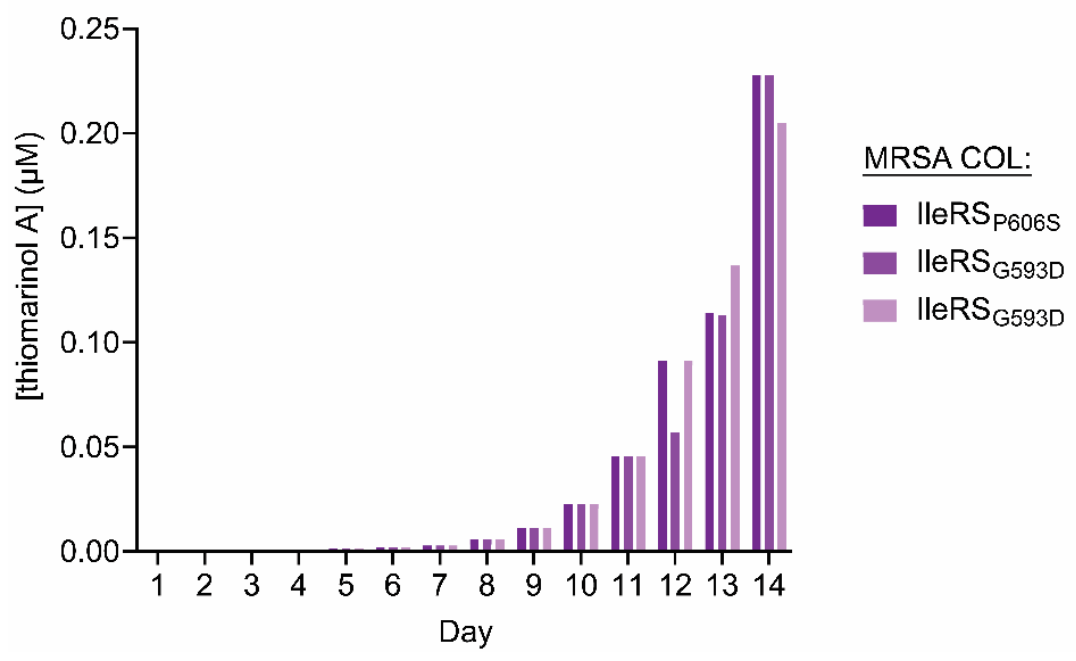

Figure S25. Serial passaging of MRSA to induce resistance to mupirocin or thiomarinol A. Highest concentration of (A) mupirocin or (B) thiomarinol A in MSRA culture on a given day during serial passaging. These mutants exhibit a lower MIC against thiomarinol upon removal of consistent antibiotic pressure. The MICs are similar in NB and MBHII (within two-fold difference). 


\section{Supplementary Tables}

Table S1. Thermodynamic values for mupirocin and thiomarinol A binding to IleRS.

\begin{tabular}{|c|c|c|c|c|}
\hline $\begin{array}{c}\text { Antibiotic } \\
\text { Binding to } \\
\text { lleRS }\end{array}$ & $\begin{array}{c}\Delta \boldsymbol{H}^{\circ \prime} \\
\mathbf{( k c a l} / \mathbf{m o l})\end{array}$ & $\boldsymbol{K}_{\mathrm{d}, 25^{\circ} \mathrm{C}(\mathbf{p M})}$ & $\begin{array}{c}\Delta \mathbf{G}^{\circ \prime} \\
(\mathbf{k c a l} / \mathbf{m o l})\end{array}$ & $\begin{array}{c}\Delta \boldsymbol{S}^{\circ \prime} \\
(\mathbf{c a l} / \mathbf{m o l} \cdot \mathbf{K})\end{array}$ \\
\hline ThioA & $-12.4 \pm 0.4$ & $0.011 \pm 0.006$ & $-19.0 \pm 0.1$ & $22 \pm 1$ \\
\hline Mupirocin & $-14.6 \pm 0.4$ & $18 \pm 7^{*}$ & $-14.6 \pm 0.1$ & $0 \pm 1$ \\
\hline
\end{tabular}

* A $\mathrm{T}_{\mathrm{m}}$ of $52{ }^{\circ} \mathrm{C}$ for an IleRS control and a $\mathrm{T}_{\mathrm{m}}$ of $69.5^{\circ} \mathrm{C}$ and $\Delta H^{\circ \prime}$ of $-15 \mathrm{kcal} / \mathrm{mol}$ for pseudomonic acid A (mupirocin) binding to IleRS were reported by Brown et al. ${ }^{23}$ These values are similar to ours, however, a different equation from Brandts et al. ${ }^{22}$ was used in this study to calculate the dissociation constant at the melting temperature for pseudomonic acid A, resulting in a $K_{\mathrm{d}, 25^{\circ} \mathrm{C}}$ of $140 \mathrm{pM} \cdot{ }^{23}$ 
Table S2. Matrix of $p$ values comparing the IleRS melting temperatures in the presence of small molecules by a Tukey-test.

\begin{tabular}{|c|c|c|c|c|c|}
\hline $\begin{array}{c}\text { lleRS } \\
\text { treatment }\end{array}$ & Methanol & Holomycin & Mupirocin & PAC-holo & ThioA \\
\hline Methanol & & 0.995 & $\star \star \star$ & $\star * *$ & $\star \star \star$ \\
\hline Holomycin & 0.995 & & $\star \star \star * \star$ & $\star \star \star \star *$ & 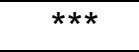 \\
\hline Mupirocin & 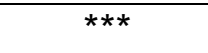 & $\star \star \star \star ~$ & & 0.760 & 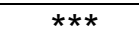 \\
\hline PAC-holo & $\star \star \star \star *$ & 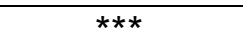 & 0.760 & & 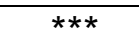 \\
\hline ThioA & *** & 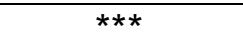 & $\star \star \star *$ & *** & \\
\hline
\end{tabular}

${ }^{* * *} p$ value is less than $1 \cdot 10^{-7}$ 
Table S3. List of primers used in this study.

\begin{tabular}{|c|c|c|}
\hline Primer & Sequence (5'-3') & Description \\
\hline AC-0365 & GATACAGGATCCATGGATTACAAAGAAACGTTATTAATG & MRSA ileS fwd (BamHI) \\
\hline AC-0366 & GATACACTCGAGCAATTATACAAGTGATTTTACAACTTG & MRSA ileS rev (Xhol) \\
\hline AC-0367 & GCGATTACCGTTCATCCTG & MRSA iles Seq 1 \\
\hline AC-0368 & CAGTGAATCATGTTGCTG & MRSA iles Seq 2 \\
\hline AC-0369 & GTTCAAAACTTTATCAATGTTGAG & MRSA iles Seq 3 \\
\hline CAM-001 & ATGGATTACAAAGAAACGTTATTAATGC & MRSA iles Seq 4 \\
\hline CAM-002 & TTATACAAGTGATTTTACAACTTGTTGG & MRSA iles Seq 5 \\
\hline CAM-003 & ATTGAACAAGCATTAACGAAAAAAG & MRSA iles Seq 6 \\
\hline CAM-004 & CAATTTGAAGGGATGTTCTATGATAA & MRSA iles Seq 7 \\
\hline CAM-005 & TTCTTACTTTCTCATGGTTTTGTTAT & MRSA iles Seq 8 \\
\hline CAM-006 & GTGCATACAGCTGAAGAAGTT & MRSA iles Seq 9 \\
\hline
\end{tabular}




\section{Supplementary References}

1. Hjelmgaard, T.; Givskov, M.; Nielsen, J., Expedient total synthesis of pyrrothine natural products and analogs. Org. Biomol. Chem. 2007, 5 (2), 344-348.

2. $\quad$ Dunn, Z. D.; Wever, W. J.; Economou, N. J.; Bowers, A. A.; Li, B., Enzymatic basis of "hybridity" in thiomarinol biosynthesis. Angew. Chem. Int. Ed. 2015, 54 (17), 5137-5141.

3. Clayton, J. P.; O'Hanlon, P. J.; Rogers, N. H.; King, T. J., The chemistry of pseudomonic acid. Part 5. Structure and chemistry of pseudomonic acid C. X-Ray crystal structure of ethyl monate C. $J$. Chem. Soc., Perkin Trans. 1 1982, 2827.

4. Kritikos, G.; Banzhaf, M.; Herrera-Dominguez, L.; Koumoutsi, A.; Wartel, M.; Zietek, M.; Typas, A., A tool named Iris for versatile high-throughput phenotyping in microorganisms. Nat. Microbiol. 2017, 2 (5), 17014.

5. Szklarczyk, D.; Gable, A. L.; Lyon, D.; Junge, A.; Wyder, S.; Huerta-Cepas, J.; Simonovic, M.; Doncheva, N. T.; Morris, J. H.; Bork, P.; Jensen, L. J.; Christian, STRING v11: protein-protein association networks with increased coverage, supporting functional discovery in genome-wide experimental datasets. Nucleic Acids Res. 2019, 47 (D1), D607-D613.

6. Collins, S. R.; Schuldiner, M.; Krogan, N. J.; Weissman, J. S., A strategy for extracting and analyzing large-scale quantitative epistatic interaction data. Genome Biol. 2006, 7, R63.

7. Peters, J. M.; Colavin, A.; Shi, H.; Czarny, T. L.; Larson, M. H.; Wong, S.; Hawkins, J. S.; Lu, C. H. S.; Koo, B. M.; Marta, E.; Shiver, A. L.; Whitehead, E. H.; Weissman, J. S.; Brown, E. D.; Qi, L. S.; Huang, K. C.; Gross, C. A., A comprehensive, CRISPR-based functional analysis of essential genes in bacteria. Cell 2016, 165 (6), 1493-1506.

8. $\quad$ Medema, M. H.; Kottmann, R.; Yilmaz, P.; Cummings, M.; Biggins, J. B.; Blin, K.; de Bruijn, I.; Chooi, Y. H.; Claesen, J.; Coates, R. C.; Cruz-Morales, P.; Duddela, S.; Düsterhus, S.; Edwards, D. J.; Fewer, D. P.; Garg, N.; Geiger, C.; Gomez-Escribano, J. P.; Greule, A.; Hadjithomas, M.; Haines, A. S.; Helfrich, E. J. N.; Hillwig, M. L.; Ishida, K.; Jones, A. C.; Jones, C. S.; Jungmann, K.; Kegler, C.; Kim, H. U.; Kötter, P.; Krug, D.; Masschelein, J.; Melnik, A. V.; Mantovani, S. M.; Monroe, E. A.; Moore, M.; Moss, N.; Nützmann, H.-W.; Pan, G.; Pati, A.; Petras, D.; Reen, F. J.; Rosconi, F.; Rui, Z.; Tian, Z.; Tobias, N. J.; Tsunematsu, Y.; Wiemann, P.; Wyckoff, E.; Yan, X.; Yim, G.; Yu, F.; Xie, Y.; Aigle, B.; Apel, A. K.; Balibar, C. J.; Balskus, E. P.; Barona-Gómez, F.; Bechthold, A.; Bode, H. B.; Borriss, R.; Brady, S. F.; Brakhage, A. A.; Caffrey, P.; Cheng, Y.-Q.; Clardy, J.; Cox, R. J.; De Mot, R.; Donadio, S.; Donia, M. S.; van der Donk, W. A.; Dorrestein, P. C.; Doyle, S.; Driessen, A. J. M.; Ehling-Schulz, M.; Entian, K.-D.; Fischbach, M. A.; Gerwick, L.; Gerwick, W. H.; Gross, H.; Gust, B.; Hertweck, C.; Höfte, M.; Jensen, S. E.; Ju, J.; Katz, L.; Kaysser, L.; Klassen, J. L.; Keller, N. P.; Kormanec, J.; Kuipers, O. P.; Kuzuyama, T.; Kyrpides, N. C.; Kwon, H.-J.; Lautru, S.; Lavigne, R.; Lee, C. Y.; Linquan, B.; Liu, X.; Liu, W.; Luzhetskyy, A.; Mahmud, T.; Mast, Y.; Méndez, C.; Metsä-Ketelä, M.; Micklefield, J.; Mitchell, D. A.; Moore, B. S.; Moreira, L. M.; Müller, R.; Neilan, B. A.; Nett, M.; Nielsen, J.; O'Gara, F.; Oikawa, H.; Osbourn, A.; Osburne, M. S.; Ostash, B.; Payne, S. M.; Pernodet, J.-L.; Petricek, M.; Piel, J.; Ploux, O.;

Raaijmakers, J. M.; Salas, J. A.; Schmitt, E. K.; Scott, B.; Seipke, R. F.; Shen, B.; Sherman, D. H.; Sivonen, K.; Smanski, M. J.; Sosio, M.; Stegmann, E.; Süssmuth, R. D.; Tahlan, K.; Thomas, C. M.; Tang, Y.; Truman, A. W.; Viaud, M.; Walton, J. D.; Walsh, C. T.; Weber, T.; van Wezel, G. P.; Wilkinson, B.; Willey, J. M.; Wohlleben, W.; Wright, G. D.; Ziemert, N.; Zhang, C.; Zotchev, S. B.; Breitling, R.; Takano, E.; Glöckner, F. O., Minimum information about a biosynthetic gene cluster. Nat. Chem. Biol. 2015, 11 (9), 625-631.

9. $\quad$ Maansson, M.; Vynne, N. G.; Klitgaard, A.; Nybo, J. L.; Melchiorsen, J.; Nguyen, D. D.; Sanchez, L. M.; Ziemert, N.; Dorrestein, P. C.; Andersen, M. R.; Gram, L., An integrated metabolomic and genomic mining workflow to uncover the biosynthetic potential of bacteria. mSystems 2016, 1 (3), e00028-15.

10. Timmermans, M. L.; Picott, K. J.; Ucciferri, L.; Ross, A. C., Culturing marine bacteria from the genus Pseudoalteromonas on a cotton scaffold alters secondary metabolite production. MicrobiologyOpen 2019, 8 (5), e00724. 
11. Chan, A. N.; Wever, W. J.; Massolo, E.; Allen, S. E.; Li, B., Reducing holomycin thiosulfonate to its disulfide with thiols. Chem. Res. Toxicol. 2018, 32 (3), 400-404.

12. Okamura, K.; Soga, K.; Shimauchi, Y.; Ishikura, T.; Lein, J., Holomycin and Npropionylholothin, antibiotics produced by a cephamycin C producer. J. Antibiot. (Tokyo) 1977, 30 (4), 334-6.

13. Chan, A. N.; Shiver, A. L.; Wever, W. J.; Razvi, S. Z. A.; Traxler, M. F.; Li, B., Role for dithiolopyrrolones in disrupting bacterial metal homeostasis. Proc. Natl. Acad. Sci. USA 2017, 114 (10), 2717-2722.

14. Grim, K. P.; San Francisco, B.; Radin, J. N.; Brazel, E. B.; Kelliher, J. L.; Párraga Solórzano, P. K.; Kim, P. C.; McDevitt, C. A.; Kehl-Fie, T. E., The metallophore staphylopine enables

Staphylococcus aureus to compete with the host for zinc and overcome nutritional immunity. mBio 2017, $8(5), \mathrm{e} 01281-17$.

15. Thomas, D. G.; Wilson, J. M.; Day, M. J.; Russell, A. D., Mupirocin resistance in

Staphylococci: Development and transfer of isoleucyl-tRNA synthetase-mediated resistance in vitro. $J$. Appl. Microbiol. 1999, 86 (4), 715-722.

16. Balouiri, M.; Sadiki, M.; Ibnsouda, S. K., Methods for in vitro evaluating antimicrobial activity: A review. J. Pharm. Anal. 2016, 6 (2), 71-79.

17. Lee, A. S.; Gizard, Y.; Empel, J.; Bonetti, E. J.; Harbarth, S.; Francois, P., Mupirocin-induced mutations in ileS in various genetic backgrounds of methicillin-resistant Staphylococcus aureus. J. Clin. Microbiol. 2014, 52 (10), 3749-3754.

18. Fersht, A. R.; Ashford, J. S.; Bruton, C. J.; Jakes, R.; Koch, G. L.; Hartley, B. S., Active site titration and aminoacyl adenylate binding stoichiometry of aminoacyl-tRNA synthetases. Biochemistry 1975, 14 (1), 1-4.

19. Pope, A. J.; Moore, K. J.; McVey, M.; Mensah, L.; Benson, N.; Osbourne, N.; Broom, N.; Brown, M. J.; O'Hanlon, P., Characterization of isoleucyl-tRNA synthetase from Staphylococcus aureus. II. Mechanism of inhibition by reaction intermediate and pseudomonic acid analogues studied using transient and steady-state kinetics. J. Biol. Chem. 1998, 273 (48), 31691-31701.

20. Copeland, R. A., Tight binding inhibition. In Evaluation of Enzyme Inhibitors in Drug Discovery, John Wiley \& Sons, Inc.: 2013; pp 245-285.

21. Weeks, K. M.; John, D. M., van't Hoff enthalpies without baselines. Protein Sci. 2000, 9 (7), 1416-1419.

22. Brandts, J. F.; Lin, L.-N., Study of strong to ultralight protein interactions using differential scanning calorimetry. Biochemistry 1990, 29 (29), 6927-6940.

23. Brown, M. J.; Mensah, L. M.; Doyle, M. L.; Broom, N. J.; Osbourne, N.; Forrest, A. K.; Richardson, C. M.; O'Hanlon, P. J.; Pope, A. J., Rational design of femtomolar inhibitors of isoleucyl tRNA synthetase from a binding model for pseudomonic acid A. Biochemistry 2000, 39 (20), 6003-6011. 24. Waterhouse, A. M.; Procter, J. B.; Martin, D. M. A.; Clamp, M.; Barton, G. J., Jalview version 2- a multiple sequence alignment editor and analysis workbench. Bioinformatics 2009, 25, 1189-1191.

25. Koo, B.-M.; Kritikos, G.; Farelli, J. D.; Todor, H.; Tong, K.; Kimsey, H.; Wapinski, I.; Galardini, M.; Cabal, A.; Peters, J. M.; Hachmann, A.-B.; Rudner, D. Z.; Allen, K. N.; Typas, A.; Gross, C. A., Construction and analysis of two genome-scale deletion libraries for Bacillus subtilis. Cell Syst. 2017, 4 (3), 291-305. 